NBER WORKING PAPER SERIES

\title{
PARTISAN PROFESSIONALS: EVIDENCE FROM CREDIT RATING ANALYSTS
}

\author{
Elisabeth Kempf \\ Margarita Tsoutsoura \\ Working Paper 25292 \\ http://www.nber.org/papers/w25292
NATIONAL BUREAU OF ECONOMIC RESEARCH
1050 Massachusetts Avenue
Cambridge, MA 02138 \\ November 2018
}

We thank Pat Akey, John Barrios, Marianne Bertrand, Kimberly Cornaggia (discussant), Steve Davis, Carola Frydman (discussant), Jiekun Huang (discussant), Emir Kamenica, Anil Kashyap, Stefan Lewellen (discussant), Raghuram Rajan, David Schoenherr (discussant), Jesse Shapiro, Chester Spatt, Laura Starks (discussant), Amir Sufi, Vikrant Vig, and seminar participants at Aalto University, Bocconi University, Chicago Booth, Cornell University, Dartmouth College, the 2018 FRA Conference, Imperial College, the 2019 NBER Corporate Finance Summer Institute, MIT Sloan, New York Fed, the 2019 Political Economy of Finance Conference, Rice University, Stockholm School of Economics, the 2019 UNC/Duke Corporate Finance Conference, University of Illinois at Chicago, University of Luxembourg, University of Minnesota Carlson, University of Rochester, UVA Darden, Vanderbilt University, and Yale University for valuable comments. Kempf gratefully acknowledges financial support from the James S. Kemper Foundation, the Initiative on Global Markets, and the Fama-Miller Center for Research in Finance at the University of Chicago, Booth School of Business. We thank Yu Gao, Dong Ryeol Lee, Tianshu Lyu, Michael Schwartz, and Pan Yingru for excellent research assistance. The views expressed herein are those of the authors and do not necessarily reflect the views of the National Bureau of Economic Research.

NBER working papers are circulated for discussion and comment purposes. They have not been peerreviewed or been subject to the review by the NBER Board of Directors that accompanies official NBER publications.

(C) 2018 by Elisabeth Kempf and Margarita Tsoutsoura. All rights reserved. Short sections of text, not to exceed two paragraphs, may be quoted without explicit permission provided that full credit, including $(\odot)$ notice, is given to the source. 
Partisan Professionals: Evidence from Credit Rating Analysts

Elisabeth Kempf and Margarita Tsoutsoura

NBER Working Paper No. 25292

November 2018, Revised June 2020

JEL No. G14,G24,G41

\begin{abstract}
$\underline{\text { ABSTRACT }}$
Partisan perception affects the actions of professionals in the financial sector. Using a novel dataset linking credit rating analysts to party affiliations from voter records, we show that analysts who are not affiliated with the U.S. president's party downward-adjust corporate credit ratings more frequently. By comparing analysts with different party affiliations covering the same firm in the same quarter, we ensure that differences in firm fundamentals cannot explain the results. We also find a sharp divergence in the rating actions of Democratic and Republican analysts around the 2016 presidential election. Our results show analysts' partisan perception has sizable price effects on rated firms and may influence firms' investment policies.
\end{abstract}

\author{
Elisabeth Kempf \\ Booth School of Business \\ University of Chicago \\ 5807 South Woodlawn Avenue \\ Chicago, IL 60637 \\ elisabeth.kempf@chicagobooth.edu \\ Margarita Tsoutsoura \\ SC Johnson College of Business \\ Cornell University \\ Ithaca, NY 14853 \\ and NBER \\ tsoutsoura@cornell.edu
}




\section{Introduction}

Recent evidence suggests a large increase in polarization across political parties in the U.S. (e.g., Iyengar, Sood, and Lelkes (2012); Mason (2013); Lott and Hassett (2014); Mason (2015); Gentzkow (2016); Boxell, Gentzkow, and Shapiro (2017)). In particular, voters have an increased tendency to view the economy through a "partisan perceptual screen;" 1 that is, their assessment and interpretation of economic conditions and economic policies depend on whether the White House is occupied by the party they support (e.g., Bartels (2002); Gaines, Kuklinski, Quirk, Peyton, and Verkuilen (2007); Gerber and Huber (2009); Curtin (2016); Mian, Sufi, and Khoshkhou (2018)).

To understand how partisan perceptions may affect the U.S. economy, establishing whether and when they translate into differences in the behavior of economic agents is important. Whereas researchers have documented partisan bias in households' assessment of future economic conditions, evidence on actual economic behavior is mixed. ${ }^{2}$ Moreover, the extent to which partisan perception influences the economic expectations and actions of individuals with greater economic sophistication, and in high-stake professional environments, has remained an open question. ${ }^{3}$

We aim to fill this gap by investigating whether partisan perception affects the actions of an important set of professionals in the financial sector: credit rating analysts. Focusing on credit analysts provides an interesting setting, because their expertise and career concerns should reduce the effect of partisan perception (e.g., Gentzkow, Glaeser, and Goldin (2006); Hong and Kacperczyk (2010)). At the same time, any effect of partisan perception on credit rating actions is likely to have implications for firms' cost of financing (Fracassi, Petry, and Tate (2016)), as well as their financial policy and investment decisions (Chernenko and Sunderam (2011); Begley (2015); Almeida, Cunha, Ferreira, and Restrepo (2017)).

To identify the effect of partisan perception, we test whether the rating actions of credit analysts depend on their political alignment with the U.S. president. This test poses a number of empirical challenges. First, it requires observable actions at the level of the individual analyst. Second, analysts need to be linked to information about their

\footnotetext{
${ }^{1}$ Campbell, Converse, Miller, and Stokes (1960) introduced the idea of the partisan perceptual screen; "Identification with a party raises a perceptual screen through which the individual tends to see what is favorable to his partisan orientation" (Campbell, Converse, Miller, and Stokes (1960), p. 133). In this paper, we use "partisan perceptual screen," "partisan perception," and "partisan bias" interchangeably.

${ }^{2}$ Whereas Makridis (2019) documents a significant effect of partisan bias on household spending, McGrath (2017) and Mian, Sufi, and Khoshkhou (2018) find no significant effect. Focusing on households' investment decisions, Meeuwis, Parker, Schoar, and Simester (2018) show political affiliation affects portfolio choice around the U.S. election of November 2016.

${ }^{3}$ Notable exceptions are Jelveh, Kogut, and Naidu (2018), who document partisan bias in economic research, and Posner (2008), McKenzie (2012), and Chen (2019), who document partisan bias among judges.
} 
political affiliation. Third, it requires comparing the actions of analysts with different political affiliations on the same task and in the same information environment. Fourth, we need to separate the effect of political alignment with the president from time-invariant characteristics of Democratic and Republican analysts.

To address these challenges, we compile a novel hand-collected dataset that links credit rating analysts to the ratings they issue, as well as to information on party affiliation from voter registration records. Our sample consists of 557 corporate credit analysts with nonmissing information on their party affiliation, working at Fitch, Moody's, and Standard and Poor's (S\&P) between 2000 and 2018. These analysts cover a total of 1,984 U.S. firms. By comparing rating actions of analysts who rate the same firm at the same point in time, we ensure our results cannot be driven by differences in the fundamentals of rated firms (i.e., we can compare analysts on the same "task").

We find partisan perception affects credit ratings. Analysts who are not affiliated with the president's party are more likely to adjust ratings downward, relative to other analysts covering the same firm at the same point in time. Specifically, analysts who are not affiliated with the president's party downward-adjust ratings more by 0.013 notches per quarter. This effect corresponds to $11.4 \%$ relative to the average absolute quarterly rating adjustment and is therefore economically sizable. Over a four-year presidency (i.e., 16 quarters), these estimates imply analysts who are misaligned with the president downwardadjust the rating of the average firm by $0.21(=0.0134 \times 16)$ notches more than aligned analysts. This amount corresponds to a one-notch rating downgrade (e.g., A to A-) of approximately one out of every five firms. Overall, the effect of partisan perception that we document is comparable to other non-fundamental factors influencing rating agencies' information production identified in the literature, such as the effect of competition or the home-bias effect.

Our empirical strategy ensures this result cannot be explained by several potential confounding factors. Most importantly, following Fracassi, Petry, and Tate (2016), we control for non-random matching of analysts to firms by including firm $\times$ quarter fixed effects in the regressions. Thus, we can rule out the possibility that Democratic analysts rate firms that tend to do well under the policies of Democratic presidents. Our empirical strategy also allows us to control for differences in rating methodologies across rating agencies via agency $\times$ quarter fixed effects. Finally, we control for unobserved time-invariant differences across analysts with different party affiliations via party-affiliation fixed effects. In other words, we focus on how the behavior of analysts changes depending on whether their preferred party is in power, as opposed to static differences between Democratic and Republican analysts. 
To further support our conclusion that the above finding reflects partisan perception, we conduct an event study around the 2016 presidential election. The 2016 election provides a particularly clean setting because the outcome was unexpected and the two candidates had very different views on economic policy. We find a sharp and sizable divergence in the rating actions of Democratic and Republican analysts (see Figure 4). To the best of our knowledge, this study is one of the first to document that the highly polarized 2016 election was accompanied by a differential response in the behavior of sophisticated economic agents. Furthermore, we find substantially larger effects for analysts who are more politically active, proxied by the frequency with which an analyst votes.

We proceed to show that rating actions by partisan analysts have non-negligible price as well as real effects. Regarding price effects, we begin by documenting that the stockprice response to a downgrade is very similar, regardless of whether the downgrade is announced by an analyst who is ideologically misaligned or aligned with the president. In other words, securities prices do not seem to differentiate between analysts' ideological leanings. As a result, replacing an analyst who is aligned with the president with an analyst who is misaligned leads to a difference in the firm's market capitalization of $0.52 \%-0.62 \%$, or $\$ 89$ million-\$107 million, over a four-year presidential term. We also find a significant increase in bond yields, which corresponds to 5.9 basis points over a four-year period. As we argue below, these effects likely represent lower bounds for the true price effects of analysts' partisan perception. Finally, we also show that firms rated by analysts who transition from aligned to misaligned with the president experience a significant decrease in firm investment around presidential elections.

After establishing the consequences of partisan perception on credit ratings, securities prices, and firm investment, we next investigate the economic mechanism. We interpret the evidence in this paper as showing that analysts with opposing political views differ in their beliefs about how the economic policies of the U.S. president affect the credit risk of firms in the economy. One important advantage of our setting for isolating belief disagreement from other factors is that the rating actions of analysts are unlikely to be driven by how the election of their preferred candidate affects analysts' personal economic condition. To further support our interpretation, we provide three additional pieces of evidence. First, we conduct an online survey of credit rating analysts and find striking differences in the assessment of current economic conditions by Democrats and Republicans, consistent with the existing evidence from U.S. households. Second, we show analysts' alignment with the president's party has no effect on the ratings of firms with low cyclicality. Hence, the disagreement is focused precisely on the set of firms whose fundamentals should be most affected by changing aggregate economic conditions. Third, we investigate whether 
the effect is more pronounced in periods when views of economic conditions are more politically polarized in the U.S. population. We use the absolute difference in the views of economic conditions between Democrats and Republicans from the Gallup Daily Survey as a measure of political polarization in economic views. The effect of political alignment with the president is $83 \%$ larger when polarization increases by one standard deviation.

This study is the first to identify a significant effect of partisan perception on the actions of finance professionals; specifically, on the rating actions of credit analysts. If partisan perception affects the decisions of credit rating analysts, it may also affect decisions of other relevant economic agents. Given that the effect of partisan perception prevails even in a setting where pecuniary and professional gains are at stake, it may be even more pronounced in less competitive labor markets. We look forward to future research exploring this phenomenon in other labor market settings.

The rest of this study proceeds as follows. In the next section, we discuss the related literature. Section 3 presents the data, the sample construction, and summary statistics. Section 4 describes the empirical strategy. Section 5 examines whether analysts' rating actions are influenced by partisan perception. Section 6 investigates the price and real effects of partisan perception. Section 7 discusses the economic mechanism, and section 8 concludes.

\section{Motivation and Related Literature}

Our study is motivated by the growing evidence that partisanship has become more pervasive in the U.S., and that partisan conflict penetrates into a greater number of issue areas (e.g., Brewer (2005)). According to Pew Research Center (2017), party identification is now a more significant predictor of Americans' fundamental political values than any other social or demographic divide, including gender, race, education, and religion. Similarly, Bertrand and Kamenica (2018) find that differences in social attitudes by political ideology have increased in the U.S. since the 1970s, whereas they did not find a similar increase in differences across gender or race. Moreover, a growing literature, described in detail below, documents the importance of political partisanship as af predictive variable for the economic expectations of U.S. households. The documented importance of partisan perception for individuals' economic views and society more broadly highlights the need for an empirical study on how political partisanship shapes information production in financial markets. Our paper fills this gap and contributes to several strands of the literature.

First, our findings contribute to a growing literature on the connection between partisanship and economic behavior. Most of the existing studies have focused on households, 
and studies of consumption behavior have produced mixed results. In an early paper, Gerber and Huber (2009) demonstrate consumption changes following a political election are correlated with whether the election was won by the respondent's preferred political party. Gillitzer and Prasad (2018), analyzing Australian elections, find that changes in sentiment around elections are also associated with future vehicle purchase rates. Benhabib and Spiegel (2018) document a positive relation between partisan-related sentiment and state-level GDP growth. Makridis (2019) uses individual-level data from Gallup and shows that self-reported consumption of non-durable goods rose more among conservatives around the 2016 presidential election. However, other studies have not found a significant connection between partisanship and household consumption. McGrath (2017) extends the sample in Gerber and Huber (2009) and concludes that no evidence exists of an effect of partisan ideology on spending. Mian, Sufi, and Khoshkhou (2018) combine data on vehicle purchases and credit-card spending with an estimated propensity to vote for the Republican candidate in presidential elections at the county and state level. They find a significant relationship between party affiliation and economic expectations, but not between party affiliation and household spending. ${ }^{4}$ In addition to consumption, studies have examined partisanship and household asset allocation. Addoum and Kumar (2016) show the industry-level composition of investors' portfolios changes when the party in power changes. Bonaparte, Kumar, and Page (2017) find investors' portfolio allocation to risky assets is influenced by whether their preferred party is in power. Similarly, Meeuwis, Parker, Schoar, and Simester (2018) document Republican investors actively increase the equity share and the market beta of their portfolios relative to Democrats following the U.S. election of November 2016. We add to this literature by establishing that partisan perception affects the behavior of finance professionals and has non-trivial price and real effects.

Moreover, our results contribute to studies that have investigated the effect of partisan ideology among other groups of professionals. Hersh and Goldenberg (2016) find evidence of partisan bias among medical doctors, as doctors with different political affiliations recommend different treatment plans for politically sensitive health issues. Posner (2008), McKenzie (2012), and Chen (2019) document evidence of partisan biases among judges. Our work complements these studies by focusing on financial experts.

Our study also adds to the literature on non-fundamental determinants of credit ratings at the analyst level. Fracassi, Petry, and Tate (2016) find evidence of systematic optimism and pessimism among credit analysts and show they affect credit spreads. Cornaggia,

\footnotetext{
${ }^{4}$ Several factors could explain the mixed findings when linking partisan ideology to household consumption, such as using survey-based, self-reported consumption data versus administrative data, studying different countries and time periods, as well as employing different methods to infer political affiliation.
} 
Cornaggia, and Israelsen (2019) and Cornaggia, Cornaggia, and Xia (2016) document that home bias and the revolving door, respectively, influence credit ratings. Adding to this research, our study explores the role of partisan perception as a driver of credit ratings that is not related to economic fundamentals. Our paper also relates more broadly to the literature on the determinants and consequences of credit ratings (see, e.g., Becker and Milbourn (2011); Kisgen and Strahan (2010); Xia (2014); Griffin and Tang (2012); Cornaggia, Cornaggia, and Israelsen (2017); Cunha, Ferreira, and Silva (2019)).

Furthermore, our study contributes to the literature that studies how political affiliation correlates with the behavior of financial analysts, sell-side equity analysts, corporate managers, investment managers, and investors. Prior studies have documented that mutual-fund managers who make campaign donations to the Democratic party hold less of their portfolios in companies that are deemed socially irresponsible (Hong and Kostovetsky (2012)), left-wing voters are less likely to invest in stocks (Kaustia and Torstila (2011)), sell-side equity analysts who make political contributions to the Republican Party are less likely to issue bold recommendations (Jiang, Kumar, and Law (2016)), and Republican firm managers maintain more conservative corporate policies (Hutton, Jiang, and Kumar (2014)). These studies focus on the time-invariant attributes that characterize Democrats versus Republicans, whereas we focus on how the behavior of analysts changes depending on whether their preferred party is in power. We can therefore separate the effect of partisan perception from unobserved time-invariant characteristics of individuals with different political affiliations.

Finally, our findings relate to the broader literature on belief heterogeneity, which argues agents do not interpret public information identically, and investigates the implications on asset prices (e.g., Harris and Raviv (1993); Kandel and Pearson (1995); Bamber, Barron, and Stober (1999); Banerjee and Kremer (2010); Banerjee (2011); Meeuwis, Parker, Schoar, and Simester (2018)). Our setting allows us to provide direct evidence that Democratic and Republican analysts update their beliefs about credit risk differently in response to the same public event. Although we cannot distinguish between all possible theories of belief formation, we can exclude several stories based on our findings. For example, since we study presidential elections, which are very salient public signals, our results are unlikely to be explained by limited attention (e.g., DellaVigna and Pollet (2009); Hirshleifer, Lim, and Teoh (2009)). 


\section{Data and Sample Construction}

\subsection{Data}

The main dataset used in the analysis is constructed from the combination of credit ratings on corporate debt issuers, press releases with analyst information, and voter registration records. We also complement the data with a variety of other data sources. The datasets are described below, and further details can be found in Internet Appendix IA.A.

\subsubsection{Corporate Credit Ratings}

We collect rating actions on U.S. corporate debt issuers from all three major ratings agencies: Fitch, Moody's, and S\&P. We obtain these for S\&P from S\&P RatingXpress, for Moody's from Moody's Default and Recovery Database (DRD), and for Fitch from Mergent FISD. ${ }^{5}$ The time period spans the years from the first quarter of 2000 to the first quarter of 2018. We restrict the sample period to post 2000 because press releases with analyst information are sparse prior to 2000. Credit ratings are transformed into a cardinal scale, starting with 1 for AAA (Aaa) and ending with 21 for D (C), as in Fracassi, Petry, and Tate (2016). We match each rating action (i.e., new rating, downgrade, upgrade, affirmation, internal review, reinstatement, and withdrawal) to a press release that contains the name(s) of the analyst(s) covering the firm. The press releases are collected from Moody's and Fitch's websites and from S\&P's Global Credit Portal. They usually contain two names: the name of the lead analyst as well as the name of a second analyst (often the rating-committee chair or the backup analyst).

\subsubsection{Political Affiliation}

Our political-affiliation measure comes from the voter registration records from the State of Illinois, the State of New Jersey, and New York City. ${ }^{6}$ The voter registration records contain identifying information, such as voter names, date of birth, and mailing address, the voter's party affiliation at the time of a given election, and an indicator for the election(s) in which the individual has voted. The elections covered are general, primary, and municipal elections during the period of 1983-2017 for New York City, 1976-2017 for Illinois,

\footnotetext{
${ }^{5}$ Because Mergent provides bond ratings rather than issuer ratings, we follow the procedure by Fracassi, Petry, and Tate (2016) and select a representative issuer rating after excluding bonds that are exchangeable, putable, convertible, pay-in-kind, subordinated, secured, or guaranteed, as well as zero-coupon bonds and bonds with variable coupons.

${ }^{6}$ We use data from New York City as opposed to the State of New York, because the State of New York does not provide voter histories.
} 
and 2007-2017 for New Jersey. In Internet Appendix IA.A, we describe the information available in the voter registration records of each location in more detail.

For the purpose of our study, the voter registration data have several advantages. First, relative to the commonly used data on financial contributions to political parties, candidates, and committees, found on the Federal Election Committee (FEC) website, ${ }^{7}$ the voter registration data cover a larger part of the population. In fact, according to a study by Hill and Huber (2017), less than 10\% of registered U.S. voters are federal or state donors. Although these differences in the sample restriction may not be as crucial when studying the influence of the political affiliation of high-profile individuals, such as CEOs and board members, they are increasingly important when looking at employees who are not at the highest level of the firm, such as credit analysts, who are less likely to contribute financially to political campaigns. Second, voter registration records are able to capture political beliefs separately from the intention of political influence and social pressure. The latter is a particularly important concern, given the evidence in Babenko, Fedaseyeu, and Zhang (2019) that CEOs influence the political contributions of their employees. Political affiliation inferred from voter registration records is less likely to be subject to such influence. Third, party registration has been shown to be a good predictor of self-reported party identification. Igielnik, Keeter, Kennedy, and Spahn (2018) match commercial voter files, which are based on data from voter registration records, with a large-scale survey on political attitudes and voter behavior and show that, for more than two-thirds of the panelists, the party affiliation in the commercial voter file correctly infers the self-reported party identification. The accuracy is even higher for states with party registration, such as New York.

\subsubsection{Additional Data Sources}

We rely on a variety of complementary data sources. First, to measure political polarization in the views of economic conditions in the general public, we use the Daily Survey by Gallup, Inc. The Gallup Daily data cover around 1,000 individuals every day for years 2008 to 2017. We require two main variables from the survey in order to measure the polarization in economic views: (i) a measure of an individual's view on the current economic conditions, and (ii) a measure of her political affiliation. To measure the views on current economic conditions, the Gallup survey asks the following question: "How would you rate economic conditions in this country today — as excellent, good, only fair, or poor?" The responses to this question are converted into a numerical scale that ranges from 1 (poor) to 4 (excellent). Moreover, the Gallup survey contains two questions about political affiliation, which allows

\footnotetext{
${ }^{7}$ https://www.fec.gov/
} 
classification of survey respondents into Democrats, Republicans, or Independents. Our measure of political polarization in economic views is the absolute difference in the average economic views of Democrats and Republicans in a given calendar quarter.

For additional robustness tests, we use an alternative measure of the views of economic conditions based on the Michigan Survey. Specifically, we use the Current Economic Conditions Index. We provide more details on the two surveys in the Internet Appendix, and we plot the time series of both measures of polarization in economic views in Internet Appendix Figure IA.1.

Second, we obtain quarterly firm-level financial information from Compustat. Third, we obtain bond transactions from TRACE and merge them with the Mergent FISD issue file using CUSIPs. Following Fracassi, Petry, and Tate (2016), we remove bonds with special features, that is, bonds that are exchangeable, putable, convertible, pay-in-kind, subordinated, secured, guaranteed, or denominated in foreign currency. We further drop zero-coupon and variable-coupon bonds, as well as bonds with missing maturity dates. We compute daily bond prices as the trade size-weighted average transaction price in TRACE, after applying several filters to reduce the influence of erroneous entries. ${ }^{8}$ We then use daily bond prices to calculate the yield to maturity and the duration of each bond. We remove bonds with a duration of less than one year. The benchmark rate that we use to compute credit spreads is based on an interpolation of the yields of the two government bonds with the next lower and the next higher duration relative to the corporate bond.

Finally, we further supplement the data with hand-collected biographical information from online searches. We also use analysts' first and last names to obtain additional characteristics. For example, we infer analysts' ethnicity from their first and last names, using the API name-prism.com (see Ye, Han, Hu, Coskun, Liu, Qin, and Skiena (2017) for details). Moreover, we infer the gender of the analysts from their first name, using the publicly available API genderize.io, as well as manual online searches. ${ }^{9}$

\subsection{Sample Construction}

The rating actions are converted into an analyst-firm-quarter panel by using the most recent rating at the end of a given quarter and the analyst information from the most recent press release for the firm. To minimize measurement error in the analyst assignment, we do not use analyst information from press releases that are older than three years as

\footnotetext{
${ }^{8}$ As in Dick-Nielsen (2009), we delete duplicates, reversals, cancellations, and same-day corrections. We further follow Dion Bongaerts and Goetzmann (2012) and remove trades that include a commission, have a settlement period of more than 5 days, or a negative reported yield.

${ }^{9}$ The API uses a large dataset of first names and known genders gathered from user profiles across major social networks in order to predict gender. See http://api.genderize.io/.
} 
of quarter end, and we do not assign analysts to quarters beyond the date of the final report for a given agency-firm pair. After we focus on analysts who work in the offices of Chicago and New York City, our sample consists of 2,402 issuers rated by 1,211 analysts. ${ }^{10}$ Because we require information on political-party affiliation, we further restrict the sample to analysts who can be matched to a voter registration record. We match analysts to voters as follows. In a first step, we merge analysts to voters using first name, middle initial, and last name, keeping only exact matches. In the case of duplicate matches, we try to determine the correct match based on voter age and ZIP code. ${ }^{11}$ In a second step, we merge the remaining unmatched analysts to voter records using only their first name and last name. The merging procedure is described in more detail in the Internet Appendix. Our final sample includes 557 analysts, covering 1,984 firms.

To put the resulting match rate of approximately $46 \%(=557 / 1,211)$ in context, consider the following statistics. The share of registered voters among the total voting-age population of individuals aged 25 to 64 years with a Bachelor's degree or higher is approximately $75.6 \%$, as of November 2016. ${ }^{12}$ We lose analysts who work in New York City but reside in Connecticut or in other parts of the State of New York. According to New York City commuter data, approximately $12 \%$ of analysts should fall in this category. ${ }^{13}$ Moreover, we lose analysts who did not update their voter registration to the state of their work location, whose names are spelled differently in the press releases than in the voter records, and who match to multiple voters among whom we cannot determine a single correct match. ${ }^{14}$ Of course, these statistics have to be treated with caution, because we do not know how the population of credit rating analysts compares to the U.S. population. We nevertheless find them useful because they suggest a match rate with voter registration records of $46 \%$ is not unreasonable.

Even though our analysis does not require a random sample, we would still like to understand the potential differences between our sample and the overall population of analysts and firms. First, we investigate whether analysts whom we are able to match to voter records rate different types of companies. The results, reported in Table IA.3 in the Internet Appendix, show that analysts for whom we are able to obtain party affiliation

\footnotetext{
${ }^{10}$ When the press release does not provide any office information, we assume the analyst is based in New York. Given that more than $85 \%$ of all analysts with non-missing office location are based in New York, we believe this assumption is reasonable.

${ }^{11}$ Analyst age is approximated by assuming the analyst was 21 years old upon graduation from college, following Chevalier and Ellison (1999). Information on analysts' graduation year is obtained via manual online searches.

${ }^{12}$ U.S. Census Bureau. Data available at https ://www. census.gov/data/tables/time-series/demo/ voting-and-registration/p20-580.html.

${ }^{13}$ NYC Department of City Planning. Data available at https://www1.nyc.gov/assets/planning/ download/pdf/data-maps/nyc-population/acs/ctpp_p6_nyc_boro_06_10.pdf.

${ }^{14}$ For 65 analysts, we are unable to determine a unique match out of multiple potential voter matches.
} 
rate firms that are not statistically different on observable characteristics from firms rated by analysts without a matching voter record. Second, in terms of selection based on observable analyst characteristics, we do not expect analysts who are registered voters to be representative of the overall analyst population. Given the focus of our study, which is to estimate the importance of political alignment with the president on the decisions of financial experts, restricting the sample to analysts who are registered voters, even if they differ from the general population of analysts, is justified. We provide a comparison of partisan analysts relative to the population of unregistered analysts, as well as a comparison of Democratic and Republican analysts, in Table IA.4 in the Internet Appendix.

Our analysis relies on comparisons of rating actions across agencies. We note that we do not need split-ratings, but split-rating actions (i.e., one rating agency changing the rating differently than another agency). Our sample has 9,464 firm-quarters in which a firm is rated by more than one rating agency. Of these 9,464 firm-quarters, 1,617 have a split-rating action.

\subsection{Summary Statistics}

Table 1 and Figure 1 report summary statistics. Twenty-six percent of the analysts who are registered voters are unaffiliated, 39\% are registered Democrats, 34\% are Republicans, and $1 \%$ are registered with a party other than the Democratic or Republican party. Figure 1a reports the average party affiliation by GICS sector. The sectors with the highest share of Democratic analysts are utilities (63\%) and consumer staples (50\%), and the sector with the highest share of Republican analysts is energy (59\%). These patterns could be driven by factors such as the geography of where analysts grew up, which may influence both their party affiliation and the sectors they choose to cover. For example, analysts who grew up in New York (a "blue state") likely had more exposure to the financial sector, whereas analysts from Texas (a "red state") may be more familiar with energy companies. Figure 1b shows the percentage of Democratic analysts is higher in New York City (44\%) than in Chicago (27\%). Figure 1c compares the political affiliation of analysts in the three different rating agencies. At S\&P, Fitch, and Moody's, 54\%, 34\%, and 33\% of the analysts are Democrats, respectively. The median analyst is in the sample for approximately five years (unreported for brevity).

Our main dependent variable is the quarterly change in the credit rating (measured in notches). To limit the influence of outliers, we winsorize the quarterly rating change at the top and bottom 1\%. ${ }^{15}$ Because credit ratings are transformed into a cardinal scale,

\footnotetext{
${ }^{15}$ Table IA.8 in the Internet Appendix shows that our results are robust to using unwinzorized changes (Panel A), removing firms which are in default, where ratings are less likely to be subjective (Panel B),
} 
starting with 1 for AAA (Aaa) and ending with 21 for D (C), as in Fracassi, Petry, and Tate (2016), a positive rating change indicates a downgrade. The average credit rating change is 0.023 notches, confirming evidence from prior studies that downgrades are more common than upgrades (Dichev and Piotroski (2001); Hand, Holthausen, and Leftwich (1992); Holthausen and Leftwich (1986)). Ten percent of the observations in our sample have a rating change, which is also consistent with the literature (e.g., Becker and Ivashina (2014)).

Figure 2 presents the average adjusted rating change for Democratic, Republican, and unaffiliated analysts during the five presidential terms in our sample period. Adjusted rating changes are computed by taking the quarterly rating change and subtracting the average rating change within the same firm and quarter across all agencies rating the firm. This measure allows us to control for the possibility that the party affiliation of the analysts covering a given firm may correlate with the firm's fundamentals and investment opportunities under different administrations. Even in this univariate comparison, we observe a pattern that is consistent with our main multivariate analysis: During a Republican presidency, Republican analysts upward-adjust ratings more relative to Democratic analysts. Under Obama's presidency, the sign of this difference reverses: Republican analysts downward-adjust more than Democratic analysts. The Trump presidency is particularly interesting because the outcome of the 2016 election was unexpected, it led to the Republican party controlling both the Senate and the White House, and the two candidates involved in the election had very different views on economic policy. The disagreement between Democratic and Republican analysts is particularly large during Trump's presidency, with Democratic analysts downward-adjusting more than Republicans. Importantly, the rating behavior of unaffiliated analysts is relatively similar under Democratic and Republican presidents. An additional pattern that emerges from Figure 2 is that the disagreement between Republican and Democratic analysts is greater during Republican administrations. This finding is consistent with existing survey evidence on households, where the partisan divide in views of the economy is also stronger under Republican presidents (e.g., Pew Research Center (2019)).

\section{Empirical Strategy}

Measuring the influence of political alignment with the president on rating decisions by credit analysts is empirically challenging. If analysts were randomly assigned to firms and agencies and party affiliation was randomly assigned to analysts, we could measure the and to dropping rather than winsorizing outliers (Panel C). 
effect of partisan perception by comparing the rating actions of analysts who are aligned with the president's party with the rating actions of analysts who are not aligned with the president's party. However, analysts are unlikely randomly assigned to firms. Analysts with a certain political ideology could specialize in sectors or firms whose fundamentals are directly affected by presidential policies (see Figure 1a for the distribution of analyst party affiliation across sectors). For example, Republican analysts could be more likely to rate firms whose value increases under the policies of Republican presidents and decreases under the policies of Democratic presidents (e.g., oil and gas companies), and therefore downgrade more often under Democratic than under Republican administrations. In the presence of such non-random matching, the estimated average difference in the rating actions between analysts with different party affiliations may not reflect the effect of partisan perception, but rather differences in the fundamentals of the firms they cover. Second, party affiliation is not randomly assigned to analysts and may be correlated with other time-invariant characteristics of the analyst, such as upbringing, education, prior work experience, or attitudes towards certain industries or firms. Third, credit analysts may not be randomly assigned to rating agencies. As Figure 1c shows, the mix of Democratic and Republican analysts varies substantially across agencies. If political cycles correlate with asset returns (see Pástor and Veronesi (2018)), and rating agencies' methodologies differ in how they incorporate economic variables into their models, differences in ratings between agencies over the political cycles might not be due to partisan perception, but to the non-random composition of political affiliations across agencies.

Our identification strategy removes the above confounding factors by regressing the rating change for firm $f$ rated by analyst $i$ in quarter $t$ on firm $\times$ quarter fixed effects, political-affiliation fixed effects, as well as agency $\times$ quarter fixed effects:

$$
\Delta R_{i f t}=\alpha_{f t}+\alpha_{j t}+\alpha_{p}+\beta \text { Ideologicalmismatch }{ }_{i t}+\gamma^{\prime} X_{i t}+\epsilon_{i f t},
$$

where $\Delta R_{\text {ift }}$ refers to the quarterly rating change, $j$ denotes the rating agency, $p$ denotes the analyst's political affiliation (Democrat, Republican, Unaffiliated, and Other), and ideological mismatch it $_{\text {is }}$ an indicator equal to 1 if the analyst's party affiliation does not match the party of the elected president in quarter $t$. In a presidential-election quarter, we define ideological mismatch using the newly elected president, because the election result is known by the end of the quarter. $X_{i t}$ refers to analyst-level controls, including analyst tenure and the number of firms rated by the analyst.

In our baseline definition, ideological mismatch is equal to 1 for analysts whose party affiliation does not match the president's, and zero for analysts whose party affiliation matches that of the president as well as for unaffiliated analysts. This definition results in 
$37 \%$ of the analyst-firm-quarters having misalignment with the president's party (see Table 1). Due to the inclusion of party-affiliation fixed effects in all regressions, the coefficient on ideological mismatch will be identified only based on Republican and Democratic analysts, because their party switches at least once from aligned to misaligned with the president. ${ }^{16}$ The main benefit of including unaffiliated analysts in our analysis is that it allows us to estimate the fixed effects and coefficients on control variables more precisely. In Internet Appendix Table IA.5, we show we obtain very similar results if we only keep Democratic and Republican analysts.

We study rating changes instead of rating levels for two main reasons. First, rating changes allow us to better isolate the decisions of the current analyst from other confounding factors, such as the influence of the previous analyst. Second, rating levels are sticky because analysts do not adjust them very frequently. We will show in Section 5.3.1 that in levels, the effect is there but takes some time to show up, consistent with the view that there is slow adjustment of ratings.

By including firm $\times$ quarter fixed effects, we are effectively comparing analysts who cover the same firm at the same point in time. Hence, our results cannot be driven by analysts with ideological mismatch covering different types of firms. Including agency $\times$ quarter fixed effects addresses concerns that different methodologies of credit agencies might be correlated with the political cycle during our sample period. Furthermore, we present specifications where we include agency $\times$ sector instead of agency $\times$ quarter fixed effects to address any concerns related to agencies with different compositions of Democratic and Republican analysts having different rating models for different industries. Finally, our estimator of partisan perception is, by construction, orthogonal to the baseline effect of the analyst's political affiliation, and hence to a number of unobserved time-invariant analyst characteristics that may be correlated with party affiliation. Thus, our estimator of partisan perception captures how the behavior of Democratic and Republican analysts changes depending on whether their preferred party occupies the White House, and not time-invariant characteristics correlated with party affiliation.

Although it would also be possible to control for unobserved analyst heterogeneity via analyst fixed effects, what heterogeneity analyst fixed effects capture that is (i) correlated with our measure of ideological mismatch and (ii) orthogonal to party affiliation is unclear. Because including analyst fixed effects is much more demanding on the data - doing so would require estimating more than 500 additional parameters - we have chosen to include only party-affiliation fixed effects in our baseline, while reporting a specification with

\footnotetext{
${ }^{16}$ Because unaffiliated analysts and analysts with other party affiliations never change from aligned to misaligned with the president, whether we code them as aligned or misaligned does not affect our estimate of $\beta$ in equation (1).
} 
analyst fixed effects in our robustness tests in Table 3. Our main results are qualitatively and quantitatively very similar if we include analyst fixed effects.

We double-cluster standard errors at the analyst and firm level throughout the analysis. In Table 3, we show our results are robust to triple clustering by firm, analyst, and quarter.

\subsection{Can Individual Analysts Influence Ratings?}

A necessary condition for analysts' political ideology to affect ratings is that the ratings process needs to provide sufficient room for individual analysts to affect the rating of an issuer. Whether individual analysts can affect ratings is not obvious given that the final rating decision is taken by a committee. Upon receiving a rating application from a potential customer, rating agencies typically assign a lead analyst to the ratings process. The lead analyst meets with the customer to discuss relevant information, which she subsequently analyzes with the help of an analytical team. She then proposes a rating and provides a rationale to the rating committee, which consists of a number of credit-risk professionals determined by the analyst in conjunction with the committee chair. Once the rating committee has reached its decision, the rating agency communicates the outcome to the customer and publishes a press release. ${ }^{17}$ The ratings process therefore provides ample opportunities for individual analysts to influence the final rating, even if the final decision is taken by a committee. Lead analysts guide meetings with the customer, request and interpret information, and play a key role in the rating committee by proposing and defending a rating recommendation based on their own analysis. In addition, the rating-committee chair serves a special role by influencing the composition of the rating committee and acting as the moderator.

How much individual analysts are able to influence ratings is ultimately an empirical question. Fracassi, Petry, and Tate (2016) attribute a substantial part of the variation in corporate bond ratings to individual analysts: They explain $30 \%$ of the within-firm variation in ratings. For securitized finance ratings, Griffin and Tang (2012) provide evidence that CDO ratings by a major credit rating agency frequently deviated from the agency's main model, reflecting room for subjectivity in the ratings process. In addition, Kisgen, Nickerson, Osborn, and Reuter (2019) and Kempf (2020) document that the rating decisions of lead analysts and committee chairs predict both internal promotions and

\footnotetext{
${ }^{17}$ See Fracassi, Petry, and Tate (2016) and https://www.moodys.com/sites/products/ ProductAttachments/mis_ratings_process.pdf for a description of the ratings process at Moody's, https : //www. standardandpoors . com/en_AU/delegate/getPDF?articleId=2053416\&type=COMMENTS\& subType=REGULATORY for the ratings process at S\&P, and https://www.fitchratings.com/site/dam/ jcr:b05b5bd2-0443-4338-815b-81a809840e65/Form\%2025-101F1\%20Item\%205.pdf for the ratings process at Fitch.
} 
external hiring by investment banks, suggesting that, by revealed preference, these parties see valuable information in analysts' rating decisions.

\subsection{Why Do Corporate Credit Analysts Provide a Useful Set- ting?}

Corporate credit rating analysts provide a suitable setting to study the effect of partisan perception on economic behavior in a high-stakes environment for a number of reasons. First, it is one of the few settings where decisions can be linked to the identity of the individual decision maker. Second, credit ratings have been shown to affect firms' cost of financing (Fracassi, Petry, and Tate (2016)), as well as their financial policy and investment decisions (Chernenko and Sunderam (2011); Almeida, Cunha, Ferreira, and Restrepo (2017)). Hence, the views and actions of credit rating analysts have real consequences for the rated firms. Third, because multiple analysts can rate the same firm at the same point in time, we are able to control for differences in the type of firms that analysts rate. Finally, one of the challenges of addressing our question is that we need to match individual analysts to voter registration data. The geographical location of credit analysts is very concentrated in New York City and Chicago, which reduces problems related to heterogeneous data availability and data quality in the voter registration records across different U.S. states.

\section{Analysts' Partisan Perception and Credit Rating Actions}

This section presents our main results. We first document that partisan perception has a significant influence on analysts' credit rating decisions, by showing that analysts whose party affiliation does not match the president's are more likely to adjust ratings downward. This result is robust to various measures of rating changes, sample restrictions, and estimation methods. Next, we focus on presidential elections. We document a sharp divergence in the rating actions of Democratic and Republican analysts during the month of the 2016 presidential election, with Democratic analysts downward adjusting ratings more than Republican analysts. 


\subsection{Main Results}

We estimate the regression from equation (1) with different sets of fixed effects and report the results in Table 2. Specifically, we regress quarterly ratings changes on ideological mismatch, an indicator equal to 1 if the analyst's party does not match the current president's, and 0 otherwise, as well as on controls. We include party-affiliation fixed effects in all regressions.

We begin by including agency fixed effects in addition to firm $\times$ quarter fixed effects and analyst's party-affiliation fixed effects, because Figure 1 documents pronounced differences in political ideological across different agencies. The results, reported in column (1), suggest partisan perception affects analysts' rating behavior. Specifically, analysts who do not support the president's party are more likely to adjust ratings downward by 0.0168 notches relative to analysts who are aligned with the president's party. The economic and statistical significance of the effect of partisan perception remains high as we tighten the identification to include agency $\times$ sector (column (2)) as well as agency $\times$ quarter fixed effects (column (3)). The estimate in column (3) suggests an analyst who is misaligned with the president's party on average downward-adjusts ratings more by 0.0134 notches. Relative to the average absolute rating change of 0.118 notches, this change is an economically sizable increase of 11.4\%. Over a four-year presidency (i.e., 16 quarters), these estimates imply analysts who are misaligned with the president downward-adjust the rating of the average firm by 0.21 $(=0.0134 \times 16)$ notches more than aligned analysts. ${ }^{18}$ As a reference point, a one-notch downgrade would be equivalent to moving from $\mathrm{A}$ to $\mathrm{A}-$ on the credit rating scale.

Comparing the effect of the analyst's political alignment with the president to other unobserved factors at the analyst level is also informative. We measure the importance of unobserved analyst factors using the distribution of analyst fixed effects (i.e., we estimate the regression with analyst fixed effects reported in Table 3, Panel C). We find that the effect of ideological mismatch is roughly equivalent to moving from the 50th to the 75th percentile of the analyst fixed-effects distribution.

The effect of partisan perception that we document is comparable to other non-fundamental factors influencing information production at rating agencies identified in the literature. For example, the effect of competition among rating agencies documented by Becker and Milbourn (2011) is equal to 0.19 notches, the revolving-door effect documented by Cornaggia, Cornaggia, and Xia (2016) is equal to 0.23 notches, and the home-bias effect documented by Cornaggia, Cornaggia, and Israelsen (2019) is equal to 0.10 notches on

\footnotetext{
${ }^{18}$ Since coefficient $\beta$ in equation (1) captures the difference between misaligned and aligned analysts during the average quarter, we need to multiply by 16 quarters in order to obtain the cumulative effect over a presidential term.
} 
average. ${ }^{19}$

Our set of high-dimensional fixed effects eliminates a lot of potentially confounding variation and allows us to overcome some of the central challenges in empirical studies of partisan behavior. Most importantly, firm $\times$ quarter fixed effects address the possibility that the relationship between partisan perception and rating actions may be confounded by non-random matching of analysts to firms. Second, by including agency $\times$ quarter fixed effects, we can remove any differences in rating methodologies across rating agencies. Third, by including party-affiliation fixed effects, we are removing any time-invariant differences across individuals with different party affiliations, and can isolate changes in their rating behavior as the president changes.

In Internet Appendix Table IA.5, we repeat our main analysis but report the effects separately for Democratic and Republic analysts (Panel A) as well as for Democratic, Republican, and unaffiliated analysts (Panel B). In Panel A, the coefficient on Democrat captures the difference in the average rating adjustment between Democratic and Republican analysts under Republican presidents, which is equal to 0.0268 notches (column (3)). Under Democratic presidents, the difference between Democratic and Republican analysts is equal to -0.0031 notches $(=0.0268-0.0299)$ and statistically insignificant. Hence, consistent with Figure 2, we find the difference between Democratic and Republican analysts is more pronounced under Republican presidents than under Democratic presidents. Moreover, Panel B further shows Democratic analysts behave more similarly to unaffiliated analysts, because the difference between Democratic and unaffiliated analysts is almost never statistically significant.

A potential concern could be that our ideological mismatch variable picks up the effect of other analyst characteristics that may be correlated with party affiliation. Note such unobservable characteristics would pose a threat to our identification only if they can explain differential behavior under Democratic versus Republican administrations. What characteristics that might be is not obvious. To still directly address this potential issue, Table IA.6 in the Internet Appendix repeats the analysis from Table 2, while including additional analyst characteristics as well as their interaction with an indicator for Democratic presidents. We include characteristics that are known to be important predictors of political affiliation: ethnicity, gender, and age. Across all three specifications, the coefficient estimate on ideological mismatch is remarkably stable.

\footnotetext{
${ }^{19}$ This comparison has to be taken with a grain of salt, because the various studies differ in their econometric specification and empirical setting.
} 


\subsection{Presidential Elections}

\subsubsection{All Presidential Elections}

To further support the interpretation that our results reflect the effect of analysts' partisan perception, we conduct an event study around presidential elections. We focus on presidential elections where the party of the president changes (i.e., the 2000, 2008, and 2016 elections) in order to isolate the effect of a change in ideological alignment on rating changes. Specifically, we estimate the following regression:

$$
\Delta R_{i f t}=\alpha_{f t}+\alpha_{j t}+\sum_{\tau=-4}^{\tau=+4} \beta_{\tau} \text { Mismatch }_{i, \tau=0} \times D_{t}^{\tau}+\epsilon_{i f t}
$$

where Mismatch $_{i, \tau=0}$ refers to an indicator equal to 1 for analysts who switch from aligned to misaligned with the president around the election in $\tau=0$, and $D_{t}^{\tau}$ stand for calendar quarter dummies. We restrict the analysis to Democratic and Republican analysts only. $\alpha_{f t}$ and $\alpha_{j t}$ refer to firm $\times$ quarter and agency $\times$ quarter fixed effects, respectively.

Figure 3 plots the results. We find small and insignificant differences between aligned and misaligned analysts during the quarters leading up to the election. During the election quarter, we then see a striking and statistically significant divergence in rating actions, with misaligned analysts downward-adjusting rating more by 0.0601 notches. Overall, we see larger downward adjustments by misaligned analysts in the post-election period (quarters 0 to +4 ) than in the pre-election period (quarters -4 to -1 ), with the difference being statistically significant at the $10 \%$ level.

\subsubsection{Presidential Election}

We next focus on the 2016 election because it is unique - the outcome was unexpected and the two candidates had very different positions on economic issues. Moreover, unlike the 2008 election, the 2016 election did not overlap with any major economic events.

Figure 4 plots the difference in the average rating adjustment between Democratic and Republican analysts around the 2016 election. We estimate the same regression as in equation (2), but use monthly rather than quarterly data in order to better isolate the effect of the election.

The difference in the average rating adjustment between Democrats and Republicans is close to zero prior to the election. The difference then spikes significantly during the election month, November 2016, indicating Democratic analysts downward-adjusted firms more by 0.034 notches. Despite the data limitations related to this event study and the fact that rating changes are infrequent events, the results indicate a significant change in 
the rating behavior between Democratic and Republican analysts around the 2016 election. We see a small reversal during February 2017, where Democratic analysts upward-adjust ratings slightly more than Republican analysts, although the difference is not statistically significant. When we expand the event window to span the period from 2015Q1 to 2018Q1, we do not find that this reversal continues. Internet Appendix Table IA.11 reports the results from this analysis that uses quarterly data. We find that Democratic analysts, on average, downward-adjust credit ratings by 0.0245 notches more than Republicans in the post-Trump period relative to the pre-Trump period.

Due to the unexpected outcome of the election, the event study allows us to rule out several alternative stories. Given the evidence that economic conditions can influence voting behavior (see Lewis-Beck and Stegmaier (2000) for a review of the relevant literature), a potential concern about our main analysis could be that the political affiliation of analysts might change in response to presidential policies or economic conditions. The event study mitigates such reverse-causality concerns, given that political attitudes of the analysts are unlikely to change discontinuously during the election month. It also makes it unlikely that we are picking up disagreement about other economic events unrelated to the presidential election, because the election month did not coincide with other major events.

\subsection{Robustness Tests}

Table 3 presents additional robustness tests for the main result in Table 2 and shows our main result is robust to a battery of additional tests. Unless otherwise mentioned, we report results for the specification in Table 2, column (3), and suppress all control variables for brevity.

In Panel A, we alter the definition of the dependent variable. To mitigate the concern that our main result could be driven by outliers in the dependent variable, we modify the rating-change variable to take only three possible values: +1 for downgrades, 0 for no change, and -1 for upgrades. The result is very similar and the statistical significance, if anything, increases. When we separate the propensity to upgrade versus downgrade, we find the effect is coming from both sides: Analysts who are not aligned with the White House are both more likely to downgrade and less likely to upgrade.

Panel B shows results for alternative definitions of mismatch. For example, we use a definition of mismatch that uses only party-affiliation information from presidential elections, as opposed to all elections. We also test a definition of mismatch that complements our party affiliation from voter registration records with party information from analysts' financial contributions to political parties, candidates, and committees. ${ }^{20}$ Both alternative

\footnotetext{
${ }^{20}$ Data on financial contributions are obtained from Stanford's Database on Ideology, Money in Politics,
} 
definitions of ideological mismatch yield results that are similar to our baseline.

In Panel C, we assess the robustness of our results with respect to alternative estimation methods. Triple-clustering by firm, analyst, and quarter leads to smaller standard errors. We also verify that we find similar results if we estimate the regression in equation (1) at the agency-firm-quarter level instead of at the analyst-firm-quarter level; that is, we compute the average ideological mismatch across all analysts from the same rating agency covering the same firm at the same point in time. Next, we estimate a weighted regression, where weights are proportional to the total book assets of the rated firm. We also show our results are robust to including analyst fixed effects. The latter result is important, because it reinforces our argument that we are capturing the effect of partisan perception separately from time-invariant characteristics of the analyst, which may be correlated with party affiliation. Moreover, our results are robust when we replace agency $\times$ quarter fixed effects with agency $\times$ sector $\times$ quarter fixed effects, to address the possibility that rating agencies with different compositions of Democratic and Republican analysts might use different rating methodologies in different sectors across Democratic or Republican presidencies. Furthermore, our results do not change when we introduce NBER recession interacted with party-affiliation fixed effects. The latter mitigates the potential concern that our baseline results reflect a differential response of Democratic and Republican analysts to recessions, as opposed to a differential response to different White House administrations.

In Internet Appendix Table IA.10, we also test whether ideological mismatch with the party that controls the U.S. Senate or the U.S. House of Representatives matters for rating decisions. In column (1), we find analysts misaligned with the party majority in the Senate downward-adjust ratings more. We do not find a significant effect from misalignment with the party majority in the House of Representatives (column (2)). When we add misalignment with the president as an additional control in columns (3) and (4), neither ideological mismatch with the Senate nor with the House of Representatives has incremental explanatory power. This insignificance of the party in control of Congress is consistent with existing studies of political cycles and stock returns (Santa-Clara and Valkanov (2003); Pástor and Veronesi (2018)), as well as with prior studies of political cycles and GDP growth (Blinder and Watson (2016)). We do not have a complete explanation for why disagreement with the president matters, whereas disagreement with Congress does not matter incrementally. We speculate this result could be driven by the party of the U.S. president being more salient to analysts than the identity of the party that controls Congress. According to a Gallup poll from 2014, only $41 \%$ of the surveyed registered and Elections (DIME) (see Bonica (2016)). We are able to match 57 analysts to a federal or statelevel contribution. In the Internet Appendix, we provide additional information regarding the merging procedure. 
voters were able to correctly identify the majority in both the Senate and the House (Saad (2014)). Although this percentage could be different in the population of credit rating analysts, it still highlights that the party of the president is more salient to voters than the party majority in Congress. Moreover, only $32 \%$ of registered voters prefer a one-party control of Congress (Jones (2014)), indicating they do not have a strong preference for their own party controlling Congress.

Finally, Internet Appendix Figure IA.2 plots our coefficient estimates after sequentially excluding each GICS sector that represents at least $5 \%$ of our total observations. The coefficient estimate is remarkably consistent across all specifications, suggesting our main result is not driven by a single sector. Moreover, in Internet Appendix Figure IA.3, we find the effect of partisan perception is fairly consistent across issuers of different credit quality.

\subsubsection{Robustness to Using Rating Levels}

We also assess the robustness of our main results to studying rating levels instead of rating changes. Figure 5 repeats the same analysis as in Figure 3, but uses the quarter-end rating level as the dependent variable. The figure shows a change in the difference in rating levels between aligned and misaligned analysts after the election, as it is evident from the change in slope following the election. Moreover, consistent with Figure 3, we observe that the effect on the rating level is gradual. It takes a few quarters quarters - until $t=2-$ for the difference in rating levels to switch sign. The difference between the average difference in rating levels is statistically significant at the $10 \%$ level if we compare the average in quarters 0 to +4 to the average in quarters -4 to -1 . It is statistically significant at the $5 \%$ level if we allow for a gradual response and exclude quarters 0 and +1 .

We also study the effect of alignment with the president on rating levels over the full sample period. We use the same specification as in Internet Appendix Table IA.5 and regress the quarter-end rating on an indicator for Democratic analysts and an interaction between Democratic analysts and Democratic presidents. Internet Appendix Table IA.7 presents the results. Using the estimates in Panel A, column (3), we observe that, relative to Republican analysts, Democratic analysts are 0.137 notches more positive under Democratic presidents than under Republican presidents (see coefficient on the interaction term Democrat $\times$ DemPresident). The estimated effect of 0.137 notches is lower than our baseline estimate of 0.21 notches mainly due to the slow adjustment of ratings. As we show in Panel B, the coefficient gets closer to our baseline effect of 0.21 notches once we remove quarters close to the election (here we remove quarters 0 and +1 ). Specifically, we obtain an effect of 0.184 notches in Panel B, column (3).

In sum, these results highlight the robustness of our main results to using rating levels. 


\subsection{Heterogeneity across Analysts}

We next test for heterogeneous effects across analysts. Specifically, we investigate whether the effect of political alignment with the president is more pronounced among analysts who are politically active.

In Table 4, we test three alternative proxies for political activeness, based on how frequently the analyst votes. First, we identify analysts who have voted in a primary or midterm election. Second, we compute the average time gap (in quarters) between the elections in which the analyst votes. Third, we create an indicator variable Frequent voter that is equal to 1 for analysts who either have voted in a midterm or primary election, or for whom the the average election gap is in the bottom quartile across all analysts within a given quarter indicator is equal to 1 , and 0 otherwise (column (3)). Because some of these measures are correlated with voter age, we also control for the interaction between voter age and ideological mismatch. All three measures indicate the effect of partisan bias is substantially stronger for analysts who vote more frequently. The importance of voting frequency supports the interpretation that our results reflect differences in partisan perception, and further raises the bar for alternative explanations.

\section{Price and Real Effects of Analysts' Partisan Per- ception}

Our results so far show partisan perception affects corporate credit ratings. The goal of this section is to gauge the potential consequences of the main result on firms' cost of financing and investment decisions. First, regarding price effects, we document that firms that are rated by misaligned analysts experience a greater reduction in their stock prices and a larger increase in their bond yields compared to firms rated by aligned analysts. Second, to explore the effect of partisan perception on firm investment, we examine the difference in the investment policies of firms rated by aligned versus misaligned analysts in the quarters around presidential elections.

\subsection{Stock Prices}

A number of studies have documented the reaction of common stock prices to credit rating changes. The general conclusion of this literature, starting with the work by Holthausen and Leftwich (1986), is that downgrades are associated with significant negative abnormal stock returns, even after eliminating observations that contain potentially contaminating 
concurrent news releases. Little evidence supports the assertion that upgrade announcements trigger significant abnormal returns.

We replicate these findings for our sample of rating-change announcements. Retaining all rating actions by analysts whom we can match to a voter record, we compute abnormal stock returns around the date of the rating change reported in Moody's DRD, S\&P RatingXpress, and Mergent, respectively. Abnormal returns are calculated using the Fama and French (1993) and Carhart (1997) model estimated over trading days (-300,-50) relative to the rating change. In Figure 6, we plot the abnormal returns in the 21 days around the upgrade and downgrade announcements in our sample. We also remove any rating changes where the firm makes an earnings announcement or an M\&A announcement inside the $(-10,+10)$ window. $^{21}$ Consistent with prior studies (e.g., Holthausen and Leftwich (1986); Hand, Holthausen, and Leftwich (1992)), we find large negative average abnormal returns $(-1.9 \%)$ in the three days around rating downgrades, and very small abnormal returns $(0.2 \%)$ around upgrades after excluding concurrent events. Further consistent with prior evidence, we also find a substantial anticipation effect in stock prices prior to downgrades, indicating either information leakage or deteriorating creditworthiness prior to the downgrade.

Given that we have established that analysts whose party affiliation does not match the president's downward-adjust more frequently, a remaining question is how well the market is able to "correct" for analysts' partisan perception. In other words, is the stock market reaction to downgrades muted when they are issued by misaligned analysts? Figure 6 suggests it is not. The overall pattern in the cumulative abnormal returns is very similar for analysts who are aligned and misaligned with the president. ${ }^{22}$

Why do stock prices not differentiate more between the downgrades by partisan analysts? Although a complete answer to this question is beyond the scope of this paper, we suggest at least two possible reasons. First, because access to registered voter lists in Illinois, New York City, and New Jersey is limited to the purpose of political campaigns and education, analysts' party affiliation is not public information and may therefore not be fully reflected in the stock price. Second, in the presence of rating-based regulatory frictions, downgrades may affect the supply of capital to firms, even if the rating change itself does not reveal any new information to the market. ${ }^{23}$

\footnotetext{
${ }^{21}$ Earnings-announcement dates are obtained from IBES and M\&A announcement dates from SDC Platinum.

${ }^{22}$ Although Figure 6 indicates slightly higher cumulative abnormal returns for misaligned analysts over a three-day window around rating downgrades, this difference disappears once we control for agency and calendar month effects, as we do in Internet Appendix Table IA.12.

${ }^{23}$ See Sangiorgi and Spatt (2017) for an excellent review of the literature on the regulatory role of credit ratings.
} 
Using the cumulative abnormal returns estimated above as a measure of the change in the firm's market capitalization induced by rating changes, we next examine whether firms rated by misaligned analysts experience, on average, a greater reduction in their market capitalization. We aggregate the three-day and seven-day cumulative abnormal returns around rating changes within a given rating agency, firm, and quarter, and replace them with zero when no rating change occurs in a given quarter. We then reestimate the regression in equation (1), after replacing the dependent variable with the cumulative abnormal returns around rating changes during the quarter.

Table 5 presents the results for cumulative abnormal returns measured over two event windows, $(-1,+1)$ (columns $(1)$ and $(2)$ ), and $(-3,+3)$ (columns $(3)$ and $(4)$ ), respectively. In columns (2) and (4), we exclude rating changes with a concurrent corporate event in the event window. We find that, in any given quarter after excluding corporate events, firms rated by misaligned analysts lose 3.2-3.9 basis points more of their market capitalization when they are rated by a misaligned analyst, depending on whether cumulative abnormal returns are measured over a $(-1,+1)$ or a $(-3,+3)$ event window. Because these losses accumulate over time, they are economically sizable: Over a four-year political cycle, a firm rated by a misaligned analyst loses $0.52 \%(=0.0322 \times 16)$ to $0.62 \%(=0.0386 \times 16)$ more of its market capitalization if it is rated by a misaligned analyst as opposed to an analyst who is politically aligned with the president. For the average-sized firm in our sample, this difference amounts to a total dollar loss of $\$ 89$ million- $\$ 107$ million.

We believe the estimated losses above likely represent an underestimation of the true losses in market capitalization due to analysts' partisan perception. First, although voter registration records provide a very useful proxy for analysts' political-party affiliation, they surely come with measurement error. Classical measurement will bias our estimates of the effect of partisan bias downward. Second, if rating changes are partially anticipated by the market, as Figure 6 suggests, the cumulative abnormal returns during the three or seven days around the rating change will underestimate the actual change in the firm's market capitalization due to a rating change. Our estimates above should therefore be interpreted as a lower bound on the magnitude of the stock price effect of analysts' partisan perception.

\subsection{Bond Yields}

We next turn to investigate the changes in bond yields around rating changes. We obtain daily yield to maturity and yield spreads for bonds issued by our sample of issuers from TRACE (see section 3 for a more detailed description on how we process the TRACE data). Yield spreads are computing using the closest maturity Treasury bond. Because bonds trade less frequently than stocks, we follow Hand, Holthausen, and Leftwich (1992) 
and compute the change in the bond yield (spread) around a rating action as the difference between the bond yield (spread) from the first day following the event and the yield (spread) on the most recent trading day prior to the event. For example, if a bond trades on days $-3,-2,+1$, and +2 , the yield (spread) change is calculated from transaction prices on day -2 and day +1 . We restrict the sample to bonds that are traded at least once in the 30 days prior and in the 30 days post the rating-change announcement. If multiple bonds of the same issuer are traded on the same day, we select a maximum of five bonds with the highest trading volume. In the analysis that follows, yield (spread) changes for each bond for a given firm are equally weighted and the average is treated as a single observation.

First, in Internet Appendix Table IA.13, we investigate whether yield spreads respond differently to a rating change depending on whether the rating change was initiated by an aligned or misaligned analyst. Consistent with our findings for stock returns, we do not find significant differences in the yield spread reaction. Moreover, Table 5, Panel B, mirrors our analysis of abnormal stock returns by examining whether firms rated by misaligned analysts experience on average larger increases in bond yields (spreads) due to rating changes. We first compute the average change in bond yields around the rating actions in our sample. ${ }^{24}$ Next, we replace the bond-yield change with zero in quarters where no rating change occurs. Finally, we reestimate the regression in equation (1), after replacing the dependent variable with the yield change around rating changes during the quarter. In columns (3) and (4), we repeat the same procedure, using the yield spread change around the rating action rather than the yield change. Our most conservative estimate in column (4) suggests firms rated by a misaligned analyst experience an increase of 5.9 basis points $(=0.3680 \times 16)$ over a four-year term relative to firms rated by aligned analysts.

This point estimate indicates a $28.1(=5.9 / 0.21)$ basis-point increase in bond yields for a one-notch rating change. Our estimate is smaller than the estimates from Almeida, Cunha, Ferreira, and Restrepo (2017), who exploit exogenous variation in corporate ratings due to rating agencies' sovereign ceiling policies and find a 0.7 -notch decrease in credit ratings is associated with an increase in bond yields of 34 basis points over three months. ${ }^{25}$ Our estimate is closer to causal estimates from the U.S. municipal bond market: Cornaggia, Cornaggia, and Israelsen (2017) exploit exogenous variation in municipal bond ratings due to a recalibration of Moody's rating scale and find a one-notch upgrade is, on average, associated with a decrease in bond yields of 12 to 18 basis points.

For the same reasons as we discussed in section 6.1, our estimated effects on bond yields

\footnotetext{
${ }^{24}$ In case there are multiple rating actions within a given agency, firm, and quarter, we sum up the average change in bond yields around each rating action.

${ }^{25} \mathrm{~A}$ potential explanation for this difference could be the different geographical focus of our study: whereas we focus on U.S. issuers, Almeida, Cunha, Ferreira, and Restrepo (2017) study an international sample of issuers.
} 
likely represent a lower bound for the true effect of partisan perception. By focusing on a relatively narrow window around the rating change, we are missing some of the sizable anticipation in bond yields prior to the rating change. In Internet Appendix Table IA.14, we further show that firms rated by misaligned analysts issue new bonds at higher yields than otherwise similar firms rated by aligned analysts. This set of results is less well identified, because we cannot include firm $\times$ quarter fixed effects as we do in the analysis above. Instead, we estimate a regression with lagged median rating $\times$ quarter fixed effects and control as best as we can for observable firm characteristics. Unfortunately, we cannot include firm fixed effects as we have very few repeated issuers. In terms of magnitude, the yield spreads of new bonds issued by firms with majority misaligned analysts are 12 basis points higher than yields on new bonds issued by firms with majority aligned analysts. These results are useful because they provide direct evidence that firms rated by misaligned analysts experience an increase in their cost of borrowing.

\subsection{Firm Investment}

Finally, we test whether partisan perception influences firm investment. In Figure 7, we examine whether firms rated by misaligned analysts experience, on average, a decrease in investment around the election of a new president. As in Figure 3, we focus again on presidential elections where the party of the president changes (i.e., the 2000, 2008, and 2016 elections) in order to isolate the effect of a change in analysts' ideological alignment with the president on firm investment. Because investment is observed at the firm-quarter level, we compute a firm-quarter-level measure of ideological mismatch, which is the share of misaligned analysts covering the firm. Specifically, we estimate the following regression:

$$
\operatorname{Ln}\left(\text { Capex }_{f t}\right)=\alpha_{f}+\alpha_{t}+\sum_{\tau=-4}^{\tau=+4} \beta_{\tau} \text { Mismatch }_{f t, \tau=0} \times D_{t}^{\tau}+\epsilon_{f t}
$$

where Mismatch $_{f t, \tau=0}$ is the share of misaligned analysts in a given quarter, where alignment is computed based on the party of the president who is elected in $\tau=0$. To compute the share of misaligned analysts, in each firm-quarter we first compute the share of Democratic (Republican) analysts rating the firm, while treating unaffiliated analysts as in between Democrats and Republicans. Around the 2000 and 2016 election, we use the share of Democratic analysts as the share of misaligned analysts, and around the 2008 election, we use the share of Republican analysts as the share of misaligned analysts. ${ }^{26} \operatorname{Ln}($ Capex) is the logarithm of the firm's quarterly capital expenditures. $\alpha_{f}$ and $\alpha_{t}$ refer to firm and

\footnotetext{
${ }^{26}$ In unreported results, we find qualitatively similar results if, rather than using the continuous share of misaligned analysts, we sort firms into terciles or quartiles based on their share of misaligned analysts.
} 
quarter fixed effects, respectively.

Figure 7 shows a strong decline in capital expenditures around the election for firms that are rated by analysts who are misaligned with the newly elected president relative to firms rated by aligned analysts. The difference between the average difference in investment levels post election (quarters 0 to +4 ) and the average difference in investment levels preelection (quarters -1 to -4 ) is statistically significant at the $5 \%$ level (see column (1) of Table IA.15 in the Internet Appendix). In terms of economic magnitude, the decrease in investment by firms who transition from $0 \%$ misaligned analysts to $100 \%$ misaligned analysts is equal to $10.2 \%$, which corresponds to a decrease of $\$ 17$ million for the average firm in our sample. This suggests that firms are curtailing capital expenditures when they are rated by misaligned analysts. Moreover, in Internet Appendix Table IA.15, columns (2) and (3), we show the robustness of the result when sorting firms into terciles or quartiles based on their share of misaligned analysts. In unreported results, we also repeat the analysis using the full sample and find qualitatively similar results, although they are not statistically significant.

A potential concern about the analysis above is that firms rated by aligned versus misaligned analysts could differ on unobserved dimensions, which could lead to a differential response to a presidential election even in the absence of differential rating actions. This concern is difficult to address, because it would require exogeneity in the assignment of analysts to firms. Although the analysis of firm investment has more shortcomings compared to our previous tests, which include firm $\times$ quarter fixed effects, we nevertheless find the above analysis useful because it provides strong suggestive evidence that the differences in analysts' rating behavior documented above have real consequences. This finding is also in line with prior evidence in the literature that credit ratings affect firm investment (e.g., Almeida, Cunha, Ferreira, and Restrepo (2017)).

\subsection{Analyst Accuracy}

Our main results suggest analysts make different rating adjustments for the same firm at the same point in time depending on whether the White House is controlled by the party with which they are affiliated. Because, by construction, these rating differences are orthogonal to firm fundamentals, we would expect partisan perceptions to also affect credit rating accuracy. What we cannot disentangle based on the existing results is which of the two groups of analysts - those with and without ideological mismatch - is relatively more "right" or "wrong." In other words, whether the analysts who are aligned with the president's party downward-adjust by too little, or whether those who are misaligned downward-adjust by too much, or both is unclear. 
Finding suitable measures of analyst accuracy is challenging for a number of reasons. First, no clear benchmark of analysts who are not subject to partisan perception exists. Using unaffiliated or unregistered analysts as a "neutral" benchmark might be tempting, but both groups suffer from substantial measurement error. In particular, given the location of the analysts in our sample (Chicago and New York), the chance that an unaffiliated or unregistered analyst is leaning Democratic is high, which would bias us toward finding that Democratic analysts are less biased. Second, the firm's true probability of default and expected loss given default are unobservable, and traditional metrics of rating accuracy that are based on ex-post default rates by rating category rely on a large number of sample events in order to be meaningful. Third, due to the causal effect of credit ratings (see Almeida, Cunha, Ferreira, and Restrepo (2017)), ex-post firm outcomes reflect both, firm fundamentals in the absence of credit ratings, as well as the causal effect of the credit rating. Fourth, determining systematic differences across analysts in their ex-post rating accuracy across Democratic and Republican presidents requires a long time-series of election cycles.

To at least partially address these challenges, we present two distinct tests of analyst accuracy. To rule out that our coding of unaffiliated analysts influences the results, we restrict our analysis below to Democratic and Republican analysts. Our first measure builds on work by Fracassi, Petry, and Tate (2016) and Kisgen, Nickerson, Osborn, and Reuter (2019), by capturing the correlation between rating changes and future movements in yield spreads. Intuitively, if the analyst issues a downgrade $\left(\Delta R_{i f t}>0\right)$, and subsequently credit spreads on the firm's bonds increase (decrease), she would be considered more accurate (inaccurate). We operationalize this idea by regressing future changes in yield spreads $\left(s_{f, t+h}-s_{f t}\right)$ on the analyst's current-quarter change in the rating $\left(\Delta R_{i f t}\right)$, ideological mismatch $\left(M_{i t}\right)$, an interaction term, and controls:

$$
s_{f, t+h}-s_{f t}=\alpha_{j t}+\alpha_{p}+\beta_{1} \Delta R_{i f t}+\beta_{2} \Delta R_{i f t} \times M_{i t}+\beta_{3} M_{i t}+\gamma^{\prime} X_{f t}+\epsilon_{i f t} .
$$

We control for agency $\times$ quarter and party-affiliation fixed effects as in our baseline regression. Because we are unable to include firm $\times$ quarter fixed effects as yield spreads do not vary within firm-quarter, we include median lagged rating $\times$ quarter fixed effects as well as controls for observable firm characteristics $\left(X_{f t}\right)$. A positive (negative) coefficient $\beta_{2}$ in equation (4) would indicate higher (lower) accuracy for mismatched analysts.

Table 6, Panel A, reports the results. We vary the horizon over which the future change in yield spreads is measured from 4 to 8 to 12 quarters. Across all horizons, we find the interaction between the current-quarter rating change and ideological mismatch is negative, indicating lower accuracy for misaligned analysts. However, when movements in yield spreads are measured over 12 quarters, we no longer find statistical significance, which 
could be due to the fact that we lose more observations. Taken together, the results imply that rating changes by ideologically mismatched analysts are less positively correlated with future changes in spreads.

An important drawback of spread-based accuracy measures is that credit spreads may be directly affected by analysts' rating actions. In particular, Almeida, Cunha, Ferreira, and Restrepo (2017) show bond yields continue to increase for several months following a downgrade. To somewhat mitigate this problem, our second measure builds on existing work by Kempf (2020) and Jiang, Kumar, and Law (2016) by measuring analyst (in)accuracy based on future revisions of the previously assigned rating. Specifically, we measure accuracy as -1 times the absolute difference between the current rating and the prevailing rating 4, 8, or 12 quarters in the future. The intuition behind this measure is that larger revisions in the future indicate less accurate ratings.

Table 6, Panel B, reports the results from regressing this measure of accuracy on analysts' ideological mismatch. All specifications include agency $\times$ quarter fixed effects, firm $\times$ quarter fixed effects, and party-affiliation fixed effects. Across all horizons, we observe that ideologically mismatched analysts are less accurate, because their ratings need to be revised more in the future. The point estimate in column (3) indicates ideological mismatch reduces analyst accuracy by 0.102 notches, which corresponds to $11.2 \%$ of the mean in analyst accuracy measured over 12 quarters. These results therefore confirm the conclusion from our first test that misaligned analysts are less accurate.

To sum up, the results in Table 6 suggest analysts who do not support the president tend to be less accurate. Measuring rating accuracy using yield spreads and deviations between the initial rating and subsequent ratings has important advantages. First and foremost, it does not require a large number of ratings for each individual analyst in order to be meaningful. Second, it allows us to capture smaller changes in the expected default probability that may not always lead to a default. Third, to the extent that future rating revisions or changes in spreads are driven by the arrival of new information, this information would affect the accuracy measure of all analysts rating the same firm at the same point in time.

Although these tests allow us to address some of the empirical challenges associated with establishing differences in accuracy that we highlighted above, some important caveats remain. First, determining systematic differences across analysts in their ex-post rating accuracy under Democratic and Republican presidents with sufficient confidence requires a much longer time-series of election cycles than our current sample period. Second, and perhaps more importantly, any test of analyst accuracy involves a comparison of ex-ante credit ratings with ex-post outcomes (e.g., defaults, rating revisions, or credit spreads). 
Due to the causal effect of credit ratings, ex-post outcomes reflect both firm fundamentals in the absence of the credit rating, and the causal effect of the rating. Hence, one of the crucial advantages of our setting - credit ratings having causal effects on securities prices and firm policies - is also a drawback when testing analyst accuracy.

\section{Mechanisms}

So far, we have documented that partisan perception affects credit ratings and has price and real effects for firms. In this section, we investigate potential channels through which political-party affiliation influences credit ratings.

\subsection{Belief Disagreement}

The existing literature has established a strong influence of political alignment with the U.S. president on households' beliefs about aggregate economic conditions (e.g., Bartels (2002); Gerber and Huber (2009); Mian, Sufi, and Khoshkhou (2018)). Thus, a natural explanation for our results could be that analysts with different party affiliations differ in their views on how the economic policies and regulations of the U.S. president will affect the credit risk of firms in the economy.

We provide three pieces of evidence to support the interpretation that our results are driven by belief disagreement. First, we conduct an online survey of credit rating analysts and document more pessimistic views on current economic conditions among credit rating analysts who are not aligned with the president. Second, we find the effect is stronger when political polarization in views of the economic condition is high. Third, we show that differences in rating behavior disappear when analysts rate firms whose fundamentals are less correlated with the U.S. economy and with presidential policies.

\subsubsection{Survey Evidence}

We first present survey evidence to directly support our interpretation that credit analysts with different partisan identities differ in their economic beliefs. To keep the survey as brief as possible and maximize the potential response rate, we focused on the state of the economy as the object of analyst disagreement. Specifically, we conducted an online survey of current and former credit rating analysts to ask them about their views on current economic conditions as well as about their political ideology and demographic characteristics. We invited alumni of Cornell University Johnson School of Management and of the University of Chicago Booth School of Business who work or used to work at 
credit rating agencies, as well as members of the LinkedIn group "Credit Rating Agency Alumni + Friends," to participate in the survey. Overall, we invited 402 individuals and received 91 responses (i.e., we have a response rate of $22.6 \%$ ).

To infer analysts' views on current economic conditions, we used the following question from the Gallup Daily survey: "How would you rate economic conditions in this country today?" with possible answers of "excellent," "good," "fair," and "poor." We code the answers with numerical values from 1 to 4 , with 1 indicating the least favorable view and higher values representing more favorable views. In addition to the question on economic views, we also asked analysts about the number of years of experience and their demographic characteristics, such as age, gender, ethnicity, and residence. To infer the political affiliation of the analysts, we used the following question (same as in the Gallup Daily survey): "In politics, as of today, do you consider yourself a Republican, a Democrat, an Independent or Unaffiliated?" We classify a respondent's political affiliation as Republican, Democrat, or Independent (if she responded Independent or Unaffiliated). We drop 17 individuals who indicated they had never worked as credit rating analysts and 17 respondents who did not finish the survey. Our final sample of individuals who responded to both questions consists of 57 responses.

Table IA.2 in the Internet Appendix presents summary statistics of the respondents. The vast majority of the respondents had more than 10 years of work experience as credit rating analysts, with $35 \%$ of the respondents having more than 15 years of experience. Regarding their political affiliation, 39\% identified as Democrat, 28\% as Republican, and $33 \%$ as Independent, which is very similar to the political composition in our main sample. Also consistent with our main dataset, the majority of the respondents were white and male.

Table 7 presents the analysis of analysts' self-reported views on the state of the economy. We observe that Republicans held a more positive view of current economic conditions than Independents, whereas Democrats were statistically indistinguishable from Independents. The difference is robust to including controls for analysts' demographic characteristics (gender, age, and ethnicity) and years of experience. The difference between Democrats and Republicans is statistically significant at the $1 \%$ level in column (1) and at the $10 \%$ level in columns (2) and (3), and ranges between 0.366 (column (2)) to 0.432 (column (1)). Because the survey was conducted under a Republican administration, the results confirm the findings from prior household surveys that individuals' views of economic conditions depend on whether the White House is occupied by their preferred political party (Bartels (2002); Gaines, Kuklinski, Quirk, Peyton, and Verkuilen (2007); Gerber and Huber (2009); Curtin (2016); Mian, Sufi, and Khoshkhou (2018)). The economic 
magnitude of the difference between Democrats and Republican is also plausible. As of the fourth quarter of 2017, the last quarter with available data from the Gallup Daily survey, the difference in views of economic conditions between Republican and Democratic households was 0.57. The difference in our sample of credit rating analysts is somewhat smaller, but it is still economically large, which is remarkable given that we are studying a sample of financial experts who have a much higher level of economic sophistication than the average U.S. household. Moreover, the result provides direct evidence for our interpretation that the differences in credit rating actions documented above could be driven by differences in economic beliefs.

\subsubsection{Political Polarization in Views of Economic Conditions}

To further support the interpretation that our results reflect differences in economic beliefs, we investigate whether the effect of partisan bias is more pronounced during periods in which views of economic conditions are more politically polarized in the U.S. population.

To measure political polarization in the views of economic conditions, we use data from the Gallup Daily survey. To measure the views on current economic conditions, Gallup asks the following question: "How would you rate economic conditions in this country today as excellent, good, only fair, or poor?" The responses to this question are converted into a numerical scale that ranges from 1 (poor) to 4 (excellent). Our measure of polarization is the absolute difference in the average economic views between Democrats and Republicans in a given calendar quarter. We standardize the measure to have a mean of 0 and a standard deviation of 1 .

In Table 8, we interact ideological mismatch with the polarization in economic views Econ. polarization Gallup. The estimates in column (1) imply the effect of misalignment with the president increases by 0.011 notches for a one-standard-deviation increase in polarization, thereby increasing the baseline effect by $83 \%(=0.0087 / 0.0105)$. The result is robust when we add agency $\times$ sector fixed effects (column $(2)$ ) and agency $\times$ quarter fixed effects (column (3)). Internet Appendix Table IA.16 shows we find similar results if we construct our measure of polarization in economic views based on the Michigan Survey.

\subsubsection{Firm Heterogeneity}

If the main result in this paper is driven by credit analysts with different party affiliations having different views on how the economic policies of the U.S. president affect the credit risk of firms in the economy, we should see smaller differences in rating behavior when analysts rate firms whose fundamentals are less correlated with the U.S. economy. To measure cyclicality, we compute firms' equity market betas using the Fama and French 
(1993) and Carhart (1997) model estimated on monthly returns and a five-year rolling window. We then interact ideological mismatch with the estimated market beta. Table 9, columns (1) and (2) report the results. We find that the partisan disagreement is substantially more pronounced for firms with high market betas, i.e., high cyclicality. We obtain a very similar result if we compute the average market beta within a given GICS sector and quarter and then interact ideological mismatch with the sector-level market beta (columns (3) and (4)). The effect of partisan perception thus appears to be concentrated in firms with high exposure to the U.S. economy.

\subsection{Alternative Mechanisms}

Although the analysis above strongly supports belief disagreement as a potential mechanism driving our results, other non-mutually exclusive mechanisms could be present. Although we cannot exclude all potential alternative explanations, our evidence so far allows us to rule our several alternative stories.

Analysts' Personal Economic Situation. An important advantage of our setting is that rating actions are unlikely driven by differences in how analysts' personal economic situation changes when their preferred party is in power. This confounding factor represents a key challenge for studies of household behavior, but how analysts' professional assessment of the credit risk of firms in the economy could be affected by their personal economic situation is not obvious. Moreover, because the analysts whom we are comparing work for the same rating agency at the same point in time, their income is unlikely to be differentially affected by the elected president. Hence, the concern that our results could reflect differences in the wealth or income of the individuals whom we study is mitigated in our setting.

Strategic Behavior. Prior literature has shown equity analysts may be biased due to strategic behavior (e.g., Laster, Bennett, and Geoum (1999); Hong and Kostovetsky (2012)). In light of these studies, it is conceivable that our documented effect could reflect strategic behavior rather than belief disagreement.

We believe that our empirical setting substantially mitigates this concern. For strategic behavior to affect our estimates, it would not only have to correlate with political affiliation, but it would also have to vary with the party of the president. We feel it is nontrivial to think of plausible stories that could generate such strategic behavior.

One potential strategic behavior that would vary with the president's party could be that misaligned analysts downgrade firms more frequently in an effort to harm the econ-

omy and punish the president's party. Although this explanation is theoretically consistent with many results that we document, we find it less plausible for two main reasons. First, 
it assumes a high degree of coordination among analysts, because the rating decisions of any individual corporate analyst are unlikely to materially affect the economy. Such coordination would be especially difficult given that each analyst has an incentive to deviate, because her future promotion and career outcomes may depend on how accurately she assesses credit risk. Second, the results from the event study around the 2016 election are more consistent with belief disagreement and less consistent with misaligned analysts attempting to harm the president. If analysts were trying to harm the president, we would have expected no divergence in rating actions in response to the election outcome and a larger divergence when Donald J. Trump took office. Instead, we find Democratic analysts downward-adjusted credit ratings more relative to Republican analysts during the month when the election result became public, and no significant difference in the month when President Trump took office.

Another source of strategic behavior could be related to analysts' career concerns. For example, analysts could be rewarded with a career in the public sector in return for expressing positive views when the own party is in power, and negative views when the other party is in power. We think this story is unlikely to explain our results for two reasons. First, much more direct and visible ways to support a political party are available than issuing optimistic or pessimistic corporate bond ratings. For example, sovereign credit ratings would likely be more salient to a party's administration. Second, as an empirical fact, corporate credit analysts rarely pursue a career in the public sector. We hand-collected information on the career paths of the analysts in our sample and find only five out of 557 analysts started a public-sector job following their employment at the agency.

Political Connections. Another potential explanation is that analysts who are affiliated with the president's party may have "inside" information due to political connections. We think political connections are unlikely to explain our results, for at least three reasons. First, inside information due to political connections would predict a difference in rating accuracy, but not necessarily a difference in the direction of the average rating change, because why the inside information that analysts receive from their sources is always more positive relative to the beliefs of other analysts is not obvious. Second, it is again inconsistent with the timing of the effect around the 2016 presidential elections documented above. In fact, if the results reflected political connections, we should start to see a divergence shortly after Trump is inaugurated. Instead, we see a sizable divergence during the month of the election, and no significant divergence in the month when he takes office. Third, we hand-collected information on the career paths of the analysts in our sample and found only three analysts ended up transitioning to a job in the federal government after their employment at the rating agency. These numbers suggest a relatively low degree of 
political connections in our sample of analysts.

To conclude, although there is a large literature on the consequences of investor disagreement on asset prices, we know relatively little empirically about the sources of disagreement or factors that can intensify disagreement (e.g., Cookson and Niessner (2020)) . Our empirical evidence above establishes political partisanship as an important source of disagreement. Compared to other studies which have inferred differences in beliefs from differences in trading behavior, the strength of our empirical setup is that we can rule out other important drivers of dispersion in trading decisions, such as differences in hedging demands or liquidity needs as well as differences in private information. Moreover, by complementing our analysis of rating actions with the survey, we can provide direct evidence that the differences in rating actions we observe are likely due to differences in economic beliefs. Another important insight from our study is that analyst beliefs do not converge over the course of a presidency, which is consistent with frictions in learning (Xiong (2013)).

\section{Conclusion}

We show partisan perception affects the decisions of financial analysts. Using a novel dataset that links credit rating analysts to party affiliations from voter registration records, we show analysts who are not aligned with the president's party are more likely to adjust ratings downward. Our identification approach compares analysts with different party affiliations covering the same firm at the same point in time, ensuring that differences in firm fundamentals cannot explain the observed differences in rating actions. We further show rating actions by partisan analysts have significant price effects and may influence firms' investment decisions.

What could be the source of the partisan perception documented in this paper? Although a complete answer to this question is beyond the scope of this paper, we speculate that partisan perception could reflect two things. It could reflect a causal effect of party affiliation, where analysts, similar to sports fans, feel optimism or pessimism because their team won the election (Mason (2015)). Alternatively, party affiliation could be a powerful statistic that summarizes ideological differences across analysts beyond ethnicity, gender, and age and has strong incremental predictive power for their rating decisions and their response to public signals.

Given the documented increase in political polarization, understanding the potential implications of this trend for the U.S. economy is important. One potential channel for how polarization can have real effects is through the economic beliefs and actions of relevant economic agents. To the best of our knowledge, this study is the first to quantify the 
influence of partisan perception on the actions of an important set of finance professionals (credit rating analysts), as well as on securities prices and firm investment. Because the effect of partisan perception prevails even in a setting where pecuniary and professional gains are at stake, it may influence the behavior of many other relevant economic agents, such as firm managers and asset managers. This avenue is a fruitful one for future research in our view. 


\section{References}

Addoum, Jawad M., and Alok Kumar, 2016, Political Sentiment and Predictable Returns, Review of Financial Studies 29, 3471-3518.

Almeida, Heitor, Igor Cunha, Miguel A. Ferreira, and Felipe Restrepo, 2017, The real effects of credit ratings: The sovereign ceiling channel, Journal of Finance 72, 249-290.

Babenko, Ilona, Viktar Fedaseyeu, and Song Zhang, 2019, Do CEOs affect employees' political choices, Review of Financial Studies Forthcoming.

Bamber, Linda Smith, Orie E. Barron, and Thomas L. Stober, 1999, Differential interpretations and trading volume, Journal of Financial and Quantitative Analysis 34, 369-386.

Banerjee, Snehal, 2011, Learning from prices and the disperion in beliefs, Review of Financial Studies 24, 3025-3068.

, and Ilan Kremer, 2010, Disagreement and learning: Dynamic patterns of trade, Journal of Finance 65, 1269-1302.

Bartels, Larry M., 2002, Beyond the running tally: Partisan bias in political perceptions, Political Behavior 24, 117-150.

Becker, Bo, and Victoria Ivashina, 2014, Reaching for yield in the bond market, Journal of Finance 70, 1863-1902.

Becker, Bo, and Todd Milbourn, 2011, How did increased competition affect credit ratings?, Journal of Financial Economics 101, 493-514.

Begley, Taylor A., 2015, The real costs of corporate credit ratings, Working Paper.

Benhabib, Jess, and Mark M. Spiegel, 2018, Sentiments and economic activity: Evidence from U.S. states, Economic Journal 129, 715-733.

Bertrand, Marianne, and Emir Kamenica, 2018, Coming apart? Cultural distances in the United States over time, National Bureau of Economic Research Working Paper 24771.

Blinder, Alan S., and Mark W. Watson, 2016, Presidents and the U.S. economy: An econometric exploration, American Economic Review 106.

Bonaparte, Yosef, Alok Kumar, and Jeremy K. Page, 2017, Political climate, optimism, and investment decisions, Journal of Financial Markets 34, 69-94.

Bonica, Adam, 2016, Database on ideology, money in politics, and elections: Public version 2.0. Stanford, CA: Stanford University Libraries., https://data.stanford.edu/dime.

Boxell, Levi, Matthew Gentzkow, and Jesse M. Shapiro, 2017, Is the internet causing political polarization? Evidence from demographics, National Bureau of Economic Research Working Paper 23258. 
Brewer, Mark D., 2005, The rise of partisanship and the expansion of partisan conflict within the American electorate, Political Reserach Quarterly 58, 219-229.

Campbell, Angus, Philip E. Converse, Warren E. Miller, and Donald E. Stokes, 1960, The American Voter (New York: John Wiley \& Sons).

Carhart, Mark M., 1997, On persistence in mutual fund performance, Journal of Finance $52,57-82$.

Chen, Daniel L, 2019, Priming ideology: Why presidential elections affect U.S. judges, Working Paper.

Chernenko, Sergey, and Adi Sunderam, 2011, The real consequences of market segmentation, Review of Financial Studies 25, 2041-2069.

Chevalier, Judith, and Glenn Ellison, 1999, Are some mutual fund managers better than others? Cross-sectional patterns in behavior and performance, Journal of Finance 54, 875-899.

Cookson, J. Anthony, and Marina Niessner, 2020, Why don't we agree? Evidence from a social network of investors, Journal of Finance 75, 173-228.

Cornaggia, Jess, Kimberly J. Cornaggia, and Ryan D. Israelsen, 2017, Credit ratings and the cost of municipal financing, Review of Financial Studies 31, 2038-2079.

Cornaggia, Jess, Kimberly J. Cornaggia, and Han Xia, 2016, Revolving doors on Wall Street, Journal of Financial Economics 120, 400-419.

Cornaggia, Jess, Kimberly Rodgers Cornaggia, and Ryan D. Israelsen, 2019, Where the heart is: Information production and the home bias, Management Science Forthcoming.

Cunha, Igor, Miguel Almeida Ferreira, and Do Silva, Rui, 2019, Do financial markets affect election outcomes? Evidence from municipal bond ratings, Working Paper.

Curtin, Richard, 2016, Economic policy preferences, Survey of Consumers, University of Michigan, November.

DellaVigna, Stefano, and Joshua M. Pollet, 2009, Investor inattention and Friday earnings announcements, Journal of Finance 64, 709-749.

Dichev, Ilia D., and Joseph D. Piotroski, 2001, The long-run stock returns following bond ratings changes, Journal of Finance 56, 173-203.

Dick-Nielsen, Jens, 2009, Liquidity biases in trace, Journal of Fixed Income 19, 43-55.

Dion Bongaerts, K. J. Martijn Cremers, and William N. Goetzmann, 2012, Tiebreaker: Certification and multiple credit ratings, Journal of Finance 67, 114.

Fama, Eugene F., and Kenneth R. French, 1993, Common risk factors in the returns on stocks and bonds, Journal of Financial Economics 33, 3-56. 
Fracassi, Cesare, Stefan Petry, and Geoffrey Tate, 2016, Does rating analyst subjectivity affect corporate debt pricing?, Journal of Financial Economics 120, 514-538.

Gaines, Brian J., James H. Kuklinski, Paul J. Quirk, Buddy Peyton, and Jay Verkuilen, 2007, Same facts, different interpretations: Partisan motivation and opinion on Iraq, Journal of Politics 69, 957-974.

Gentzkow, Matthew, 2016, Polarization in 2016, Toulouse Network of Information Technology White Paper.

- Edward Glaeser, and Claudia Goldin, 2006, The rise of the fourth estate: How newspapers became informative and why it mattered, in Corruption and Reform: Lessons from America's Economic history 187-230.

Gerber, Alan S., and Gregory A. Huber, 2009, Partisanship and economic behavior: Do partisan differences in economic forecasts predict real economic behavior?, American Political Science Review 103, 407-426.

Gillitzer, Christian, and Nalini Prasad, 2018, The effect of consumer sentiment on consumption: Cross-sectional evidence from elections, American Economic Journal: Macroeconomics.

Griffin, John M., and Dragon Yongjun Tang, 2012, Did subjectivity play a role in CDO credit ratings?, Journal of Finance 67, 1293-1328.

Hand, John R. M., Robert W. Holthausen, and Richard W. Leftwich, 1992, The effect of bond rating agency announcements on bond and stock prices, Journal of Finance 47, $733-752$.

Harris, Milton, and Artur Raviv, 1993, Differences of opinion make a horse race, Review of Financial Studies 6, 473-506.

Hersh, Eitan D., and Matthew N. Goldenberg, 2016, Democratic and Republican physicians provide different care on politicized health issues, Proceedings of the National Academy of Sciences 113, 11811-11816.

Hill, Seth J., and Gregory A. Huber, 2017, Representativeness and motivations of the contemporary donorate: Results from merged survey and administrative records, Political Behavior 39, 3-29.

Hirshleifer, David, Sonya Seongyeon Lim, and Siew Hong Teoh, 2009, Driven to distraction: Extraneous events and underreaction to earnings news, Journal of Finance 64, 22892325 .

Holthausen, Robert W., and Richard W. Leftwich, 1986, The effect of bond rating changes on common stock prices, Journal of Financial Economics 17, 57-89.

Hong, Harrison, and Marcin Kacperczyk, 2010, Competition and bias, Quarterly Journal of Economics 125, 1683-1725. 
Hong, Harrison, and Leonard Kostovetsky, 2012, Red and blue investing: Values and finance, Journal of Financial Economics 103, 1-19.

Hutton, Irena, Danling Jiang, and Alok Kumar, 2014, Corporate policies of Republican managers, Journal of Financial and Quantitative Analysis 49, 1279-1310.

Igielnik, Ruth, Scott Keeter, Courtney Kennedy, and Bradley Spahn, 2018, Commercial voter files and the study of U.S. politics, Pew Research Report.

Iyengar, Shanto, Gaurav Sood, and Yphtach Lelkes, 2012, Affect, not ideology, Public Opinion Quarterly 76, 405-431.

Jelveh, Zubin, Bruce Kogut, and Suresh Naidu, 2018, Political language in economics, Working Paper.

Jiang, Danling, Alok Kumar, and Kelvin K. F. Law, 2016, Political contributions and analyst behavior, Review of Accounting Studies 21, 37-88.

Jones, Jeffrey M., 2014, Most U.S. voters ok with split-party control of Congress, Retrieved from https://news.gallup.com/poll/170261/ voters-split-party-control-congress.aspx/.

Kandel, Eugene, and Neil D. Pearson, 1995, Differential interpretation of public signals and trade in speculative markets, Journal of Political Economy 103, 831-872.

Kaustia, Markku, and Sami Torstila, 2011, Stock market aversion? Political preferences and stock market participation, Journal of Financial Economics 100, 98 - 112.

Kempf, Elisabeth, 2020, The job rating game: Revolving doors and analyst incentives, Journal of Financial Economics 135, 41-67.

Kisgen, Darren J., Jordan Nickerson, Matthew Osborn, and Jonathan Reuter, 2019, Analyst promotions within credit rating agencies: Accuracy or bias?, Journal of Financial and Quantitative Analysis Forthcoming.

Kisgen, Darren J., and Philip E. Strahan, 2010, Do regulations based on credit ratings affect a firm's cost of capital?, Review of Financial Studies 23, 4324-4347.

Laster, David, Paul Bennett, and In Sun Geoum, 1999, Rational bias in macroeconomic forecasts, Quarterly Journal of Economics 114, 293-318.

Lewis-Beck, Michael S., and Mary Stegmaier, 2000, Economic determinants of electoral outcomes, Annual Review of Political Science 3, 183-219.

Lott, John R., and Kevin A. Hassett, 2014, Is newspaper coverage of economic events politically biased?, Public Choice 160, 65-108.

Makridis, Christos, 2019, Sentimental business cycles and the protracted Great Recession, Working Paper. 
Mason, Lilliana, 2013, The rise of uncivil agreement: Issue versus behavioral polarization in the American electorate, American Behavioral Scientist 57, 140-159.

— - 2015, I disrespectfully agree: The differential effects of partisan sorting on social and issue polarization, American Journal of Political Science 59, 128-145.

McGrath, Mary C., 2017, Economic behavior and the partisan perceptual screen, Quarterly Journal of Political Science 11, 363-383.

McKenzie, Mark Jonathan, 2012, The influence of partisanship, ideology, and the law on redistricting decisions in the federal courts, Political Research Quarterly 65, 799-813.

Meeuwis, Maarten, Jonathan A. Parker, Antoinette Schoar, and Duncan I. Simester, 2018, Belief disagreement and portfolio choice, National Bureau of Economic Research Working Paper 25108.

Mian, Atif R., Amir Sufi, and Nasim Khoshkhou, 2018, Partisan bias, economic expectations, and household spending, Working Paper.

Pástor, Lubos, and Pietro Veronesi, 2018, Political cycles and stock returns, National Bureau of Economic Research Working Paper 23184.

Pew Research Center, 2017, Key takeaways on Americans' growing partisan divide over political values, Pew Research Center Author:Carroll Doherty.

— , 2019, Trump begins third year with low job approval and doubts about his honesty, Washington, D.C.

Posner, Eric A., 2008, Does political bias in the judiciary matter?: Implications of judicial bias studies for legal and constitutional reform, University of Chicago Law Review 75, 853-883.

Saad, Lydia, 2014, In U.S., four in 10 say party control of Congress matters, Retrieved from https://news.gallup.com/poll/176522/ four-say-party-control-congress-matters.aspx/.

Sangiorgi, Francesco, and Chester Spatt, 2017, Foundations and Trends in Finance, vol. 12 . chap. The Economics of Credit Rating Agencies, 1-116 (Wiley).

Santa-Clara, Pedro, and Rossen Valkanov, 2003, The presidential puzzle: Political cycles and the stock market, Journal of Finance 58, 1841-1872.

Xia, Han, 2014, Can investor-paid credit rating agencies improve the information quality of issuer-paid rating agencies?, Journal of Financial Economics 111, 450-468.

Xiong, Wei, 2013, Bubbles, crises, and heterogeneous beliefs, National Bureau of Economic Research Working Paper 18905.

Ye, Junting, Shuchu Han, Yifan Hu, Baris Coskun, Meizhu Liu, Hong Qin, and Steven Skiena, 2017, Nationality classification using name embeddings, in Proceedings of the 2017 ACM on Conference on Information and Knowledge Management 1897-1906. 


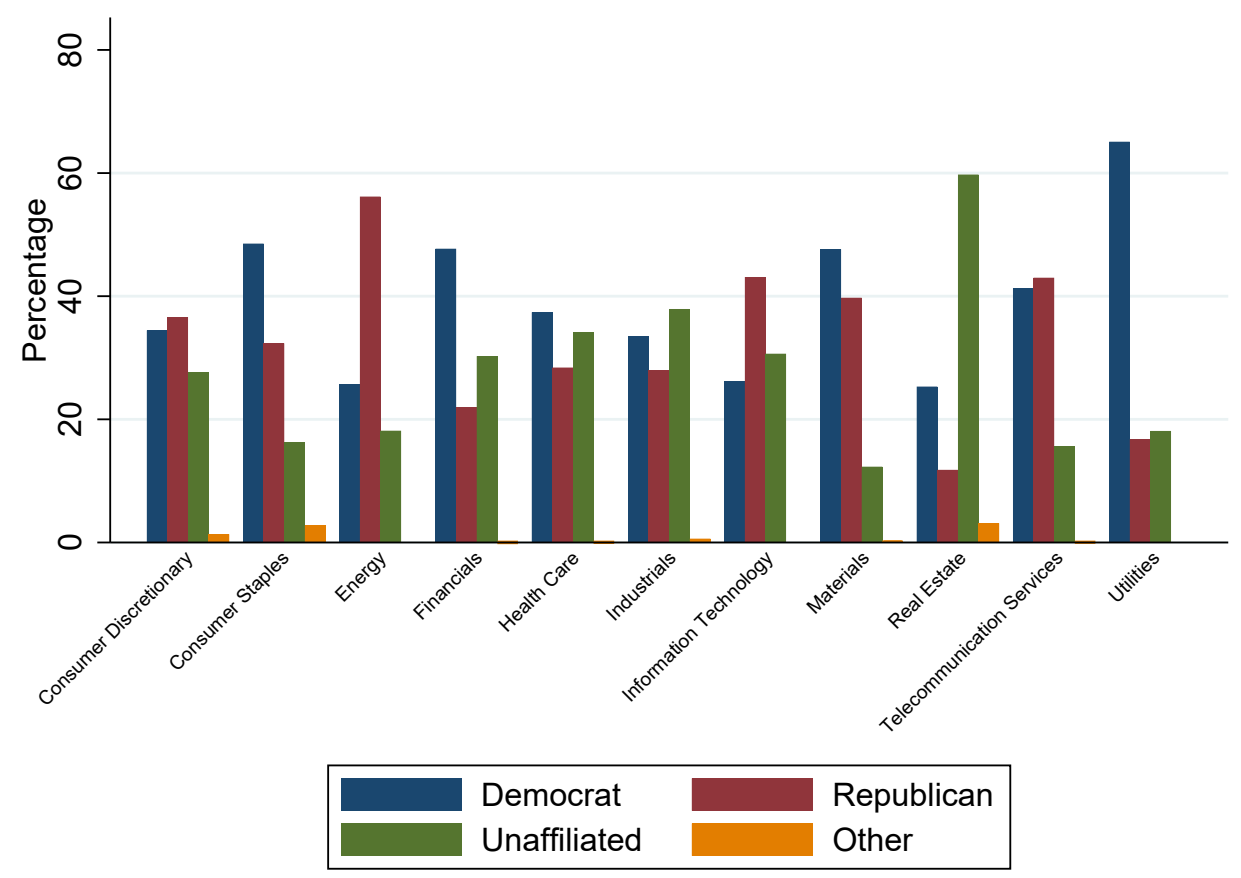

(a) Party Affiliation by GICS Sector

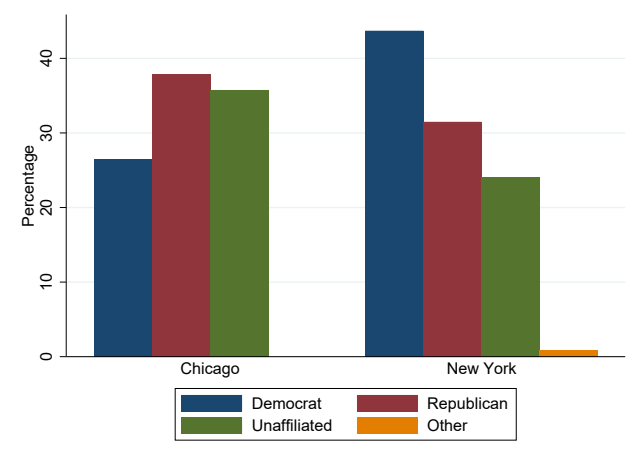

(b) Party Affiliation by City

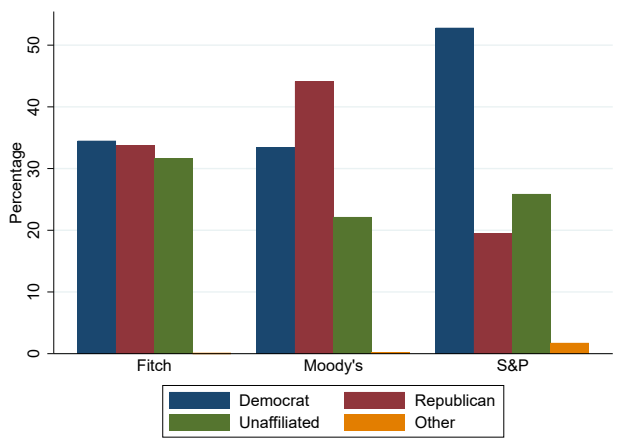

(c) Party Affiliation by Rating Agency

Figure 1: Party-Affiliation Summary. The figure plots the distribution of Democratic, Republican, unaffiliated, and other analysts by GICS sector (Panel (a)), city (Panel (b)), and rating agency (Panel (c)). 


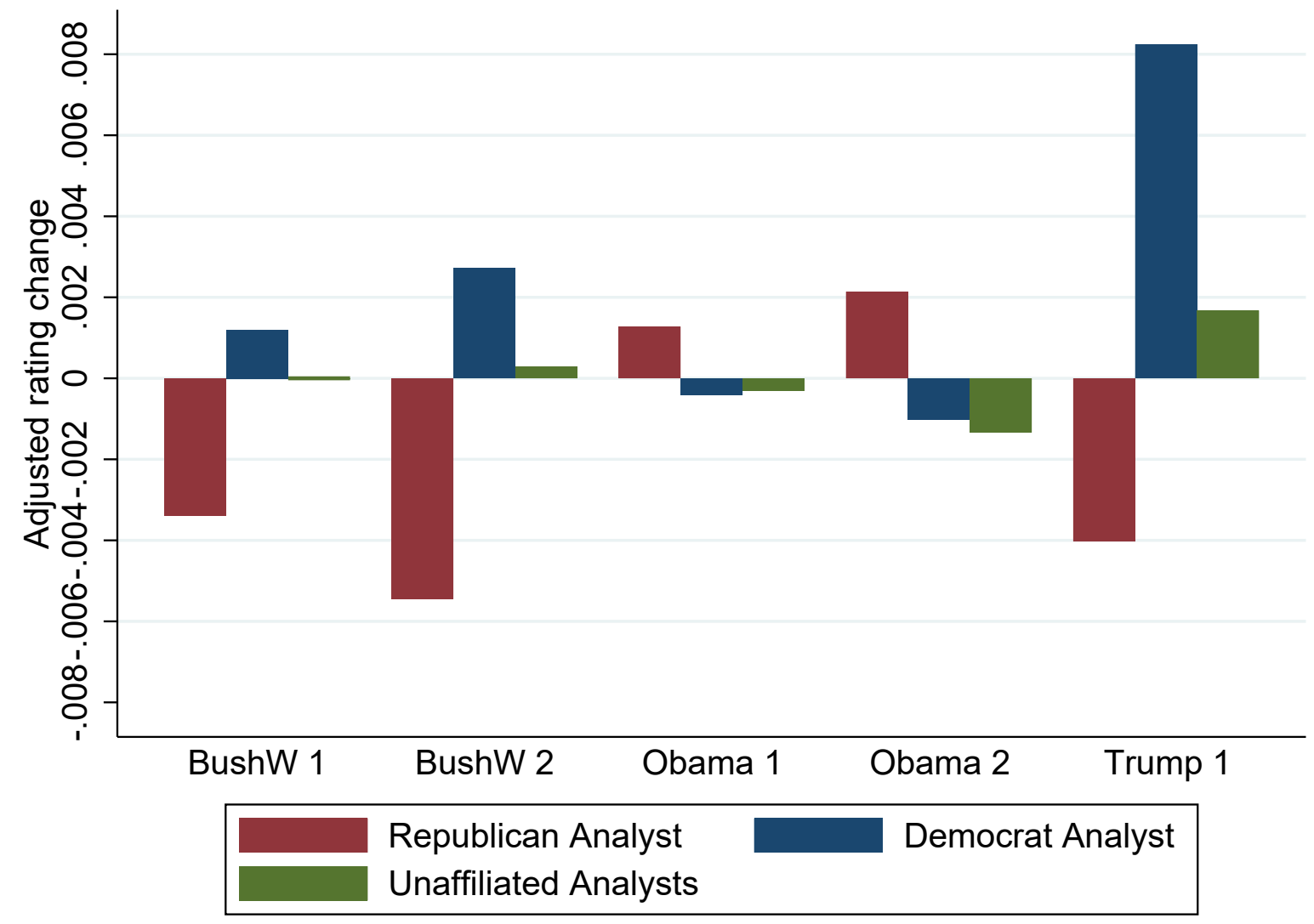

Figure 2: Average Rating Changes by Analyst Party Affiliation and Presidency. The figure plots the average adjusted rating change separately for Democratic, Republican, and unaffiliated analysts under each presidency during our sample period. Adjusted rating changes are computed by taking the quarterly rating change and subtracting the average rating change within the same firm and quarter. 


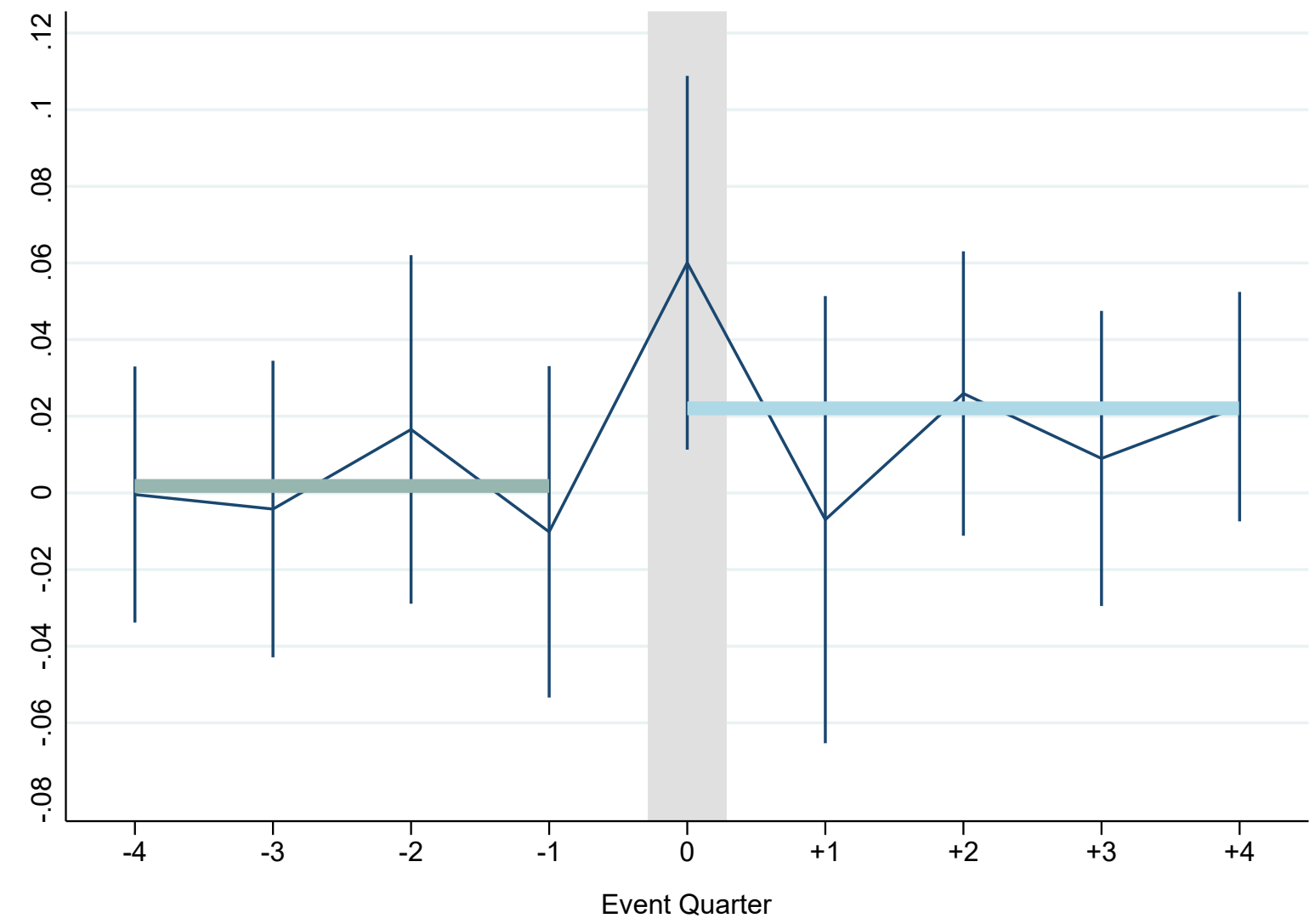

Figure 3: Quarterly Event Study around Presidential Elections. The figure plots the difference in the average quarterly rating adjustment between misaligned and aligned analysts around presidential elections. Specifically, we plot the coefficient estimates for $\beta_{\tau}$ from equation (2). The corresponding 95\% confidence intervals are based on standard errors that are double-clustered at the firm and analyst level. The green line indicates the average difference in the rating change prior to the election (i.e., -4 to -1 ) and the blue line indicates the average difference post election (i.e., 0 to +4 ). 


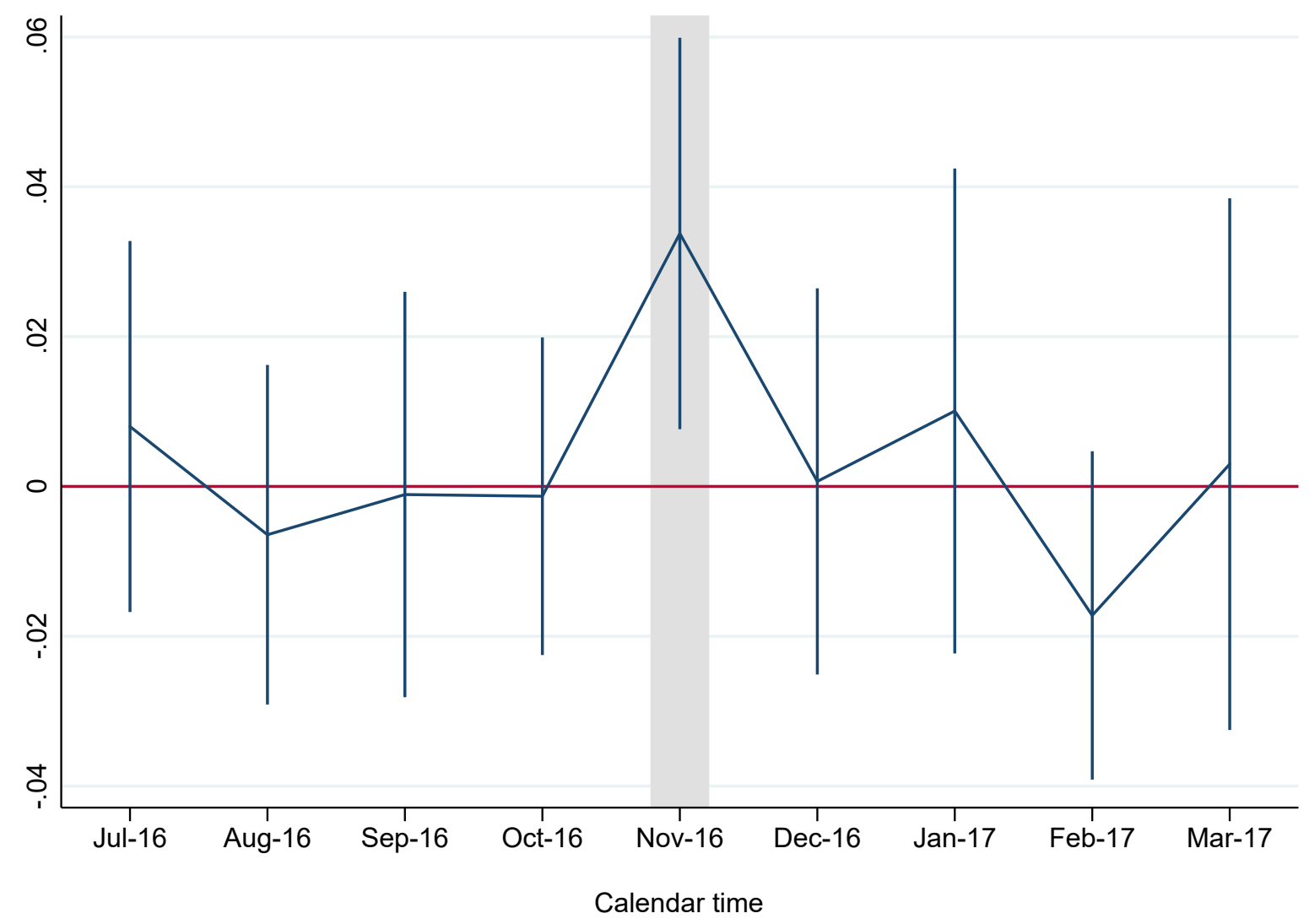

Figure 4: Monthly Event Study around the 2016 Presidential Election. The figure plots the difference in the average monthly rating adjustment between Democratic and Republican analysts around the 2016 presidential election. Specifically, we plot the coefficient estimates for $\beta_{\tau}$ from the following regression:

$$
\Delta R_{i f t}=\alpha_{f q}+\alpha_{j q}+\sum_{\tau=J u l 16}^{\tau=\text { Mar17 }} \beta_{\tau} \text { Democrat }_{i t} \times D_{t}^{\tau}+\sum_{\tau=J u l 16}^{\tau=\text { Mar } 17} \delta_{\tau} \times D_{t}^{\tau}+\epsilon_{i f t},
$$

where Democrat ${ }_{i t}$ refers to an indicator equal to 1 for analysts who are affiliated with the Democratic Party and 0 for Republican analysts; $\alpha_{f q}$ and $\alpha_{j q}$ are firm $\times$ quarter and agency $\times$ quarter fixed effects, respectively; and $D_{t}^{\tau}$ are calendar-time dummies. The corresponding $95 \%$ confidence intervals are based on standard errors that are double-clustered at the firm and analyst level. 


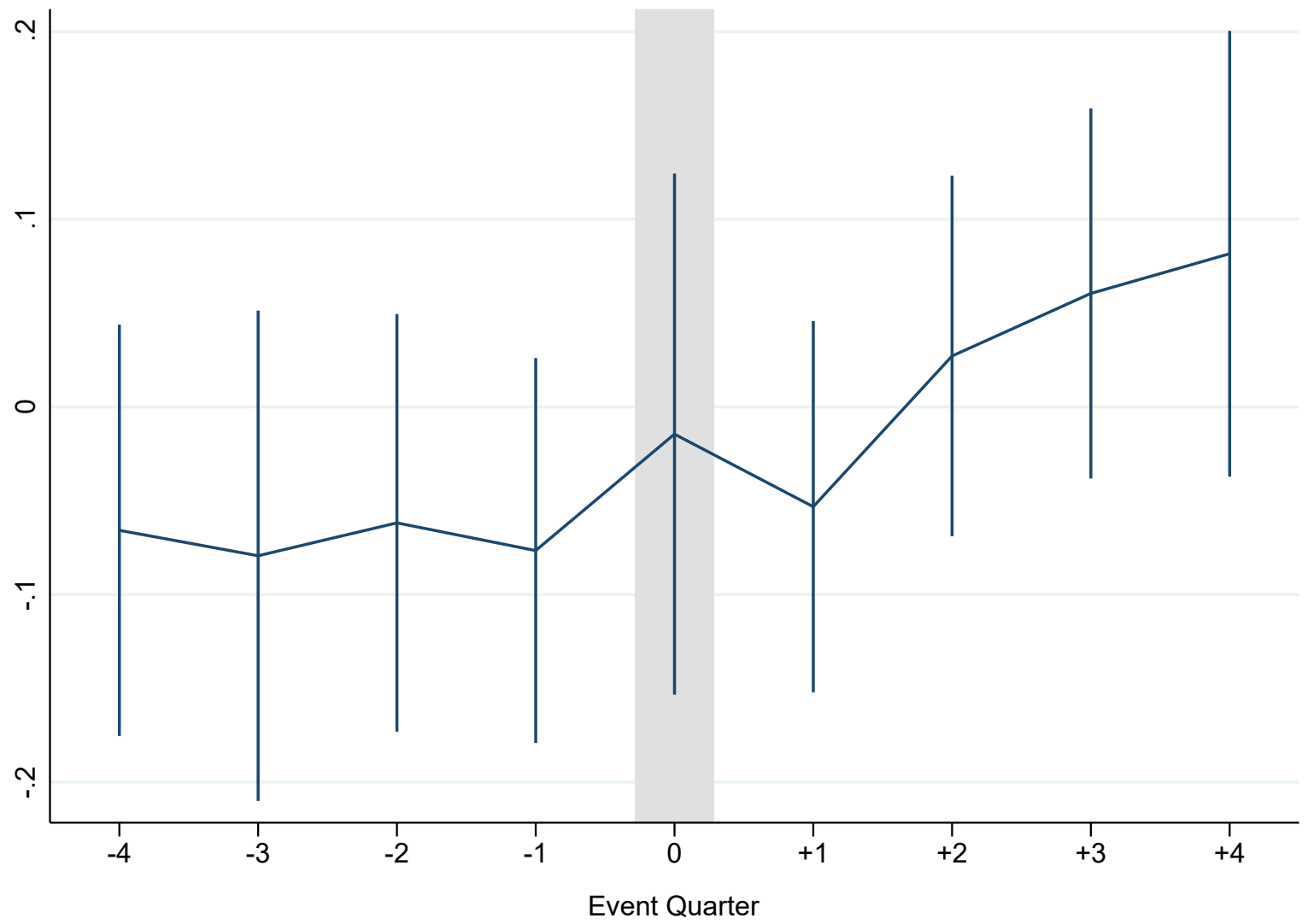

Figure 5: Quarterly Event Study around Presidential Elections: Rating Levels. The figure repeats the analysis presented in Figure 3, after replacing the quarterly rating change with the quarter-end rating level as the dependent variable. 


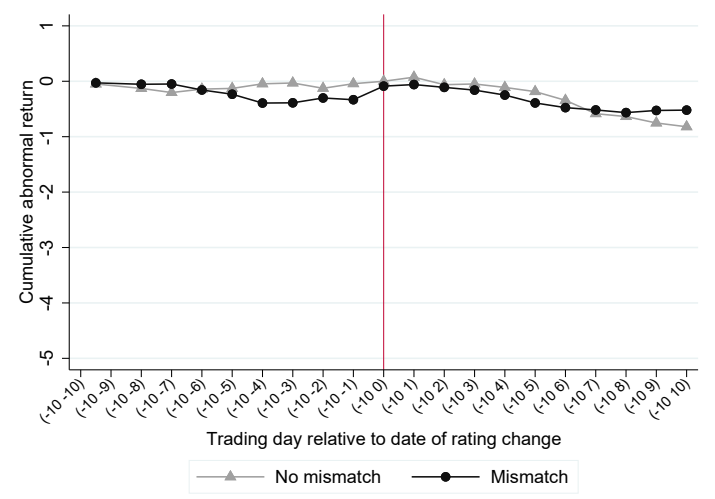

(a) All Upgrades

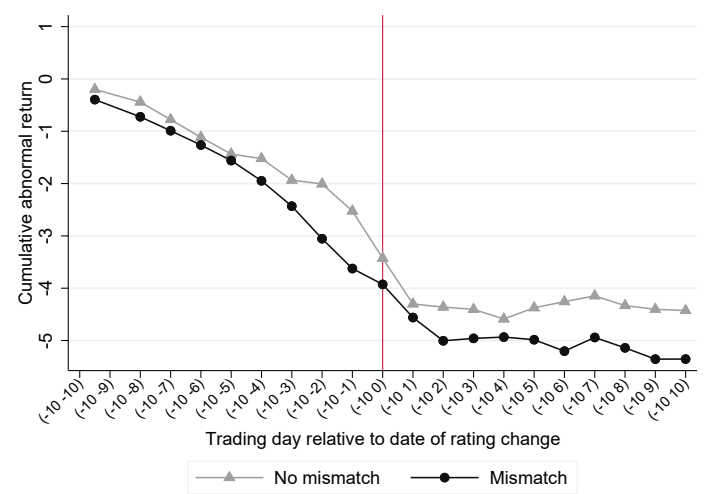

(c) All Downgrades

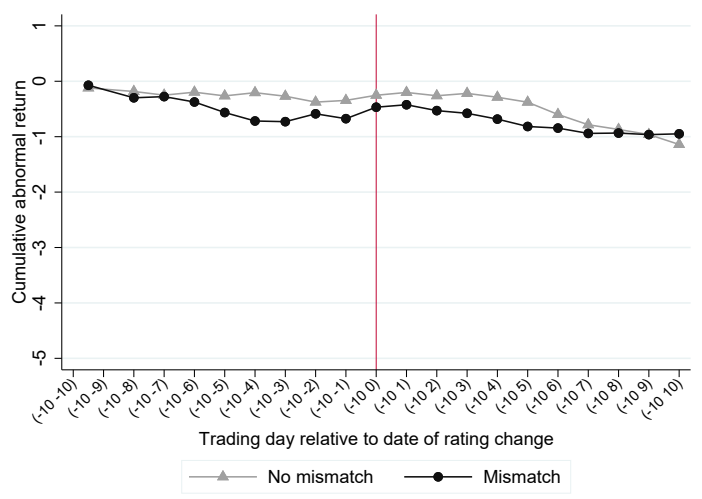

(b) Upgrades Excluding Corporate Events

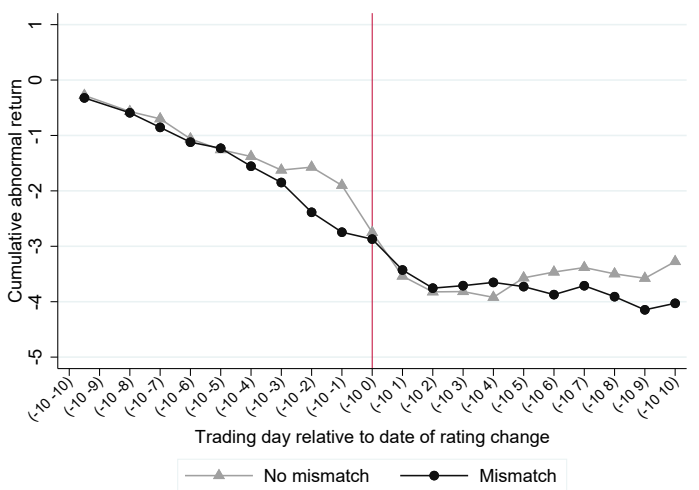

(d) Downgrades Excluding Corporate Events

Figure 6: Cumulative Abnormal Stock Returns around Rating Changes. The figure plots cumulative abnormal stock returns, measured in basis points, around rating changes. Panels (a) and (b) show returns around upgrades, and panels (c) and (d) show returns around downgrades, respectively. Abnormal returns are calculated using the Fama and French (1993) and Carhart (1997) model estimated over trading days (-300,-50) relative to the event date. In panels (b) and (d), we exclude all rating changes where a corporate earnings announcement or an M\&A announcement falls inside the $(-10,+10)$ window around the rating change. 


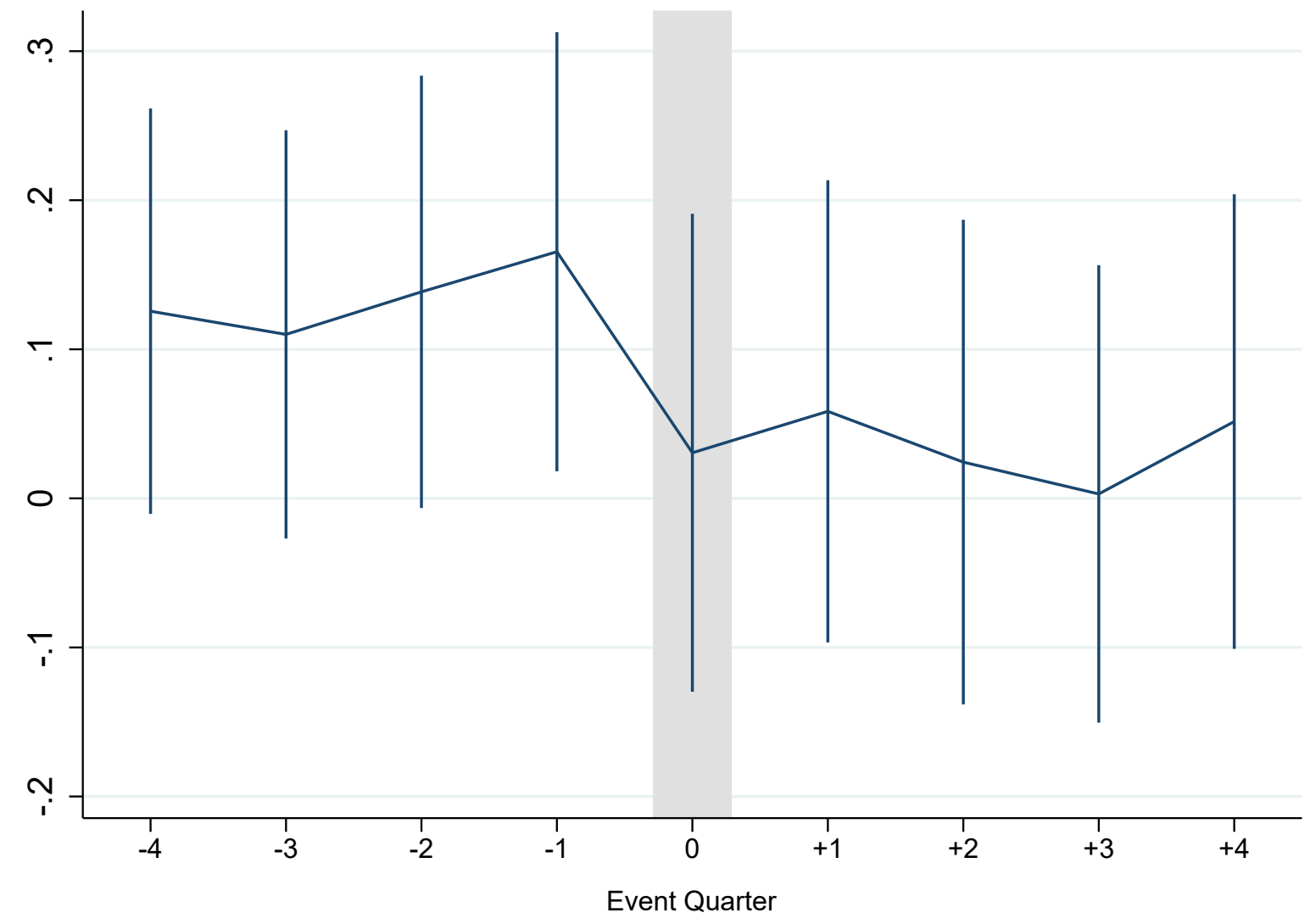

Figure 7: Quarterly Event Study around Presidential Elections: Firm Investment. The figure plots the difference in log capital expenditures between firms rated by misaligned versus aligned analysts around presidential elections which lead to a change in the party of the president. Specifically, we plot the coefficient estimates for $\beta_{\tau}$ from equation (3). The corresponding $95 \%$ confidence intervals are based on standard errors that are clustered at the firm level. 


\section{Table 1: Summary Statistics}

This table presents summary statistics for our key variables. The sample consists of all rating changes for U.S. corporate bond issuers by Fitch, Moody's, and S\&P between 2000Q1 and 2018Q1, with available information on the analyst's political-party affiliation. One observation is at the analyst-firm-quarter level. All variables are defined in Appendix A.1.

\begin{tabular}{|c|c|c|c|c|c|c|}
\hline & $\mathrm{N}$ & Mean & St.Dev. & 0.25 & Median & 0.75 \\
\hline \multicolumn{7}{|l|}{ Key Dependent Variables } \\
\hline Rating change & 72,732 & 0.026 & 0.387 & 0.000 & 0.000 & 0.000 \\
\hline CAR $(-1,+1)$ around rating changes & 71,631 & -6.354 & 158.734 & 0.000 & 0.000 & 0.000 \\
\hline CAR $(-3,+3)$ around rating changes & 71,631 & -10.622 & 234.623 & 0.000 & 0.000 & 0.000 \\
\hline$\Delta$ Yield around rating changes & 68,171 & 0.229 & 12.350 & 0.000 & 0.000 & 0.000 \\
\hline$\Delta$ Yield spread around rating changes & 68,171 & 0.228 & 11.276 & 0.000 & 0.000 & 0.000 \\
\hline$\Delta$ Yield spread $4 \mathrm{Q}$ & 24,201 & -0.082 & 2.177 & -0.572 & -0.082 & 0.396 \\
\hline$\Delta$ Yield spread 8Q & 20,923 & -0.140 & 2.552 & -0.752 & -0.096 & 0.469 \\
\hline$\Delta$ Yield spread $12 \mathrm{Q}$ & 17,946 & -0.125 & 2.578 & -0.851 & -0.120 & 0.521 \\
\hline Accuracy $4 \mathrm{Q}$ & 63,087 & -0.406 & 0.907 & -1.000 & 0.000 & 0.000 \\
\hline Accuracy 8Q & 52,880 & -0.714 & 1.180 & -1.000 & 0.000 & 0.000 \\
\hline Accuracy $12 \mathrm{Q}$ & 43,907 & -0.947 & 1.318 & -1.000 & -1.000 & 0.000 \\
\hline \multicolumn{7}{|l|}{ Key Independent Variables } \\
\hline Ideological mismatch & 76,969 & 0.370 & 0.483 & 0.000 & 0.000 & 1.000 \\
\hline \multicolumn{7}{|l|}{ Control Variables } \\
\hline Tenure & 76,969 & 3.234 & 0.761 & 2.833 & 3.466 & 3.807 \\
\hline No. of firms covered & 76,969 & 2.418 & 0.978 & 1.792 & 2.398 & 2.996 \\
\hline Votes in midterm or primary & 76,969 & 0.754 & 0.431 & 1.000 & 1.000 & 1.000 \\
\hline Avg. election gap & 74,678 & 0.263 & 0.440 & 0.000 & 0.000 & 1.000 \\
\hline Frequent voter & 76,969 & 0.782 & 0.413 & 1.000 & 1.000 & 1.000 \\
\hline Age & 76,969 & 3.852 & 0.204 & 3.738 & 3.892 & 4.007 \\
\hline Size & 65,705 & 8.820 & 1.607 & 7.707 & 8.765 & 9.826 \\
\hline Investment & 60,528 & 0.113 & 0.104 & 0.042 & 0.083 & 0.149 \\
\hline Leverage & 65,677 & 0.330 & 0.231 & 0.179 & 0.291 & 0.431 \\
\hline Tobin's Q & 53,993 & 1.530 & 0.683 & 1.065 & 1.316 & 1.764 \\
\hline Cash & 65,692 & 0.084 & 0.095 & 0.017 & 0.052 & 0.117 \\
\hline Cash flow & 59,878 & 0.017 & 0.025 & 0.009 & 0.018 & 0.029 \\
\hline Median lagged rating & 74,805 & 11.017 & 3.865 & 8.000 & 10.000 & 14.000 \\
\hline Beta & 49,626 & 1.179 & 0.669 & 0.709 & 1.093 & 1.537 \\
\hline Sector avg. beta & 76,956 & 1.140 & 0.251 & 0.862 & 1.282 & 1.285 \\
\hline Econ. polarization Gallup & 62,015 & 0.001 & 0.986 & -0.866 & 0.114 & 0.615 \\
\hline
\end{tabular}




\section{Table 2: Partisan Perception and Rating Changes}

This table regresses quarterly rating changes on Ideological mismatch, an indicator equal to 1 for analysts whose party affiliation does not match the president's party, and 0 otherwise. All variables are defined in Appendix A.1. $t$-statistics, reported in parentheses, are based on standard errors that allow for double-clustering at the analyst and firm level.

\begin{tabular}{lccc}
\hline \hline & & Rating Change & $(3)$ \\
\hline Ideological mismatch & $(1)$ & $(2)$ & 0.0134 \\
& $(4.18)$ & 0.0170 & $(3.79)$ \\
Tenure & 0.0001 & $(4.26)$ & -0.0004 \\
& $(0.03)$ & -0.0006 & $(-0.15)$ \\
No. of firms covered & -0.0001 & $(-0.23)$ & -0.0000 \\
& $(-0.10)$ & 0.0001 & $(-0.02)$ \\
\hline Observations & 49,792 & $(0.05)$ & 49,790 \\
$R^{2}$ & 0.804 & 49,792 & 0.808 \\
Firm $\times$ Quarter FE & Yes & 0.804 & Yes \\
Agency FE & Yes & Yes & No \\
Agency $\times$ Sector FE & No & No & Yes \\
Agency $\times$ Quarter FE & No & Yes & No \\
\hline \hline
\end{tabular}




\section{Table 3: Robustness}

This table presents robustness tests. The baseline regression refers to specification (3) from Table 2. For brevity, we only report coefficients of interest and suppress control variables. In Panel A, Rating change indicator is equal to 0 if the quarterly rating change is zero; -1 if the rating change is negative (i.e., upgrade); and +1 if the rating change is positive (i.e., downgrade). Downgrade (Upgrade) is an indicator equal to 1 if the quarterly rating change is positive (negative), respectively, and 0 otherwise. In Panel $\mathrm{B}$, we use alternative definitions of ideological mismatch, using party affiliation from presidential elections only (first row), and adding party-affiliation information from analysts' political contributions. In Panel C, Triple clustering by analyst, firm, and quarter refers to triple-clustering standard errors at the analyst, firm, and quarter level. Firm-agency level refers to a regression of quarterly rating changes on average ideological mismatch, after collapsing the data at the firm-agency-quarter level and averaging ideological mismatch across all analysts rating the same firm for the same rating agency in the same quarter. Weighted least squares refers to a weighted-least-squares regression, where weights are proportional to the total lagged book assets of the rated firm. Add Analyst FE adds analyst fixed effects. Add Agency $\times$ Sector $\times$ Quarter FE replaces Agency $\times$ Quarter fixed effect with Agency $\times$ Sector $\times$ Quarter fixed effect. Add NBER Recession $\times$ Party affiliation $F E$ replaces party-affiliation fixed effects with party affiliation $\times$ recession dummy fixed effects. Recessions are defined following the National Bureau of Economic Research (NBER). $t$-statistics are based on standard errors that allow for double-clustering at the analyst and firm level (except for the value in row Firm-agency level, where standard errors are clustered at the firm level).

\begin{tabular}{lccc}
\hline \hline & Coeff. & $t$-statistic \\
\hline Baseline & 0.0134 & 3.79
\end{tabular}

Panel A: Alternative dependent variables

$\begin{array}{lll}\text { Rating change indicator } & 0.0111 & 3.88\end{array}$

Downgrade $\quad 0.0064 \quad 3.24$

Upgrade $\quad-0.0046 \quad-2.21$

Panel B: Alternative definitions of ideological mismatch

$\begin{array}{lll}\text { Use only party affiliation from presidential elections } & 0.0144 & 2.75\end{array}$

$\begin{array}{lll}\text { Add party affiliation from political contributions } & 0.0135\end{array}$

\section{Panel C: Estimation}

Triple-cluster standard errors (analyst, firm, and quarter) $\quad 0.0134$

Firm-agency level $\quad 0.0298 \quad 3.82$

$\begin{array}{lll}\text { Weighted least squares } & 3.35\end{array}$

$\begin{array}{lll}\text { Add Analyst FE } & 0.0108 & 2.40\end{array}$

Add Agency $\times$ Sector $\times$ Quarter FE $\quad 0.0087 \quad 2.82$

Add NBER Recession $\times$ Party affiliation FE $\quad 0.0150 \quad 4.03$ 


\section{Table 4: Interaction with Voting Frequency}

This table regresses quarterly rating changes on ideological mismatch as well as interactions with measures of voting frequency. Votes in midterm or primary is an indicator equal to 1 for analysts who have voted during midterm or primary elections in the past, and 0 otherwise. Avg. election gap is the logarithm of the average time gap (in quarters) between elections in which the analyst has voted. Frequent voter is an indicator equal to 1 for analysts who are either in the bottom quartile of the average election gap across all analysts in a given quarter, or for whom Votes in midterm or primary is equal to 1 , and 0 otherwise. Age is the logarithm of age of the analyst as of the end of the quarter, and it is standardized to have a mean of 0 and a standard deviation of 1 . $t$-statistics, reported in parentheses, are based on standard errors that allow for double-clustering at the analyst and firm level.

\begin{tabular}{|c|c|c|c|}
\hline & \multicolumn{3}{|c|}{ Rating Change } \\
\hline & $(1)$ & $(2)$ & $(3)$ \\
\hline \multirow[t]{2}{*}{ Ideological mismatch } & 0.0014 & 0.0288 & 0.0003 \\
\hline & $(0.21)$ & $(3.69)$ & $(0.04)$ \\
\hline \multirow[t]{2}{*}{ Votes in midterm or primary } & 0.0008 & & \\
\hline & $(0.25)$ & & \\
\hline \multirow{2}{*}{ Mismatch $\times$ Votes in midterm or primary } & 0.0140 & & \\
\hline & $(2.21)$ & & \\
\hline \multirow[t]{2}{*}{ Avg. election gap } & & 0.0003 & \\
\hline & & $(0.12)$ & \\
\hline \multirow[t]{2}{*}{ Mismatch $\times$ Avg. election gap } & & -0.0102 & \\
\hline & & $(-2.25)$ & \\
\hline \multirow[t]{2}{*}{ Frequent voter } & & & -0.0013 \\
\hline & & & $(-0.40)$ \\
\hline \multirow[t]{2}{*}{ Mismatch $\times$ Frequent voter } & & & 0.0151 \\
\hline & & & $(2.33)$ \\
\hline \multirow[t]{2}{*}{ Age } & -0.0001 & -0.0006 & 0.0001 \\
\hline & $(-0.08)$ & $(-0.38)$ & $(0.05)$ \\
\hline \multirow[t]{2}{*}{ Mismatch $\times$ Age } & -0.0007 & -0.0006 & -0.0009 \\
\hline & $(-0.25)$ & $(-0.20)$ & $(-0.33)$ \\
\hline \multirow[t]{2}{*}{ Tenure } & -0.0004 & -0.0006 & -0.0004 \\
\hline & $(-0.15)$ & $(-0.21)$ & $(-0.15)$ \\
\hline \multirow[t]{2}{*}{ No. of firms covered } & -0.0006 & -0.0004 & -0.0005 \\
\hline & $(-0.45)$ & $(-0.28)$ & $(-0.39)$ \\
\hline Observations & 49,790 & 47,454 & 49,790 \\
\hline$R^{2}$ & 0.808 & 0.808 & 0.808 \\
\hline Firm $\times$ Quarter FE & Yes & Yes & Yes \\
\hline Agency $\times$ Quarter FE & Yes & Yes & Yes \\
\hline Party affiliation FE & Yes & Yes & Yes \\
\hline
\end{tabular}




\section{Table 5: Stock Returns and Bond-Yield Changes around Rating Actions}

This table regresses cumulative abnormal stock returns and changes in bond yields around rating changes on ideological mismatch. Panel A presents results for cumulative abnormal returns (CARs), which are measured in basis points and calculated using an event window of $(-1,+1)$ (columns (1) and (2)) and $(-3,+3)$ (columns (3) and (4)), respectively. Panel B shows results for changes in bond yields ( $\Delta$ Yield) and bond-yield spreads ( $\Delta$ Yield Spread) around the rating action, measured in basis points. In quarters with no rating change, the dependent variable is set to 0 . In columns (2) and (4) for both panels, we exclude rating changes where a corporate earnings announcement or M\&A announcement falls inside the event window. All variables are defined in Appendix A.1. $t$-statistics, reported in parentheses, are based on standard errors that allow for double-clustering at the analyst and firm level.

Panel A: Abnormal Stock Returns

\begin{tabular}{lcccc}
\hline \hline & \multicolumn{2}{c}{ CAR(-1,+1) } & \multicolumn{2}{c}{ CAR(-3,+3) } \\
& $(1)$ & $(2)$ & $(3)$ & $(4)$ \\
\hline Ideological mismatch & -3.2115 & -3.2179 & -4.5770 & -3.8597 \\
& $(-1.98)$ & $(-2.29)$ & $(-2.04)$ & $(-2.10)$ \\
Tenure & -0.3710 & -0.4749 & -1.5297 & -0.7088 \\
& $(-0.28)$ & $(-0.40)$ & $(-0.76)$ & $(-0.49)$ \\
No. of firms covered & 0.0347 & 0.2822 & -0.1611 & -0.3161 \\
& $(0.06)$ & $(0.52)$ & $(-0.18)$ & $(-0.42)$ \\
\hline Observations & 48,147 & 47,580 & 48,147 & 46,934 \\
$R^{2}$ & 0.744 & 0.750 & 0.755 & 0.766 \\
Firm $\times$ Quarter FE & Yes & Yes & Yes & Yes \\
Agency $\times$ Quarter FE & Yes & Yes & Yes & Yes \\
Party affiliation FE & Yes & Yes & Yes & Yes \\
Excluding corporate events & No & Yes & No & Yes \\
\hline \hline
\end{tabular}

Panel B: Bond-Yield Changes

\begin{tabular}{lcccc}
\hline \hline & & $\Delta$ Yield & \multicolumn{2}{c}{$\Delta$ Yield Spread } \\
& $(1)$ & $(2)$ & $(3)$ & $(4)$ \\
\hline Ideological mismatch & 0.4748 & 0.3878 & 0.4508 & 0.3680 \\
& $(2.11)$ & $(1.85)$ & $(1.97)$ & $(1.76)$ \\
Tenure & 0.1188 & 0.0937 & 0.1658 & 0.1418 \\
& $(1.10)$ & $(0.97)$ & $(1.56)$ & $(1.48)$ \\
No. of firms covered & -0.0057 & -0.0046 & -0.0810 & -0.0799 \\
& $(-0.06)$ & $(-0.06)$ & $(-0.92)$ & $(-1.14)$ \\
\hline Observations & 46,724 & 46,724 & 46,724 & 46,724 \\
$R^{2}$ & 0.697 & 0.696 & 0.703 & 0.694 \\
Firm $\times$ Quarter FE & Yes & Yes & Yes & Yes \\
Agency $\times$ Quarter FE & Yes & Yes & Yes & Yes \\
Party affiliation FE & Yes & Yes & Yes & Yes \\
Excluding corporate events & No & Yes & No & Yes \\
\hline \hline
\end{tabular}




\section{Table 6: Analyst Accuracy}

This table compares the rating accuracy of analysts with and without ideological mismatch. In Panel A, the change in yield spreads over the following 4, 8, and 12 quarters is regressed on the current-quarter rating change, ideological mismatch, as well as an interaction term. Firm controls include lagged firm size, Tobin's Q, investment, leverage, cash holdings, and cash flow. In Panel B, analyst accuracy, defined as -1 times the absolute change between the current rating and the rating 4, 8, and 12 quarters in the future, is regressed on ideological mismatch. The sample is restricted to Democratic and Republican analysts in both panels. $t$-statistics, reported in parentheses, are based on standard errors that allow for double-clustering at the analyst and firm level.

Panel A: Accuracy Based on Future Changes in Yield Spreads

\begin{tabular}{lccc}
\hline \hline & & $\Delta$ Yield Spread & \\
& $4 \mathrm{Q}$ & $8 \mathrm{Q}$ & $12 \mathrm{Q}$ \\
& $(1)$ & $(2)$ & $(3)$ \\
\hline Ideological mismatch & -0.0728 & -0.0595 & -0.0260 \\
& $(-1.15)$ & $(-0.75)$ & $(-0.30)$ \\
Mismatch $\times$ Rating change & -0.2724 & -0.2934 & -0.1863 \\
& $(-2.04)$ & $(-2.48)$ & $(-1.58)$ \\
Rating change & 0.0110 & -0.1456 & -0.1287 \\
& $(0.09)$ & $(-1.29)$ & $(-1.19)$ \\
\hline Observations & 15,544 & 13,573 & 11,706 \\
$R^{2}$ & 0.646 & 0.659 & 0.648 \\
Agency $\times$ Quarter FE & Yes & Yes & Yes \\
Median lagged rating $\times$ Quarter FE & Yes & Yes & Yes \\
Party affiliation FE & Yes & Yes & Yes \\
Firm controls & Yes & Yes & Yes \\
\hline \hline
\end{tabular}

Panel B: Accuracy Based on Future Rating Revisions

\begin{tabular}{lccc}
\hline \hline & & Accuracy & \\
& $4 \mathrm{Q}$ & $8 \mathrm{Q}$ & $12 \mathrm{Q}$ \\
& $(1)$ & $(2)$ & $(3)$ \\
\hline Ideological mismatch & -0.0406 & -0.0879 & -0.1021 \\
& $(-1.99)$ & $(-2.49)$ & $(-2.64)$ \\
Tenure & -0.0064 & -0.0191 & -0.0100 \\
& $(-0.63)$ & $(-0.94)$ & $(-0.35)$ \\
No. of firms covered & 0.0076 & 0.0199 & 0.0164 \\
& $(1.25)$ & $(1.67)$ & $(0.96)$ \\
\hline Observations & 25,100 & 20,672 & 16,961 \\
$R^{2}$ & 0.872 & 0.891 & 0.897 \\
Firm $\times$ Quarter FE & Yes & Yes & Yes \\
Agency $\times$ Quarter FE & Yes & Yes & Yes \\
Party affiliation FE & Yes & Yes & Yes \\
\hline \hline
\end{tabular}




\section{Table 7: Survey of Credit Rating Analysts}

This table shows the results from our online survey of credit rating analysts. We infer analysts' views on current economic conditions by asking the following question: "How would you rate economic conditions in this country today?", with possible answers of "excellent," "good," "fair," and "poor." We code the answers with numerical values from 1 to 4 , with 1 indicating the least favorable view and higher values representing more favorable views. To infer the political affiliation of the analysts, we ask, "In politics, as of today, do you consider yourself a Republican, a Democrat, an Independent or Unaffiliated?" We classify a respondent's political affiliation as Republican, Democrat, or Independent (if she responded Independent or Unaffiliated). Demographic controls include gender, age, and ethnicity. Experience controls is the self-reported number of years of work experience as a credit rating analyst. $t$-statistics, reported in parentheses, are based on robust standard errors.

\begin{tabular}{lccc}
\hline \hline & \multicolumn{3}{c}{ Current Economic Conditions } \\
& $(1)$ & $(2)$ & $(3)$ \\
\hline Democrat & 0.1866 & 0.1903 & 0.1835 \\
& $(1.19)$ & $(1.16)$ & $(1.11)$ \\
Republican & 0.6184 & 0.5559 & 0.5639 \\
& $(3.89)$ & $(3.14)$ & $(3.13)$ \\
Constant & 2.6316 & 2.8109 & 2.8486 \\
& $(23.15)$ & $(11.19)$ & $(10.66)$ \\
\hline Observations & 57 & 54 & 54 \\
$R^{2}$ & 0.214 & 0.285 & 0.287 \\
Demographic controls & No & Yes & Yes \\
Experience controls & No & No & Yes \\
\hline \hline
\end{tabular}




\section{Table 8: Interaction with Polarization of Economic Views}

This table regresses quarterly rating changes on ideological mismatch as well as on interactions with a measure of political polarization of economic views (Econ. polarization Gallup). To measure political polarization in the views of economic conditions, we use data from the following question in the Gallup Daily survey: "How would you rate economic conditions in this country today - as excellent, good, only fair, or poor?" The responses to this question are converted into a numerical scale that ranges from 1 (poor) to 4 (excellent). Based on this question, our measure of polarization of economic views, Econ. polarization Gallup, is the absolute average quarterly difference between Democrats and Republicans. We standardize the measure to have a mean of 0 and a standard deviation of $1 . t$-statistics, reported in parentheses, are based on standard errors that allow for double-clustering at the analyst and firm level.

\begin{tabular}{lccc}
\hline \hline & & Rating Change & $(3)$ \\
\hline Ideological mismatch & $(1)$ & $(2)$ & 0.0085 \\
& 0.0105 & 0.0109 & $(1.89)$ \\
Mismatch $\times$ Econ. polarization Gallup & $(2.02)$ & $(2.10)$ & 0.0053 \\
& 0.0087 & 0.0084 & $(1.93)$ \\
Tenure & $(2.96)$ & $(2.82)$ & -0.0003 \\
& -0.0004 & -0.0011 & $(-0.12)$ \\
No. of firms covered & $(-0.15)$ & $(-0.40)$ & 0.0003 \\
& -0.0001 & 0.0005 & $(0.22)$ \\
\hline Observations & $(-0.08)$ & $(0.39)$ & 45,041 \\
$R^{2}$ & 45,041 & 45,041 & 0.808 \\
Firm $\times$ Quarter FE & 0.805 & 0.806 & Yes \\
Agency FE & Yes & Yes & No \\
Agency $\times$ Sector FE & Yes & No & No \\
Agency $\times$ Quarter FE & No & Yes & Yes \\
Party affiliation FE & No & No & Yes \\
\hline \hline
\end{tabular}




\section{Table 9: Firm Heterogeneity}

This table regresses quarterly rating changes on ideological mismatch as well as interactions with two measures of firm cyclicality. Beta refers to the firm-level market beta and is estimated using the Fama and French (1993) and Carhart (1997) four-factor model, monthly return data from CRSP, and a five-year rolling window. Sector avg. beta is computed as the average Beta of all the firms in a given GICS sector and quarter. $t$-statistics, reported in parentheses, are based on standard errors that allow for double-clustering at the analyst and firm level.

\begin{tabular}{lcccc}
\hline \hline & \multicolumn{4}{c}{ Rating Change } \\
& $(1)$ & $(2)$ & $(3)$ & $(4)$ \\
\hline Ideological mismatch & -0.0013 & -0.0023 & -0.0091 & -0.0078 \\
& $(-0.18)$ & $(-0.33)$ & $(-0.85)$ & $(-0.77)$ \\
Mismatch $\times$ Beta & 0.0130 & 0.0115 & & \\
Mismatch $\times$ Sector avg. beta & $(2.62)$ & $(2.35)$ & & \\
& & & 0.0227 & 0.0188 \\
Tenure & & & $(2.31)$ & $(2.10)$ \\
& -0.0018 & -0.0011 & 0.0002 & -0.0003 \\
No. of firms covered & $(-0.60)$ & $(-0.37)$ & $(0.08)$ & $(-0.11)$ \\
& 0.0000 & -0.0002 & -0.0002 & -0.0001 \\
Observations & $(0.02)$ & $(-0.18)$ & $(-0.14)$ & $(-0.08)$ \\
$R^{2}$ & 33,745 & 33,739 & 49,792 & 49,790 \\
Firm $\times$ Quarter FE & 0.789 & 0.794 & 0.804 & 0.808 \\
Agency FE & Yes & Yes & Yes & Yes \\
Agency $\times$ Quarter FE & Yes & No & Yes & No \\
Party affiliation FE & No & Yes & No & Yes \\
\hline \hline
\end{tabular}




\section{A Appendix}

\section{A.1 Variable Definitions}

\section{Table A.1: Variable descriptions}

\begin{tabular}{|c|c|}
\hline Variable & Description \\
\hline \multicolumn{2}{|l|}{ Dependent variables } \\
\hline Rating change & $\begin{array}{l}\text { The quarterly change (measured in notches) in the credit rating of a given firm by a given } \\
\text { rating agency. Credit ratings are transformed into a cardinal scale, as in Fracassi, Petry, } \\
\text { and Tate (2016), starting with } 1 \text { for AAA and ending with } 21 \text { for D or lower for S\&P and } \\
\text { Fitch. For Moody's, the scale starts with } 1 \text { for Aaa and ends with } 21 \text { for C. Credit ratings } \\
\text { are obtained for S\&P from S\&P RatingXpress, for Moody's from Moody's Default and } \\
\text { Recovery Database, and for Fitch from Mergent FISD. The variable is winsorized at the } \\
\text { top and bottom } 1 \% \text {. }\end{array}$ \\
\hline $\operatorname{CAR}(-1,+1)$ & Cumulative abnormal returns $(\mathrm{CARs})$ during trading days $(-1,+1)$ and $(-3,+3)$ around \\
\hline $\operatorname{CAR}(-3,+3)$ & a rating change, computed using the Fama and French (1993) and Carhart (1997) model \\
\hline $\begin{array}{l}\text { around rating } \\
\text { changes }\end{array}$ & $\begin{array}{l}\text { estimated over trading days }(-300,-50) \text { relative to the event date. CARs are aggregated } \\
\text { over all rating changes for a given agency, firm, and quarter, and are set to } 0 \text { when no } \\
\text { rating change occurs. We exclude rating actions with missing stock returns in the }(-3,+3) \\
\text { window around the event. The variable is measured in basis points and is winsorized at } \\
\text { the top and bottom } 1 \% \text {. }\end{array}$ \\
\hline $\begin{array}{l}\Delta \text { Yield (spread) } \\
\text { around } \\
\text { changes }\end{array}$ & $\begin{array}{l}\text { The change in bond yields (spreads) around a rating change, averaged across all out- } \\
\text { standing bonds by the issuer. Bond-yield (spread) changes around a rating action are } \\
\text { computed as the difference between the bond yield (spread) on the first day following } \\
\text { the event and the yield (spread) on the most recent trading day prior to the event. Av- } \\
\text { erage bond-yield (spread) changes are then aggregated over all rating changes for a given } \\
\text { agency, firm, and quarter, and are set to } 0 \text { when no rating change occurs. We restrict } \\
\text { the sample to bonds that are traded at least once in the } 30 \text { days prior and in the } 30 \text { days } \\
\text { post the rating-change announcement. If multiple bonds of the same issuer are traded on } \\
\text { the same day, we select a maximum of five bonds with the highest trading volume. The } \\
\text { benchmark rate that is used to compute credit spreads is based on an interpolation of } \\
\text { the yields of the two government bonds with the next lower and the next higher duration } \\
\text { relative to the corporate bond. The variable is measured in basis points and is winsorized } \\
\text { at the top and bottom } 1 \% \text {. }\end{array}$ \\
\hline $\begin{array}{l}\text { Accuracy over } 4,8, \\
\text { and } 12 \text { quarters }\end{array}$ & $\begin{array}{l}-1 \text { times the absolute difference between the current rating and the prevailing rating } 4 \text {, } \\
8 \text {, or } 12 \text { quarters in the future. The variable is measured in notches. }\end{array}$ \\
\hline
\end{tabular}

Continued on next page 
Table A.1 - continued

\begin{tabular}{ll}
\hline \hline Variable & Description \\
\hline$\Delta$ Yield spread over & The difference in the yield spread between quarter $t$ and quarter 4,8 , and 12 in the \\
4,8, and 12 quar- & future, respectively. We compute yield spreads as the difference between a bond's yield \\
ters & to maturity on a given trading day and the benchmark rate, winsorized at the top and \\
& bottom $1 \%$. The benchmark rate is based on an interpolation of the yields of the two \\
& government bonds with the next lower and the next higher duration relative to the \\
& corporate bond. For each bond we keep the yield to maturity as of the last trading \\
& day of the quarter and then average across all outstanding bonds by the same issuer. If \\
& multiple bonds of the same issuer are traded on the same day, we select a maximum of \\
& five bonds with the highest trading volume.
\end{tabular}

Main independent variables

Ideological mis- Indicator function equal to 1 if the analyst's party affiliation does not match the party of match the president in a given quarter, and 0 if the party matches or the analyst is unaffiliated. Information on party affiliation is obtained after merging analysts to voter records from Illinois, New Jersey, and New York City. Internet Appendix IA.A provides additional details regarding the voter files and the merging procedure.

Control variables

Tenure

Logarithm of one plus the number of quarters since the analyst's first rating action for a given rating agency.

No. of firms cov- Logarithm of the number of firms rated by the analyst in a given quarter.

ered

Votes in midterm or

An indicator equal to one for analysts who have voted in midterm or primary elections, primary and zero otherwise.

Avg. election gap

Size

Log average time gap (in quarters) between elections in which the analyst has voted.

Investment The lagged logarithm of the firm's total assets from Compustat.

The lagged ratio of the firm's capital expenditures to the lagged value of property, plant and equipment from Compustat.

Leverage The lagged ratio of the firm's total long-term debt to total assets from Compustat.

Tobin's Q The lagged ratio of the firm's quarterly market value to book value of total assets from Compustat. It is winsorized at the top and bottom $1 \%$.

Cash The lagged ratio of the firm's cash and short-term investments to total assets from Compustat.

Cash flow The lagged ratio of the firm's income before extraordinary items and depreciation to lagged property, plant, and equipment from Compustat.

Median lag rating The median lagged rating across all rating agencies rating the firm.

Econ. polarization The absolute difference between the average economic views of Democrats and RepubliGallup cans in a given quarter from Gallup Daily survey.

Beta Equity market beta estimated using the Fama and French (1993) and Carhart (1997) four-factor model, using monthly return data from CRSP and a five-year rolling window. 


\section{Internet Appendix to}

\section{"Partisan Professionals: Evidence from Credit Rating Analysts"}

This internet appendix presents additional results to accompany the paper "Partisan Professionals: Evidence from Credit Rating Analysts." The contents are as follows:

Internet Appendix IA.A describes the voter registration files used to obtain information on analysts' political affiliation.

Internet Appendix IA.B describes the measures of political polarization in the views of economic conditions used in the paper.

Internet Appendix IA.C presents summary statistics for our sample of analysts from the online survey.

Internet Appendix IA.D presents additional analyses to accompany our main empirical results. 


\section{IA.A Information on Political Affiliation}

\section{IA.A.1 Voter Registration Files}

This section describes the voter registration files and merging procedure used to assign party affiliations to individual analysts. Table IA.1 summarizes voters' party affiliations by election type for all three voter files.

\section{IA.A.1.1 New York City}

We obtain registered voter files and voter history files from the Board of Elections in the City of New York. The New York City voter records contain two types of datasets. One is the voting history, which contains the history of voting records for a given voter ID, including election type, election date, and party affiliation. The second dataset contains information regarding the full name, address, gender, date of birth, registration date, and voter status for each voter ID. The party affiliation can be Democrat, Republican, other (e.g., Conservative, Liberal, Independent), or blank. We treat blank observations as unaffiliated. The dates of the covered elections range from 1983 to 2017. The election types covered include General Elections, Primary Elections, Run-Off Elections, and Special Elections. We take the following steps to clean the NYC voter data:

- We merge the dataset that contains the individual voting histories with the static information on the voters' demographics, address, date of birth, and so on, using the voter ID. The voter address refers to his/her most recent address.

- We remove duplicates by first name, middle name, last name, and date of birth in order to obtain a dataset in which each observation is uniquely identified by full name and date of birth. The dataset contains 1,279 duplicates out of 3,780,569 observations. We drop all duplicate observations because the majority of the duplicates do not have the same voting history.

Following the two steps above, we obtain a cleaned NYC voter dataset with static voter information as well as information on each voter's voting history. Each voter is uniquely identified by first name, middle name, last name, and date of birth.

\section{IA.A.1.2 New Jersey}

We obtain statewide registered voter files and voter history files from the New Jersey Division of Elections. The information in the New Jersey voter records is very similar to the data from New York City. The main difference is the time period spanned by the dates 
of the covered elections, which ranges from 2007 to 2017. The party affiliation can be Democrat, Republican, other (e.g., Conservative, Libertarian, Green), or unaffiliated. The election types covered include General Elections, Primary Elections, Municipal Elections, and Special Elections. As with the New York City data, we remove duplicates by first name, middle name, last name, and age in order to obtain a dataset in which each observation is uniquely identified by full name and age. The dataset contains 2,945 duplicates out of $5,715,810$ observations.

\section{IA.A.1.3 Illinois}

We obtain state-wide registered voter files and voter history files from the Illinois State Board of Elections. Three main differences exist between the Illinois voter records and the records from New Jersey and New York City. First, we do not have date-of-birth information; instead, we have information on voter age, which is measured at the time we requested the data (February 2018). Second, in terms of the time period, the dates of the covered elections range from 1976 to 2017. Third, the variable party affiliation is blank in all general elections. Hence, we can infer party information only based on primary elections. As a result, the rate of voters who switch between the Democratic and Republican party is higher for Illinois (see Table IA.1). The party affiliation can be Democrat, Republican, or other (e.g., Libertarian, Independent, Green).

We remove duplicates by first name, middle name, last name, and age, in order to obtain a dataset in which each observation is uniquely identified by full name and age. The dataset contains 110,604 duplicates out of 7,080,218 observations.

\section{IA.A.1.4 Merging Analyst Data with Voter Registration Files}

We merge the analyst-firm-quarter panel dataset with the cleaned voter records from New York City, New Jersey, and Illinois, after retaining all analysts whose offices are in New York or Chicago. Information on analysts' office locations is obtained from press releases published on the websites of Moody's and Fitch, and from S\&P's Credit Portal. We assume analysts with missing office location are based in New York. We then match analysts located in New York with voter records from New York City and New Jersey, and analysts whose office is in Chicago with voter records from Illinois. We use the following method to match each analyst to an individual voter.

We first merge the analyst dataset and voter lists by first name, middle initial, and last name. In case of multiple matches, we apply the following criteria to determine the correct unique match. First, we retain the match with the smallest age difference between the analyst and the voter, conditional on the absolute age difference being three years or 
less. Information on analysts' age is obtained from online searches. ${ }^{27}$ Second, if the age criterion does not allow us to determine a unique match, we use the distance between the ZIP code of the analyst's office location and the ZIP code of the voter address as a criterion. Specifically, we define a voter as a valid unique match if (i) the voter lives within a 50-mile radius from the rating agency and (ii) the second-nearest voter match is located more than 50 miles farther away from the rating agency than the nearest voter. Third, for remaining analysts located in New York who match both to voter records from New York City and from New Jersey, we keep the match from New York City. Fourth, if the analyst matches to multiple voters who always have the same party affiliation, we keep the voter with the longest history. For those analysts who are not matched in the first step, we perform another merge by first and last name only. All other steps described above remain the same.

After removing analysts who match to multiple voters and for whom a unique match cannot be determined, as well as analysts whose implied age at the time of the rating is younger than 22 or older than 65 according to the age information in the voter record, we are able to match 557 analysts to a unique voter record.

In the merged analyst-firm-quarter dataset, we define the analyst's party affiliation at the end of a given quarter as the most recent non-blank party affiliation in the matched voter record (using all elections). If the matched voter never had a non-blank party affiliation, we set the affiliation to unaffiliated.

\section{IA.A.2 Political Contributions}

This section describes the political-contribution data and merging procedure used to obtain additional information on the political leaning of individual analysts.

\section{IA.A.2.1 Stanford's Database on Ideology, Money in Politics, and Elections (DIME)}

Political contributions are obtained from Stanford's Database on Ideology, Money in Politics, and Elections (DIME) database, which contains local, state, and federal-level contributions from individuals and organizations between 1979 and 2014. The DIME database includes information about contributors' ZIP codes as well as their employer and occupation. It relies on data from the Federal Election Commission (FEC), the National Institute on Money in State Politics, the New York City Campaign Finance Board, the Center for Responsive Politics, and the Internal Revenue Service. We restrict the sample to federal

\footnotetext{
${ }^{27} \mathrm{We}$ are able to find age information for approximately $65 \%$ of the analysts with duplicate matches to voter records.
} 
and state-level contributions. For a more detailed description of the DIME dataset, see Bonica (2016).

\section{IA.A.2.2 Merging Analyst Data with Political Contributions}

Analysts are matched to political contributions using a procedure similar to the one described in Hong and Kostovetsky (2012). Specifically, credit analysts are matched to contributions using first and last names, applying the following filters:

1. Exclude contributions with contradicting middle names.

2. Exclude contributions outside the metropolitan area of the rating agency (i.e., more than 100 miles away from the credit rating agency's office).

3. Exclude contributions for which the employer and occupation are unrelated to finance or rating agencies. We search for related strings such as "credit," "rating," "finance," and "wealth," as well as for names of the main rating agencies and other large financial firms.

4. Exclude analysts who are matched to more than three different contributors, according to the contributor identifier provided in DIME.

Following the merging procedure described above, we are able to identify a federal or state-level contribution for 57 analysts. Using this information, we create a quarterly panel of analysts' party affiliation, where Democratic analysts are defined as individuals who made most of their contributions to Democratic candidates. Republicans are defined analogously. An analyst is considered unaffiliated if none of the contributions by the analyst can be attributed to a specific political party.

In $72 \%$ of the analyst-quarter observations where we have a non-missing party affiliation from both the voter records and the contributions data, the party affiliations from both sources agree. Moreover, once we condition on Democratic and Republican affiliations only, the two sources agree in $96 \%$ of the cases. 


\section{Table IA.1: Summary Statistics - Voter Records}

This table summarizes party affiliation for all registered voters in the New York City, New Jersey, and Illinois voter files, by election type. Other refers to all voters who are affiliated with parties other than Democratic and Republican. Total Count shows the total number of voters by election type. Switch between Democratic and Republican shows the ratio of voters who have switched at least once from Democratic to Republican, or vice versa.

\begin{tabular}{lccccc}
\hline \hline New York City & Democrat & Republican & Other & Unaffiliated & Total Count \\
\hline General Elections & 0.725 & 0.116 & 0.029 & 0.129 & $21,800,991$ \\
Primary Elections & 0.869 & 0.097 & 0.006 & 0.028 & $3,663,031$ \\
Other Elections & 0.950 & 0.040 & 0.004 & 0.007 & $5,749,550$ \\
Total & 0.784 & 0.100 & 0.022 & 0.095 & $31,213,572$ \\
\cline { 2 - 6 } & \multicolumn{2}{c}{ Switch between Democratic and Republican } & \multicolumn{2}{c}{0.028} \\
\hline \hline New Jersey & Democrat & Republican & Other & Unaffiliated & Total Count \\
\hline General Elections & 0.443 & 0.299 & 0.002 & 0.255 & $21,048,052$ \\
Primary Elections & 0.625 & 0.374 & 0.000 & 0.000 & $6,471,747$ \\
Other Elections & 0.417 & 0.291 & 0.003 & 0.288 & $5,068,883$ \\
Total & 0.475 & 0.313 & 0.002 & 0.210 & $32,588,682$ \\
\multicolumn{7}{c}{ Switch between Democratic and Republican } & \multicolumn{2}{c}{0.015} \\
\hline \hline Illinois & Democrat & Republican & Other & Unaffiliated & Total Count \\
\hline General Elections & 0.000 & 0.000 & 0.000 & 1.000 & $33,567,464$ \\
Primary Elections & 0.487 & 0.371 & 0.002 & 0.141 & $18,368,420$ \\
Other Elections & 0.000 & 0.000 & 0.000 & 1.000 & $11,936,881$ \\
Total & 0.140 & 0.107 & 0.000 & 0.753 & $63,872,765$ \\
\cline { 2 - 6 } & Switch between Democratic and Republican & \multicolumn{2}{c}{0.120}
\end{tabular}




\section{IA.B Measures of Political Polarization in the Views of Economic Conditions}

Our main measure of political polarization in the views of economic conditions is based on the Gallup Daily survey by Gallup, Inc. We also construct an alternative measure based on the Thomson Reuters University of Michigan Survey of Consumers. The Gallup Daily survey is nationally representative and covers around 1,000 individuals every day for years 2008 to 2017. To measure the views on current economic conditions, the Gallup survey asks the following question: "How would you rate economic conditions in this country today - as excellent, good, only fair, or poor?" The responses to this question are converted into a numerical scale that ranges from 1 (poor) to 4 (excellent). Moreover, the Gallup survey contains two question about political affiliation, which allows classification of the survey respondents into Democrats, Republicans, or Independents. The first question asks, "In politics, as of today, do you consider yourself a Republican, a Democrat, or an Independent?" If the individual answers Republican or Democrat, no further question is asked regarding party affiliation. If the individual answers Independent, Other, or refuses to answer, he or she is asked a second question: "As of today, do you lean more to the Democratic Party or the Republican Party?" The individual can answer Republican or Democrat. We follow Mian, Sufi, and Khoshkhou (2018) and classify an individual as Republican if the individual answers Republican to either of these questions, and Democrat if the individual answers Democrat to either of these questions. The remaining individuals are classified as Independents. Our measure of political polarization in economic views is the absolute difference in the average economic views of Democrats and Republicans in a given calendar quarter.

The Michigan Survey covers around 500 individuals every month and is nationally representative. We use the Current Economic Conditions Index from the Michigan Survey to capture views of economic conditions. This index is a slightly adjusted average of the answers to two different questions meant to capture the views of individuals on current economic conditions. The first question is "We are interested in how people are getting along financially these days. Would you say that you (and your family living there) are better off or worse off financially than you were a year ago?" The second question is "About the big things people buy for their homes such as furniture, a refrigerator, stove, television, and things like that. Generally speaking, do you think now is a good time or a bad time for people to buy major household items?" To classify the political affiliation of the respondents, the survey asks the following question: "Generally speaking, do you usually think of yourself as a Republican, a Democrat, an Independent or what?" with 
possible answers being "Democrat," "Republican," or "Independent." However, the survey only asked the question on political affiliation in the following months: June 1980, January 1984, July 1984, January 1985, April 1985, May 1985, September through November 2006, March 2008 through June 2009, March 2010 through November 2010, April 2012, May 2012, September through November 2012, June 2014, June 2015, June through October 2016, and February and March of 2017. Given that the Michigan Survey does not ask the political affiliation between years 1985 and 2006, we use data from the Michigan Survey starting in 2006. For quarters with one or two consecutive missing values, we impute them by using the average of two non-missing quarters around these missing quarters. As with the Gallup Survey, our main measure of political polarization is the absolute difference in the average Current Economic Conditions Index between Democrats and Republicans in a given calendar quarter.

We standardize both variables to have a mean of 0 and a standard deviation of 1 . We plot the time-series of our two measures of polarization in economic views in Figure IA.1. 


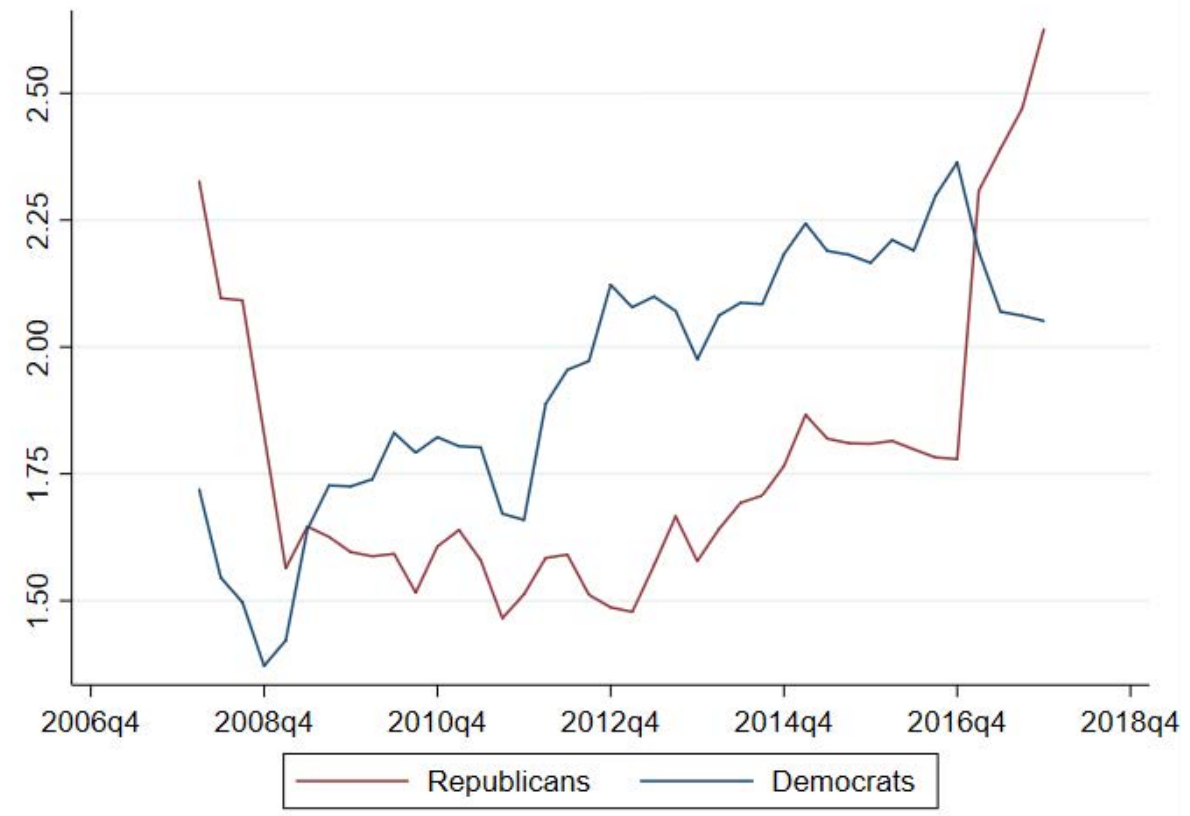

(a) Views of Republicans and Democrats from the Gallup Daily Survey

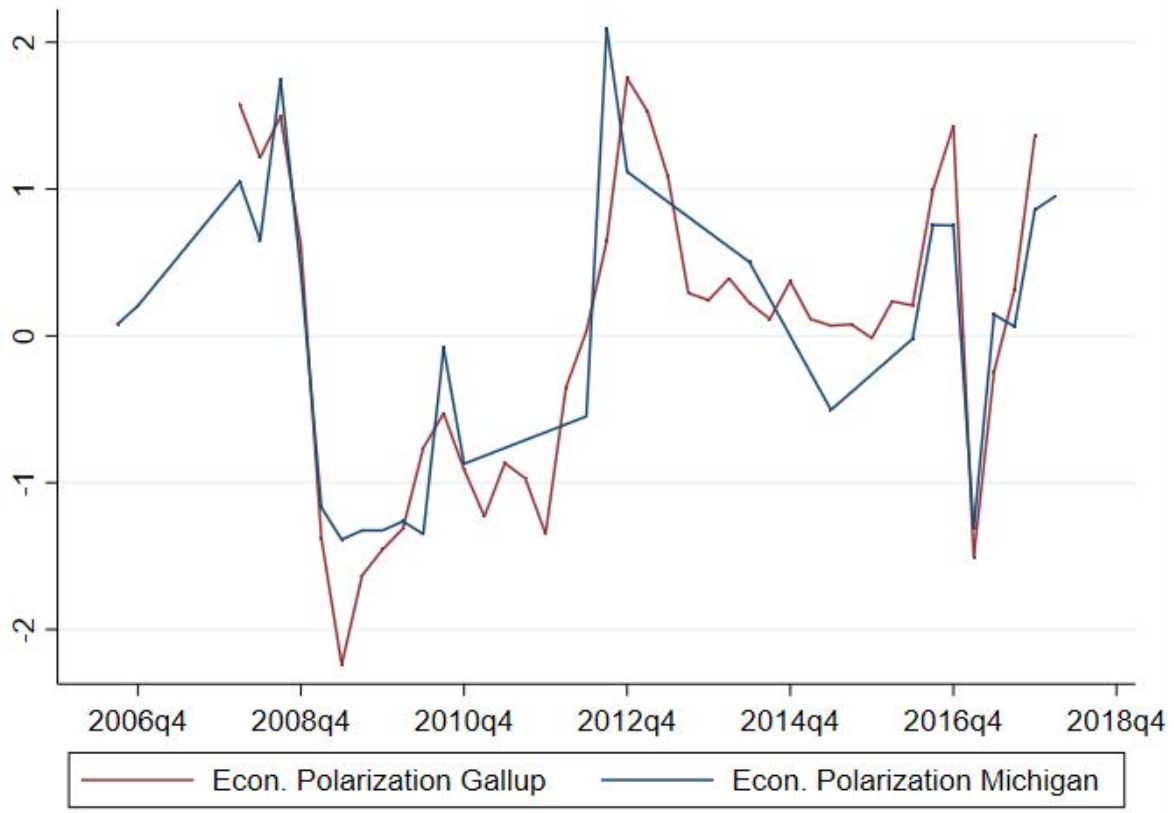

(b) Absolute Difference between Views of Republicans and Democrats

Figure IA.1: Political Polarization in the Views of Economic Conditions. The figure plots the time series of our political polarization in economic views. In panel (a), we plot the average economic views of Democrats and Republicans from the Gallup Daily Survey. In panel (b), we plot the absolute difference in economic views between Democrats and Republicans based on data from the Gallup Daily Survey (Econ. polarization Gallup), and the Current Economic Conditions Index from the Michigan Survey (Econ. polarization Michigan). Both measures in panel (b) are standardized to have a mean of 0 and a standard deviation of 1 . 


\section{IA.C Summary Statistics for Online Survey}

\section{Table IA.2: Summary Statistics - Credit Analyst Survey}

This table summarizes the responses from our online survey of credit rating analysts. The sample consists of 57 responses from individuals who indicated they have worked as credit rating analysts and who responded to the question on their view of economic conditions and their political affiliation. The survey is described in more detail in section 7.1.1 in the main paper.

\begin{tabular}{|c|c|c|c|}
\hline & $\mathrm{N}$ & Mean & $\mathrm{SD}$ \\
\hline \multicolumn{4}{|l|}{ Dependent Variables } \\
\hline Current Economic Conditions & 57 & 2.87 & 0.54 \\
\hline \multicolumn{4}{|c|}{ Years of Experience as a Credit Rating Analyst } \\
\hline$<5$ & 57 & $11 \%$ & \\
\hline $5-10$ & 57 & $22 \%$ & \\
\hline $10-15$ & 57 & $32 \%$ & \\
\hline$>15$ & 57 & $35 \%$ & \\
\hline \multicolumn{4}{|l|}{ Party Affiliation } \\
\hline Democrat & 57 & $39 \%$ & \\
\hline Republican & 57 & $28 \%$ & \\
\hline Independent & 57 & $33 \%$ & \\
\hline \multicolumn{4}{|l|}{ Age Group } \\
\hline$\overline{25-34}$ & 57 & $6 \%$ & \\
\hline $35-44$ & 57 & $28 \%$ & \\
\hline $45-54$ & 57 & $26 \%$ & \\
\hline $55-64$ & 57 & $33 \%$ & \\
\hline $65-74$ & 57 & $5 \%$ & \\
\hline $75-84$ & 57 & $2 \%$ & \\
\hline \multicolumn{4}{|l|}{ Ethnic Origin } \\
\hline Asian & 55 & $16 \%$ & \\
\hline African American & 55 & $2 \%$ & \\
\hline White & 55 & $78 \%$ & \\
\hline Other & 55 & $4 \%$ & \\
\hline \multicolumn{4}{|l|}{ Gender } \\
\hline Female & 56 & $30 \%$ & \\
\hline Male & 56 & $70 \%$ & \\
\hline
\end{tabular}




\section{IA.D Additional Analyses}

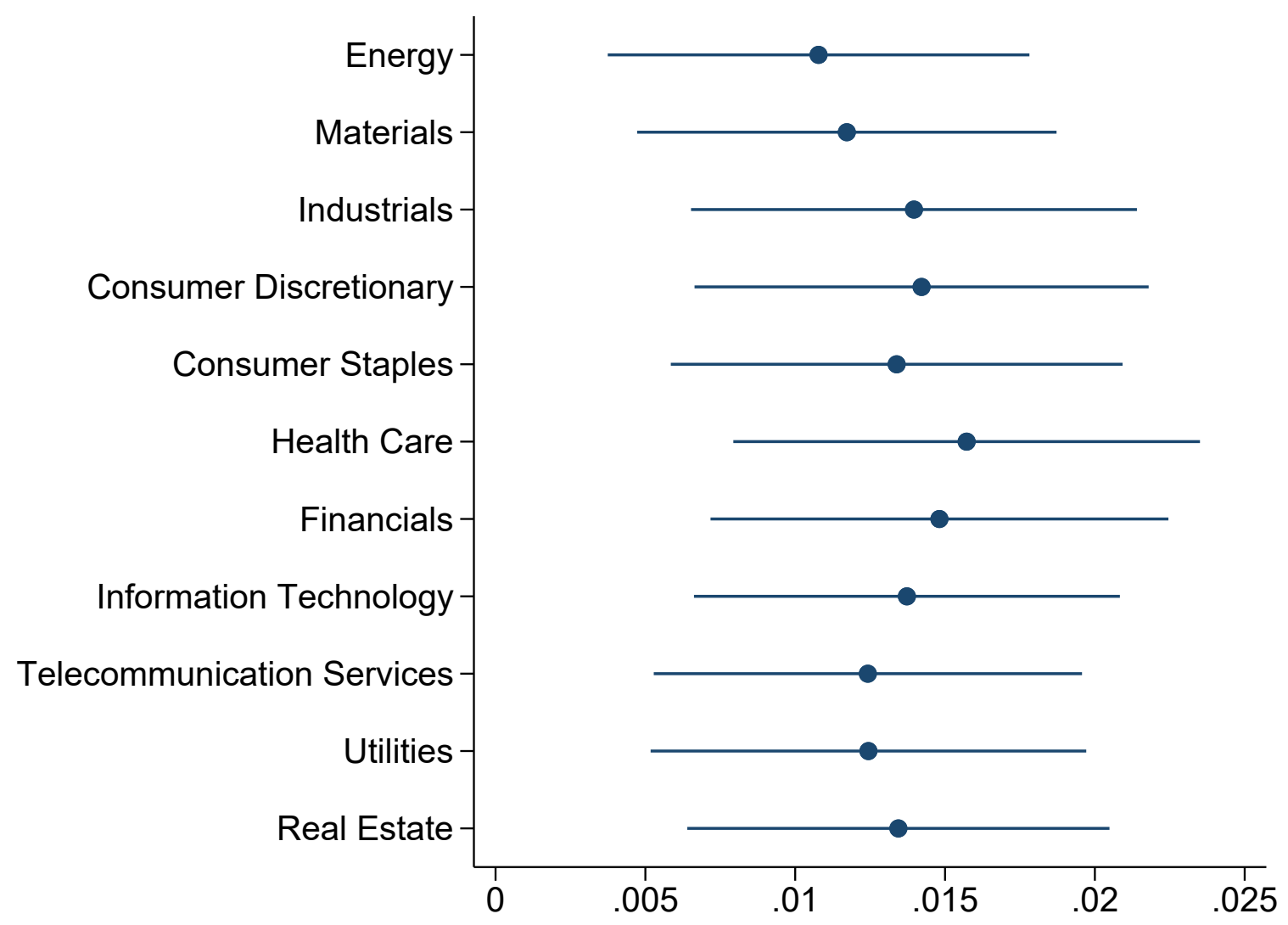

Figure IA.2: Coefficient Estimates after Excluding Each GICS Sector and by Initial Rating Category. The figure plots the coefficient estimate on ideological mismatch from the regression specification in Table 2, column (3) in the main paper, after excluding one GICS sector at a time. 


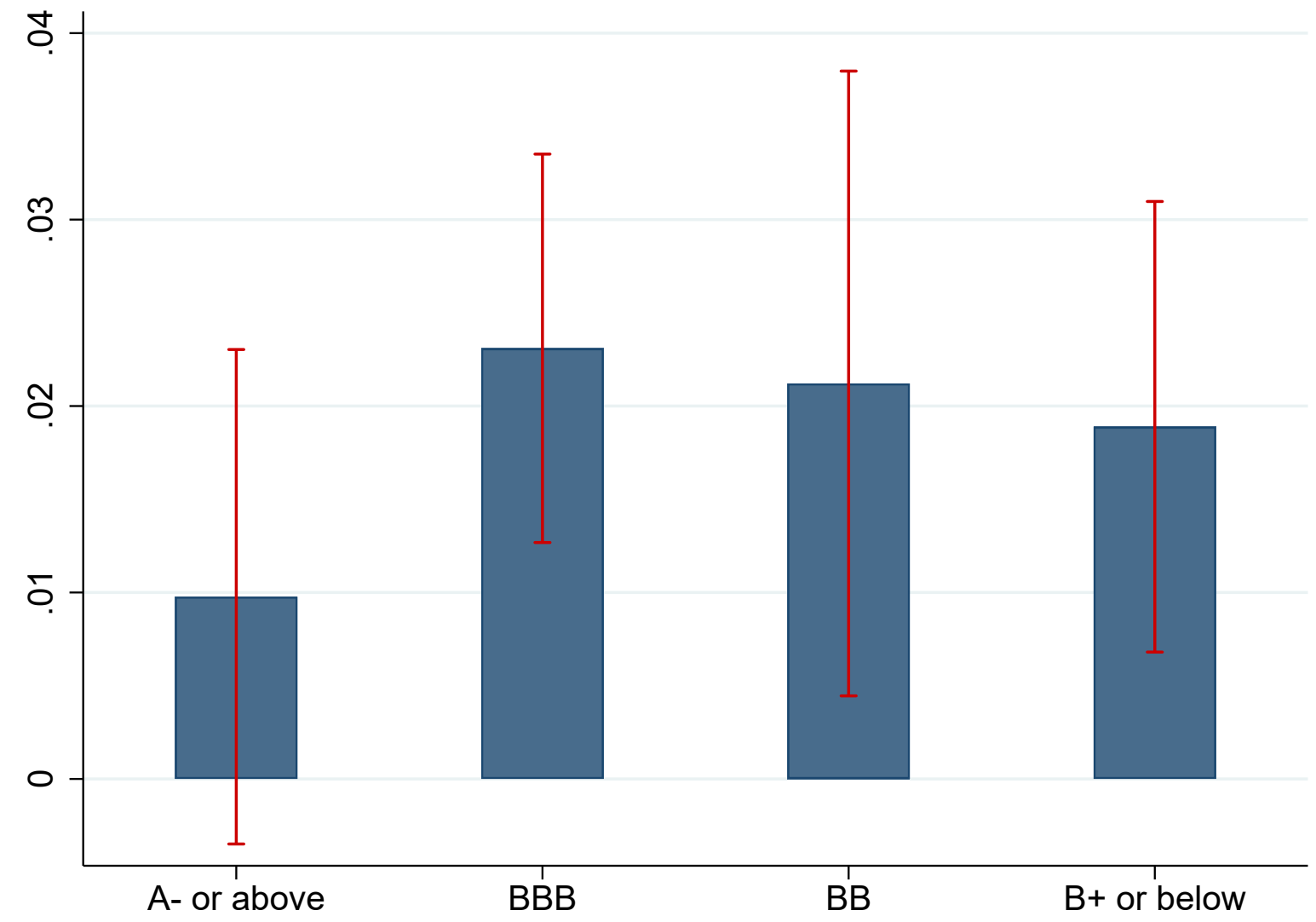

Figure IA.3: Coefficient Estimates by Initial Rating Category. The figure plots the coefficient estimate on the interaction term between ideological mismatch and four different rating categories. The regression specification is otherwise the same as in Table 2 , column (1). Rating categories refer to the credit rating at the end of the quarter prior to the ratings change. We also plot the corresponding $95 \%$ confidence intervals, based on standard errors that are double-clustered at the firm and analyst level. 


\section{Table IA.3: Predicting Registered Voter Status with Firm Characteristics}

This table regresses an indicator for analysts who are registered voters on characteristics of the rated firm. Registered Voter is an indicator equal to 1 for analysts who can be matched to a voter registration record, and 0 otherwise. All independent variables are standardized to have a mean of 0 and a standard deviation of 1 . $t$-statistics, reported in parentheses, are based on standard errors that allow for double-clustering at the analyst and firm level.

\begin{tabular}{lcc}
\hline \hline & $(1)$ & Registered Voter \\
& 0.0288 & $(2)$ \\
\hline Size & $(2.12)$ & 0.0150 \\
Investment & -0.0021 & $(1.10)$ \\
& $(-0.27)$ & -0.0014 \\
Leverage & 0.0113 & $(-0.18)$ \\
& $(0.78)$ & 0.0055 \\
Tobin's Q & 0.0159 & $(0.40)$ \\
& $(1.48)$ & 0.0171 \\
Cash & -0.0115 & $(1.63)$ \\
& $(-1.37)$ & -0.0119 \\
Cash flow & 0.0095 & $(-1.43)$ \\
Tenure & $(1.51)$ & 0.0075 \\
& 0.0653 & $(1.25)$ \\
No. of firms covered & $(3.24)$ & 0.0845 \\
& -0.0399 & $(3.85)$ \\
\hline Observations & $(-1.28)$ & -0.0481 \\
$R^{2}$ & 113,624 & $(-1.47)$ \\
Median lagged rating $\times$ Quarter FE & 0.128 & 113,624 \\
Agency $\times$ Quarter FE & Yes & 0.143 \\
\hline \hline
\end{tabular}




\section{Table IA.4: Predicting Registered Voter Status and Party Affiliation with Ana- lyst Characteristics}

This table regresses indicators for registered voters (Panel A) and Democratic analysts (Panel B) on analyst characteristics. Registered Voter is an indicator equal to 1 for analysts who can be matched to a voter registration record, and 0 otherwise. Democrat is an indicator equal to 1 for analysts who are are registered with the Democratic Party, and 0 for analysts who are registered with the Republican Party. Prob. Hispanic, Prob. Black and Prob. Asian are the probabilities that the analyst's race/ethnicity is Hispanic or Latino, black or African American, and Asian or Native Hawaiian or other Pacific Islander, respectively. The probability is inferred based on the analyst's first and last names using the API name-prism.com. Female is an indicator equal to 1 if the analyst is female, and 0 otherwise. Gender is inferred based on the analyst's first name, using the API api.genderize.io, as well as from manual online searches. $t$-statistics, reported in parentheses, are based on standard errors that allow for double-clustering at the analyst and firm level.

Panel A: Registered Voters vs. Non-registered Voters

\begin{tabular}{lccc}
\hline \hline & & Registered Voter & $(3)$ \\
\hline Prob. Hispanic & -0.4129 & $(2)$ & -0.4084 \\
& $(-2.82)$ & -0.4498 & $(-2.78)$ \\
Prob. Black & 0.0376 & $(-2.83)$ & 0.0324 \\
& $(0.14)$ & 0.0458 & $(0.12)$ \\
Prob. Asian & -0.0968 & $(0.17)$ & -0.0925 \\
& $(-1.35)$ & -0.1160 & $(-1.31)$ \\
Female & -0.0266 & $(-1.66)$ & -0.0287 \\
& $(-0.66)$ & -0.0365 & $(-0.71)$ \\
Tenure & 0.0780 & $(-0.91)$ & 0.0844 \\
& $(4.03)$ & 0.0777 & $(4.25)$ \\
No. of firms covered & -0.0463 & $(4.02)$ & -0.0467 \\
& $(-2.18)$ & -0.0498 & $(-2.16)$ \\
\hline Observations & 178,985 & $(-2.46)$ & 178,985 \\
$R^{2}$ & 0.425 & 178,890 & 0.430 \\
Firm $\times$ Quarter FE & Yes & 0.437 & Yes \\
Agency FE & Yes & Yes & No \\
Agency $\times$ Sector FE & No & No & No \\
Agency $\times$ Quarter FE & No & Yes & Yes \\
\hline \hline
\end{tabular}


Panel B: Democratic vs. Republican Analysts

\begin{tabular}{lccc}
\hline \hline & & Democrat & $(3)$ \\
\hline Prob. Hispanic & -0.4290 & $(2)$ & -0.4242 \\
& $(-1.61)$ & -0.3651 & $(-1.57)$ \\
Prob. Black & 1.2008 & $(-1.36)$ & 1.1935 \\
& $(8.57)$ & 1.1777 & $(8.75)$ \\
Prob. Asian & 0.1516 & $(7.91)$ & 0.1492 \\
& $(2.03)$ & 0.1231 & $(1.99)$ \\
Female & 0.3954 & $(1.66)$ & 0.3918 \\
& $(7.29)$ & 0.3567 & $(7.28)$ \\
Age & 0.0037 & $(6.42)$ & 0.0034 \\
& $(1.15)$ & 0.0036 & $(1.06)$ \\
Tenure & -0.0460 & $(1.13)$ & -0.0476 \\
& $(-1.51)$ & -0.0548 & $(-1.52)$ \\
No. of firms covered & -0.0582 & $(-1.74)$ & -0.0580 \\
& $(-1.50)$ & -0.0737 & $(-1.44)$ \\
\hline Observations & 30,569 & $(-2.08)$ & 30,569 \\
$R^{2}$ & 0.627 & 30,569 & 0.635 \\
Firm $\times$ Quarter FE & Yes & 0.656 & Yes \\
Agency FE & Yes & Yes & No \\
Agency $\times$ Sector FE & No & No & No \\
Agency $\times$ Quarter FE & No & Yes & Yes \\
\hline \hline
\end{tabular}


Table IA.5: Baseline Result: Democratic vs. Republican vs. Unaffiliated Analysts

This table repeats the analysis from Table 2 after replacing ideological mismatch with indicators for the analyst's party affiliation and an indicator for Democratic presidents. Panel A estimates the regression on the subsample of Democratic and Republican analysts only. We regress quarterly rating changes on Democrat, an indicator equal to 1 for analysts who are affiliated with the Democratic Party, and 0 for Republican analysts, as well as on an interaction with an indicator for Democratic presidents (DemPresident). Panel B repeats the analysis, but adds unaffiliated analysts, defined as all analysts who are classified as unaffiliated in the voter records. The coefficients on Democrat and Republican in Panel B capture the difference relative to the base group of unaffiliated analysts. At the bottom of the table, we report the results from an $F$-test that assesses whether the difference between Republican and Democratic analysts is statistically significant under Democratic and Republican presidents, respectively. $t$-statistics, reported in parentheses, are based on standard errors that allow for double-clustering at the analyst and firm level.

Panel A: Democratic vs. Republican Analysts

\begin{tabular}{lccc}
\hline \hline & & Rating Change & $(3)$ \\
\hline Democrat & 0.0313 & $(2)$ & 0.0268 \\
& $(3.88)$ & $(3.59)$ & $(3.79)$ \\
Democrat $\times$ DemPresident & -0.0365 & -0.0346 & -0.0299 \\
& $(-3.85)$ & $(-3.62)$ & $(-3.60)$ \\
Tenure & 0.0060 & 0.0056 & 0.0058 \\
& $(1.58)$ & $(1.51)$ & $(1.59)$ \\
No. of firms covered & 0.0001 & 0.0001 & -0.0002 \\
& $(0.04)$ & $(0.09)$ & $(-0.12)$ \\
\hline Observations & 29,348 & 29,348 & 29,346 \\
$R^{2}$ & 0.798 & 0.799 & 0.803 \\
DemPresident F-stat & 1.48 & 2.05 & 0.58 \\
DemPresident $p$-value & 0.225 & 0.154 & 0.447 \\
Firm $\times$ Quarter FE & Yes & Yes & Yes \\
Agency FE & Yes & No & No \\
Agency $\times$ Sector FE & No & Yes & No \\
Agency $\times$ Quarter FE & No & No & Yes \\
\hline \hline
\end{tabular}


Panel B: Democratic and Republican vs. Unaffiliated Analysts

\begin{tabular}{lccc}
\hline \hline & & Rating Change & $(3)$ \\
\hline Republican & -0.0162 & $(2)$ & -0.0138 \\
& $(-2.88)$ & -0.0157 & $(-2.52)$ \\
Republican $\times$ DemPresident & 0.0228 & $(-2.73)$ & 0.0200 \\
& $(3.32)$ & 0.0222 & $(3.00)$ \\
Democrat & 0.0117 & $(3.18)$ & 0.0089 \\
& $(1.84)$ & 0.0089 & $(1.49)$ \\
Democrat $\times$ DemPresident & -0.0103 & $(1.43)$ & -0.0066 \\
& $(-1.39)$ & -0.0111 & $(-0.94)$ \\
Tenure & 0.0005 & $(-1.54)$ & 0.0001 \\
& $(0.21)$ & -0.0001 & $(0.02)$ \\
No. of firms covered & -0.0003 & $(-0.03)$ & -0.0002 \\
& $(-0.25)$ & -0.0002 & $(-0.16)$ \\
\hline Observations & 49,316 & $(-0.14)$ & 49,314 \\
$R^{2}$ & 0.806 & 49,316 & 0.810 \\
RepPresident $F$-stat & 16.38 & 0.806 & 13.71 \\
RepPresident $p$-value & 0.000 & 13.37 & 0.000 \\
DemPresident $F$-stat & 2.01 & 0.000 & 1.30 \\
DemPresident $p$-value & 0.157 & 5.79 & Yes \\
Firm $\times$ Quarter FE & Yes & 0.017 & No \\
Agency FE & Yes & Yes & Yes \\
Agency $\times$ Sector FE & No & No & Yes \\
Agency $\times$ Quarter FE & No & No & \\
\hline \hline
\end{tabular}




\section{Table IA.6: Baseline Result: Additional Controls}

This table regresses rating changes on ideological mismatch, after adding additional analyst-level controls, as well as their interaction with an indicator for Democratic presidents (DemPresident). The coefficients on the non-interacted analyst controls are suppressed for brevity. $t$-statistics, reported in parentheses, are based on standard errors that allow for double-clustering at the analyst and firm level.

\begin{tabular}{lccc}
\hline \hline & & Rating Change & \\
& $(1)$ & $(2)$ & $(3)$ \\
\hline Ideological mismatch & 0.0145 & 0.0148 & $(3.0124$ \\
& $(3.49)$ & $(3.58)$ & -0.0115 \\
Tenure $\times$ DemPresident & -0.0130 & -0.0133 & $(-2.02)$ \\
& $(-2.22)$ & $(-2.28)$ & 0.0019 \\
No. of firms covered $\times$ DemPresident & 0.0029 & 0.0038 & $(0.55)$ \\
& $(0.76)$ & $(1.02)$ & 0.0096 \\
Prob. Hispanic $\times$ DemPresident & 0.0057 & 0.0057 & $(0.30)$ \\
& $(0.16)$ & $(0.17)$ & -0.0388 \\
Prob. Black $\times$ DemPresident & -0.0408 & -0.0432 & $(-1.18)$ \\
& $(-1.20)$ & $(-1.21)$ & 0.0051 \\
Prob. Asian $\times$ DemPresident & -0.0018 & -0.0018 & $(0.39)$ \\
& $(-0.13)$ & $(-0.13)$ & -0.0045 \\
Female $\times$ DemPresident & -0.0094 & -0.0074 & $(-0.60)$ \\
Age $\times$ DemPresident & $(-1.17)$ & $(-0.95)$ & 0.0007 \\
& 0.0008 & 0.0009 & $(2.09)$ \\
\hline Observations & $(2.38)$ & $(2.44)$ & 49,230 \\
$R^{2}$ & 49,232 & 49,232 & Y. \\
Firm $\times$ Quarter FE & 0.801 & 0.801 & Yes \\
Agency FE & Yes & Yes & No \\
Agency $\times$ Sector FE & Yes & No & No \\
Agency $\times$ Quarter FE & No & Yes \\
Party affiliation FE & No & No & Yes \\
Analyst controls & Yes & Yes & \\
\hline \hline
\end{tabular}




\section{Table IA.7: Baseline Result: Democratic vs. Republican Analysts Using Rating}

Levels

This table repeats the analysis in Table IA.5, after replacing the rating change with the rating level as the dependent variable. Panel A shows the baseline result and Panel B drops quarters 0 and +1 around all presidential elections which lead to a change in the party of the president. At the bottom of the table we report the results from an $F$-test that assesses whether the difference between Republican and Democratic analysts is statistically significant under Democratic presidents. $t$-statistics, reported in parentheses, are based on standard errors that allow for double-clustering at the analyst and firm level.

Panel A: Baseline Regression

\begin{tabular}{lccc}
\hline \hline & & Rating Level & $(3)$ \\
\hline Democrat & $(1)$ & $(2)$ & 0.0394 \\
& $(1.0629$ & 0.0273 & $(0.74)$ \\
Democrat $\times$ DemPresident & -0.1607 & $(0.56)$ & -0.1366 \\
& $(-2.45)$ & -0.1016 & $(-2.30)$ \\
Tenure & -0.0241 & $(-1.72)$ & -0.0285 \\
& $(-0.91)$ & -0.0088 & $(-1.15)$ \\
No. of firms covered & 0.0178 & $(-0.40)$ & 0.0120 \\
& $(1.05)$ & 0.0108 & $(0.78)$ \\
\hline Observations & 29,932 & $(0.72)$ & 29,932 \\
$R^{2}$ & 0.985 & 29,932 & 0.986 \\
DemPresident F-stat & 4.47 & 0.986 & 4.52 \\
DemPresident $p$-value & 0.035 & 4.14 & 0.034 \\
Firm $\times$ Quarter FE & Yes & 0.043 & Yes \\
Agency FE & Yes & Yes & No \\
Agency $\times$ Sector FE & No & No & No \\
Agency $\times$ Quarter FE & No & Yes & Yes \\
\hline \hline
\end{tabular}

Continued on next page 
Panel B: Dropping Quarters $(0,+1)$ around Presidential Elections

\begin{tabular}{lccc}
\hline \hline & & Rating Level & $(3)$ \\
\hline Democrat & $(1)$ & $(2)$ & 0.0891 \\
& $(1.58)$ & 0.0662 & $(1.44)$ \\
Democrat $\times$ DemPresident & -0.2069 & $(1.11)$ & -0.1840 \\
& $(-2.65)$ & -0.1384 & $(-2.60)$ \\
Tenure & -0.0133 & $(-1.94)$ & -0.0173 \\
& $(-0.50)$ & -0.0010 & $(-0.68)$ \\
No. of firms covered & 0.0140 & $(-0.05)$ & 0.0077 \\
& $(0.80)$ & 0.0077 & $(0.48)$ \\
\hline Observations & 27,434 & $(0.50)$ & 27,434 \\
$R^{2}$ & 0.985 & 27,434 & 0.986 \\
DemPresident F-stat & 4.02 & 0.986 & 4.16 \\
DemPresident $p$-value & 0.046 & 3.74 & 0.042 \\
Firm $\times$ Quarter FE & Yes & 0.054 & Yes \\
Agency FE & Yes & Yes & No \\
Agency $\times$ Sector FE & No & No & No \\
Agency $\times$ Quarter FE & No & Yes & Yes \\
\hline \hline
\end{tabular}




\section{Table IA.8: Robustness to Using Unwinsorized Rating Changes}

This table repeats the analysis in Table 2, after replacing the winsorized rating change with the unwinsorized rating change as the dependent variable. Panel A shows the baseline result; Panel $\mathrm{B}$ removes firms that are in default either at the end of quarter $t$ or at the end of the previous quarter; and Panel $\mathrm{C}$ removes rating changes which are larger than the 99th or smaller than the 1st percentile of the rating change distribution. $t$-statistics, reported in parentheses, are based on standard errors that allow for double-clustering at the analyst and firm level.

Panel A: Baseline Regression

\begin{tabular}{lccc}
\hline \hline & \multicolumn{3}{c}{ Unwinsorized Rating Change } \\
& $(1)$ & $(2)$ & $(3)$ \\
\hline Ideological mismatch & 0.0161 & 0.0159 & 0.0117 \\
& $(2.98)$ & $(2.88)$ & $(2.21)$ \\
Tenure & 0.0010 & 0.0002 & 0.0001 \\
& $(0.36)$ & $(0.08)$ & $(0.02)$ \\
No. of firms covered & -0.0009 & -0.0002 & -0.0003 \\
& $(-0.58)$ & $(-0.10)$ & $(-0.21)$ \\
\hline Observations & 49,792 & 49,792 & 49,790 \\
$R^{2}$ & 0.816 & 0.816 & 0.820 \\
Firm $\times$ Quarter FE & Yes & Yes & Yes \\
Agency FE & Yes & No & No \\
Agency $\times$ Sector FE & No & Yes & No \\
Agency $\times$ Quarter FE & No & No & Yes \\
Party affiliation FE & Yes & Yes & Yes \\
\hline \hline
\end{tabular}

Panel B: Removing Defaults

\begin{tabular}{lccc}
\hline \hline & \multicolumn{3}{c}{ Unwinsorized Rating Change } \\
& $(1)$ & $(2)$ & $(3)$ \\
\hline Ideological mismatch & 0.0162 & 0.0166 & 0.0127 \\
& $(3.37)$ & $(3.56)$ & $(2.85)$ \\
Tenure & 0.0007 & -0.0001 & -0.0001 \\
& $(0.26)$ & $(-0.03)$ & $(-0.03)$ \\
No. of firms covered & 0.0002 & 0.0006 & 0.0003 \\
& $(0.15)$ & $(0.44)$ & $(0.23)$ \\
\hline Observations & 49,609 & 49,609 & 49,607 \\
$R^{2}$ & 0.818 & 0.818 & 0.822 \\
Firm $\times$ Quarter FE & Yes & Yes & Yes \\
Agency FE & Yes & No & No \\
Agency $\times$ Sector FE & No & Yes & Yes \\
Agency $\times$ Quarter FE & No & No & Yes \\
Party affiliation FE & Yes & Yes & Continued on next page
\end{tabular}


Panel C: Removing Extreme Rating Changes

\begin{tabular}{lccc}
\hline \hline & \multicolumn{3}{c}{ Unwinsorized Rating Change } \\
& $(1)$ & $(2)$ & $(3)$ \\
\hline Ideological mismatch & 0.0153 & 0.0153 & 0.0137 \\
& $(3.81)$ & $(3.95)$ & $(3.92)$ \\
Tenure & -0.0013 & -0.0019 & -0.0010 \\
& $(-0.49)$ & $(-0.73)$ & $(-0.38)$ \\
No. of firms covered & 0.0007 & 0.0007 & 0.0004 \\
& $(0.57)$ & $(0.60)$ & $(0.29)$ \\
\hline Observations & 49,039 & 49,039 & 49,037 \\
$R^{2}$ & 0.788 & 0.788 & 0.792 \\
Firm $\times$ Quarter FE & Yes & Yes & Yes \\
Agency FE & Yes & No & No \\
Agency $\times$ Sector FE & No & Yes & No \\
Agency $\times$ Quarter FE & No & No & Yes \\
Party affiliation FE & Yes & Yes & Yes \\
\hline \hline
\end{tabular}




\section{Table IA.9: Baseline Result: Include Unregistered Analysts}

This table repeats the analysis from Table IA.5, Panel B, after adding unregistered analysts and treating them as unaffiliated. The coefficients on Democrat and Republican capture the difference relative to the base group of unaffiliated and unregistered analysts. At the bottom of the table, we report the results from an $F$-test that assesses whether the difference between Republican and Democratic analysts is statistically significant under Democratic and Republican presidents, respectively. $t$-statistics, reported in parentheses, are based on standard errors that allow for double-clustering at the analyst and firm level.

\begin{tabular}{lccc}
\hline \hline & & Rating Change & \\
& $(1)$ & $(2)$ & $(3)$ \\
\hline Republican & -0.0096 & -0.0088 & -0.0076 \\
& $(-3.16)$ & $(-2.81)$ & $(-2.71)$ \\
Republican $\times$ DemPresident & 0.0138 & 0.0130 & 0.0113 \\
& $(3.24)$ & $(3.06)$ & $(2.86)$ \\
Democrat & 0.0030 & 0.0003 & 0.0033 \\
& $(0.94)$ & $(0.10)$ & $(1.08)$ \\
Democrat $\times$ DemPresident & -0.0036 & -0.0028 & -0.0027 \\
& $(-0.89)$ & $(-0.70)$ & $(-0.69)$ \\
Tenure & 0.0002 & 0.0004 & 0.0000 \\
& $(0.11)$ & $(0.28)$ & $(0.02)$ \\
No. of firms covered & -0.0002 & -0.0004 & -0.0002 \\
& $(-0.32)$ & $(-0.60)$ & $(-0.35)$ \\
\hline Observations & 167,161 & 167,084 & 0.795 \\
$R^{2}$ & 0.793 & 0.793 & 7.45 \\
RepPresident $F$-stat & 8.52 & 4.42 & 0.007 \\
RepPresident $p$-value & 0.004 & 0.036 & 1.34 \\
DemPresident $F$-stat & 2.96 & 6.49 & Yes \\
DemPresident $p$-value & 0.086 & 0.011 & No \\
Firm $\times$ Quarter FE & Yes & Yes & Yes \\
Agency FE & Yes & No & Yes \\
Agency $\times$ Sector FE & No & No & \\
Agency $\times$ Quarter FE & No & & \\
\hline \hline
\end{tabular}




\section{Table IA.10: Mismatch with Congress}

This table regresses quarterly rating changes on Mismatch with Senate, an indicator equal to 1 for analysts whose party affiliation does not match the party majority in the U.S. Senate, and 0 otherwise; Mismatch with House, an indicator equal to 1 for analysts whose party affiliation does not match the party majority in the U.S. House of Representatives, and 0 otherwise; and Mismatch with President, our baseline definition of ideology mismatch based on the party affiliation of the president. $t$-statistics, reported in parentheses, are based on standard errors that allow for doubleclustering at the analyst and firm level.

\begin{tabular}{lcccc}
\hline \hline \multirow{2}{*}{} & $(1)$ & $(2)$ & $(3)$ & $(4)$ \\
\hline Mismatch with Senate & 0.0071 & & 0.0000 & \\
& $(2.55)$ & 0.0031 & $(0.01)$ & 0.0014 \\
Mismatch with House & & $(0.90)$ & & $(0.39)$ \\
& & & 0.0134 & 0.0132 \\
Mismatch with President & & & $(3.14)$ & $(3.71)$ \\
& & -0.0003 & -0.0004 & -0.0004 \\
Tenure & -0.0004 & $(-0.13)$ & $(-0.15)$ & $(-0.14)$ \\
& $(-0.14)$ & 0.0001 & -0.0000 & -0.0000 \\
No. of firms covered & 0.0001 & $(0.09)$ & $(-0.02)$ & $(-0.01)$ \\
& $(0.05)$ & 49,790 & 49,790 & 49,790 \\
\hline Observations & 49,790 & 0.808 & 0.808 & 0.808 \\
$R^{2}$ & 0.808 & Yes & Yes & Yes \\
Firm $\times$ Quarter FE & Yes & Yes & Yes & Yes \\
Agency $\times$ Quarter FE & Yes & Yes & Yes & Yes \\
Party affiliation FE & Yes & & & \\
\hline \hline
\end{tabular}




\section{Table IA.11: Event Study around the 2016 Presidential Election}

This table regresses quarterly rating changes on Democrat, an indicator equal to 1 for analysts who are affiliated with the Democratic Party, and zero for Republican analysts, as well as its interaction with Post Trump, an indicator equal to 1 for all quarters after and including the presidential election quarter (2016Q4), and 0 otherwise. The sample is restricted to Democratic and Republican analysts, as well as to the time period from 2015Q1 to 2018Q1. $t$-statistics, reported in parentheses, are based on standard errors that allow for double-clustering at the analyst and firm level.

\begin{tabular}{lccc}
\hline \hline & & Rating Change & \\
& $(1)$ & $(2)$ & $(3)$ \\
\hline Democrat & -0.0040 & -0.0092 & -0.0003 \\
& $(-0.58)$ & $(-1.32)$ & $(-0.04)$ \\
Democratic $\times$ Post Trump & 0.0323 & 0.0328 & 0.0245 \\
& $(2.12)$ & $(2.22)$ & $(1.99)$ \\
Tenure & 0.0013 & 0.0011 & 0.0013 \\
& $(0.21)$ & $(0.20)$ & $(0.23)$ \\
No. of firms covered & 0.0031 & 0.0003 & 0.0033 \\
& $(1.10)$ & $(0.11)$ & $(1.15)$ \\
\hline Observations & 7,916 & 7,916 & 7,916 \\
$R^{2}$ & 0.813 & 0.815 & 0.819 \\
Firm $\times$ Quarter FE & Yes & Yes & Yes \\
Agency FE & Yes & No & No \\
Agency $\times$ Sector FE & No & Yes & Yes \\
Agency $\times$ Quarter FE & No & No & \\
\hline \hline
\end{tabular}




\section{Table IA.12: Abnormal Stock Returns around Rating Actions}

This table regresses cumulative abnormal stock returns around downgrades (Panels A and B) and upgrades (Panels C and D) on ideological mismatch. Cumulative abnormal returns (CARs) are measured in percent and calculated using the Fama and French (1993) and Carhart (1997) model estimated over trading days $(-300,-50)$ and are measured over an event window of $(-1,+1)$ (Panels A and C) and $(-3,+3)$ (Panels B and D), respectively. In columns (3) and (4), we exclude rating changes where a corporate earnings announcement or M\&A announcement falls inside the event window. In all regressions, we control for the log of the firm's total book assets, leverage, Tobin's Q, and cash holdings, as well as for the analysts' party affiliations. All variables are defined in Appendix A.1. $t$-statistics, reported in parentheses, are based on standard errors that allow for clustering at the calendar-date level.

Panel A: CAR $(-1,+1)$ around Downgrades

\begin{tabular}{lcccc}
\hline \hline & \multicolumn{4}{c}{ CAR(-1,+1) } \\
& $(1)$ & $(2)$ & $(3)$ & $(4)$ \\
\hline Ideological mismatch & 0.8422 & 0.7225 & 0.7969 & 0.6869 \\
& $(1.47)$ & $(1.07)$ & $(1.36)$ & $(0.96)$ \\
Rating change & -1.0200 & -1.0317 & -1.0097 & -1.0932 \\
& $(-2.54)$ & $(-2.28)$ & $(-2.41)$ & $(-2.33)$ \\
\hline Observations & 1,870 & 1,740 & 1,692 & 1,560 \\
$R^{2}$ & 0.141 & 0.256 & 0.162 & 0.270 \\
Month FE & Yes & No & Yes & No \\
Agency FE & Yes & No & Yes & No \\
Agency $\times$ Month FE & No & Yes & No & Yes \\
Excluding corporate events & No & No & Yes & Yes \\
Control variables & Yes & Yes & Yes & Yes \\
\hline \hline
\end{tabular}

Panel B: CAR $(-3,+3)$ around Downgrades

\begin{tabular}{lcccc}
\hline \hline & \multicolumn{4}{c}{ CAR(-3,+3) } \\
& $(1)$ & $(2)$ & $(3)$ & $(4)$ \\
\hline Ideological mismatch & -0.1300 & -0.2108 & -0.6989 & -0.9453 \\
& $(-0.16)$ & $(-0.21)$ & $(-0.79)$ & $(-0.85)$ \\
Rating change & -1.7819 & -1.6730 & -2.1545 & -1.9289 \\
& $(-3.12)$ & $(-2.50)$ & $(-3.38)$ & $(-2.56)$ \\
\hline Observations & 1,870 & 1,740 & 1,542 & 1,411 \\
$R^{2}$ & 0.155 & 0.236 & 0.167 & 0.245 \\
Month FE & Yes & No & Yes & No \\
Agency FE & Yes & No & Yes & No \\
Agency $\times$ Month FE & No & Yes & No & Yes \\
Excluding corporate events & No & No & Yes & Yes \\
Control variables & Yes & Yes & Yes & Yes \\
\hline \hline
\end{tabular}

Continued on next page 
Panel C: CAR $(-1,+1)$ around Upgrades

\begin{tabular}{lcccc}
\hline \hline & \multicolumn{4}{c}{ CAR(-1,+1) } \\
& $(1)$ & $(2)$ & $(3)$ & $(4)$ \\
\hline Ideological mismatch & 0.1238 & 0.0335 & 0.1410 & -0.0096 \\
& $(0.46)$ & $(0.10)$ & $(0.53)$ & $(-0.03)$ \\
Rating change & 0.1976 & -0.1975 & 0.1313 & -0.1513 \\
& $(0.54)$ & $(-0.48)$ & $(0.37)$ & $(-0.37)$ \\
\hline Observations & 1,436 & 1,324 & 1,361 & 1,246 \\
$R^{2}$ & 0.182 & 0.270 & 0.173 & 0.266 \\
Month FE & Yes & No & Yes & No \\
Agency FE & Yes & No & Yes & No \\
Agency $\times$ Month FE & No & Yes & No & Yes \\
Excluding corporate events & No & No & Yes & Yes \\
Control variables & Yes & Yes & Yes & Yes \\
\hline \hline
\end{tabular}

Panel D: CAR $(-3,+3)$ around Upgrades

\begin{tabular}{lcccc}
\hline \hline & \multicolumn{4}{c}{ CAR(-3,+3) } \\
& $(1)$ & $(2)$ & $(3)$ & $(4)$ \\
\hline Ideological mismatch & 0.2368 & 0.0744 & 0.5384 & 0.3240 \\
& $(0.54)$ & $(0.14)$ & $(1.17)$ & $(0.57)$ \\
Rating change & -0.2384 & -0.5766 & -0.3031 & -0.3800 \\
& $(-0.47)$ & $(-0.89)$ & $(-0.56)$ & $(-0.55)$ \\
\hline Observations & 1,436 & 1,324 & 1,264 & 1,142 \\
$R^{2}$ & 0.165 & 0.245 & 0.168 & 0.245 \\
Month FE & Yes & No & Yes & No \\
Agency FE & Yes & No & Yes & No \\
Agency $\times$ Month FE & No & Yes & No & Yes \\
Excluding corporate events & No & No & Yes & Yes \\
Control variables & Yes & Yes & Yes & Yes \\
\hline \hline
\end{tabular}




\section{Table IA.13: Yield Spread Changes around Rating Actions}

This table regresses yield spread changes around downgrades (Panel A) and upgrades (Panel B) on ideological mismatch. Yield spread changes are computed as the difference in the yield spread between the first day on which the bond is traded after the announcement and the last day the bond is traded before the announcement, respectively, measured in basis points. In columns (3) and (4), we exclude rating changes where a corporate earnings announcement or M\&A announcement falls inside the event window. We control for the log of the firm's total book assets, leverage, Tobin's Q, cash holdings, and the analysts' party affiliations. All variables are defined in Appendix A.1. $t$-statistics, reported in parentheses, are based on standard errors that allow for double-clustering at the firm and calendar-date level.

Panel A: Changes in Yield Spreads for Downgrades

\begin{tabular}{lcccc}
\hline \hline & \multicolumn{4}{c}{$\Delta$ Yield Spread } \\
& $(1)$ & $(2)$ & $(3)$ & $(4)$ \\
\hline Ideological mismatch & 4.4910 & 4.2090 & 5.6751 & 3.1907 \\
& $(0.77)$ & $(0.50)$ & $(0.90)$ & $(0.37)$ \\
Rating change & 18.0479 & 19.7653 & 18.7856 & 21.8284 \\
& $(3.10)$ & $(2.66)$ & $(2.90)$ & $(2.72)$ \\
\hline Observations & 765 & 611 & 714 & 551 \\
$R^{2}$ & 0.210 & 0.315 & 0.218 & 0.324 \\
Month FE & Yes & No & Yes & No \\
Agency FE & Yes & No & Yes & No \\
Agency $\times$ Month FE & No & Yes & No & Yes \\
Excluding corporate events & No & No & Yes & Yes \\
Control variables & Yes & Yes & Yes & Yes \\
\hline \hline
\end{tabular}

Panel B: Changes in Yield Spreads for Upgrades

\begin{tabular}{lcccc}
\hline \hline & \multicolumn{4}{c}{$\Delta$ Yield Spread } \\
& $(1)$ & $(2)$ & $(3)$ & $(4)$ \\
\hline Ideological mismatch & -2.1086 & -5.2249 & -1.1760 & -4.4083 \\
& $(-0.47)$ & $(-0.73)$ & $(-0.25)$ & $(-0.61)$ \\
Rating change & 12.5119 & 10.2122 & 13.7761 & 11.5444 \\
& $(2.05)$ & $(1.60)$ & $(2.10)$ & $(1.63)$ \\
\hline Observations & 569 & 452 & 551 & 432 \\
$R^{2}$ & 0.339 & 0.435 & 0.346 & 0.437 \\
Month FE & Yes & No & Yes & No \\
Agency FE & Yes & No & Yes & No \\
Agency $\times$ Month FE & No & Yes & No & Yes \\
Excluding corporate events & No & No & Yes & Yes \\
Control variables & Yes & Yes & Yes & Yes \\
\hline \hline
\end{tabular}




\section{Table IA.14: Yield Spreads at Issuance}

This table regresses the average yield spread on the firm's newly issued bonds in a given quarter on an indicator equal to 1 if the fraction of misaligned analysts covering the firm exceeds $50 \%$, and 0 otherwise. Yield spreads at issuance are obtained from Mergent FISD. In column (1), we compute the equal-weighted yield spread across all bonds issued in a given firm-quarter. In column (2), we compute the weighted average yield spread, where weights are proportional to the offering amount. $t$-statistics, reported in parentheses, are based on standard errors that allow for clustering at the firm level.

\begin{tabular}{lcc}
\hline \hline & & Yield Spread \\
& $(1)$ & $(2)$ \\
\hline Ideological mismatch & 11.8865 & 11.8884 \\
& $(2.12)$ & $(2.12)$ \\
Size & -14.3991 & -14.0214 \\
& $(-3.18)$ & $(-3.09)$ \\
Investment & 19.4941 & 20.5498 \\
& $(0.64)$ & $(0.67)$ \\
Leverage & 90.0697 & 89.6481 \\
& $(3.43)$ & $(3.40)$ \\
Tobin's Q & -33.4753 & -32.9816 \\
& $(-6.09)$ & $(-5.94)$ \\
Cash & 80.6050 & 82.7209 \\
& $(3.09)$ & $(3.16)$ \\
Cashflow & -334.4361 & -330.6942 \\
& $(-1.45)$ & $(-1.43)$ \\
\hline Observations & 1,350 & 1,350 \\
$R^{2}$ & 0.865 & 0.864 \\
Median lagged rating $\times$ Quarter FE & Yes & Yes \\
\hline \hline
\end{tabular}




\section{Table IA.15: Firm Investment}

This table regresses the logarithm of the firm's quarterly capital expenditures around presidential elections on the share of misaligned analysts rating the firm as well as on an interaction with a post-election indicator. In column (1), we use the continuous share of misaligned analysts; in column (2) we sort firms into terciles based on their share of misaligned analysts; and in column (3) we sort firms into quartiles. In all columns, the sample is restricted to quarters that fall inside the $(-4,+4)$ event window around presidential elections that lead to a change in the party of the president. $t$-statistics, reported in parentheses, are based on standard errors that allow for clustering at the firm level.

\begin{tabular}{lccc}
\hline \hline & & Log Capex & $(3)$ \\
\hline Mismatch Share & $(1)$ & $(2)$ & \\
& 0.1351 & & \\
Mismatch Share $\times$ Post & $(2.09)$ & & \\
& -0.1024 & & \\
Mismatch Tercile & $(-2.20)$ & 0.0327 & \\
& & $(1.21)$ & 0.0336 \\
Mismatch Tercile $\times$ Post & & -0.0451 & $(1.62)$ \\
& & $(-2.33)$ & -0.0364 \\
Mismatch Quartile & & & $(-2.52)$ \\
Mismatch Quartile $\times$ Post & & & 11,133 \\
& & & 0.917 \\
Observations & & 11,133 & Yes \\
$R^{2}$ & Yes & 0.917 & Yes \\
Firm FE & Yes & Yes & \\
Quarter FE & & & \\
\hline \hline
\end{tabular}


Table IA.16: Interaction with Polarization of Economic Views: Alternative Measure

This table repeats the analysis presented in Table 8 using an alternative measure of political polarization in the views of economic conditions. Econ. polarization Michigan refers to the difference in economic views between Democrats and Republicans based on the Current Economic Conditions Index from the Michigan Survey. The index is standardized to have a mean of 0 and a standard deviation of 1 . Section IA.B provides more details on the survey questions. $t$-statistics, reported in parentheses, are based on standard errors that allow for double-clustering at the analyst and firm level.

\begin{tabular}{lccc}
\hline \hline & & Rating Change & $(3)$ \\
\hline Ideological mismatch & $(1)$ & $(2)$ & 0.0105 \\
& 0.0115 & 0.0121 & $(2.24)$ \\
Mismatch $\times$ Econ. polarization Michigan & $(2.20)$ & $(2.41)$ & 0.0058 \\
& 0.0087 & 0.0086 & $(1.38)$ \\
Tenure & $(2.08)$ & $(2.03)$ & 0.0015 \\
& 0.0010 & 0.0005 & $(0.45)$ \\
No. of firms covered & $(0.31)$ & $(0.16)$ & -0.0010 \\
& -0.0013 & -0.0011 & $(-0.44)$ \\
\hline Observations & $(-0.56)$ & $(-0.59)$ & 24,724 \\
$R^{2}$ & 24,724 & 24,724 & 0.818 \\
Firm $\times$ Quarter FE & 0.815 & 0.816 & Yes \\
Agency FE & Yes & Yes & No \\
Agency $\times$ Sector FE & Yes & No & No \\
Agency $\times$ Quarter FE & No & Yes & Yes \\
Party affiliation FE & No & No & Yes \\
\hline \hline
\end{tabular}

